3

FINAL REPORT

PROJECT NO. $1-273-81$

\title{
Testing the Efficiency of Different Lamps and Illumination Regimes for Photoperiodic Irradiation of Agricultural Crops
}

A. Kadman-Zahavi, T.W. Tibbitts, B. Steinitz 
itundard BARD Cover Page for scientifice Reports

$B A R D$

P.O. BOX 6

Bet Dagan, ISRAEL

BARD Project NO. I- $273=81$

Title of Research Project: Testing The Bfficiency of Different Lamps and Illwinition Regimes for Photogeriodic Irradiation of Agricultural Crops

Names of Investigators:

Principal Investigator: Avishag Tadman-'Jahavi

Cooperating Investigator(s):

T. Tinbitts; B. Steinitz

Name and Address of Affiliated Institutions:

Principal Institution: ARO, The Volcini Center, Dept. of Ortimental yinnts, Bot-bagan, 5097n, Israel.

Cooperating Institution(s): Unitrersity of Visconsin, Depta of Ilorticultume Madison, iscontin, 53706, isA

Project's starting date: Dec: 1982

Type of Report: 1st Annual.

2nd Annual

Final $\mathrm{X}$

Signatures:

Principal Investigator Institution's Authorizing official

A. Kadman-2ahavi

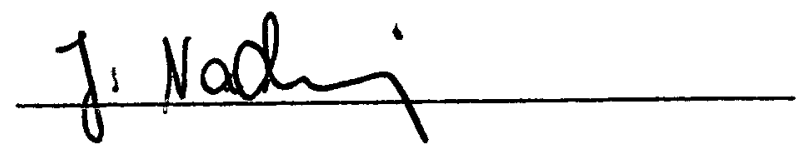




$$
\begin{aligned}
& \frac{630.72}{B A R / K A D}: 635.954: 581.134 .153: \\
& \text { 2nd copy }
\end{aligned}
$$


b. Table of contents

c. Abstract 2

d. Objectives of the original
research project

e. Report

1. Israel

Introduction

Materials and Methods 5

Legend for the figures 22

Gypsophila paniculata $\quad 23$

Kalanchoe blossfeldiana $\quad 35$

Aster pilosus $\quad 39$

Centaurea cyanus $\quad 44$

Chrysanthemum morifolium $\quad 50$

Hyoscyamus niger. $\quad 54$

Pharbitis nil. 60

Setaris italica $\quad 64$

Sinapis alba $\quad 67$

Spinacia oleracea $\quad 71$

$\begin{array}{ll}\text { Xanthium strumarium } & 77\end{array}$

Summary $\quad 82$

2. USA 84

f. Description of cooperation 98

g. Evaluation of Research

h. List of publications 101 


\section{c. Abstract}

The objective of this research was to compare the photoperiodic and photomorphogenetic effects of night-time irradiations with different lamps, with different illumination regimes, and to define their agricultural efficiency. In Israel the plants were growing in greenhouses, in high-intensity sunlight during the photoperiod. In the USA the plants were grown in a Biotron.

The photoperiodic response was a function of the time of application of the irradiations and the total light fluence administered. In most cases light applied in the central part of the night was much more effective than that applied early in the evening or early in the morning. Between threshold and saturated response there was a logIinear response-curve. There was no consistent difference between Long-Day-Plants and Short-Day-Plants. In most plants the differences in the effectiveness of light of lamps emitting light in the range 500-700 $\mathrm{nm}$ (Incandescent, $C W$ and GL-Fluorescent, High-Pressure Sodium, and Low-Pressure Sodium) were rather slight. With Incandescent light there was no difference between continuous and intermittently applied light, provided the same total fluence was applied.
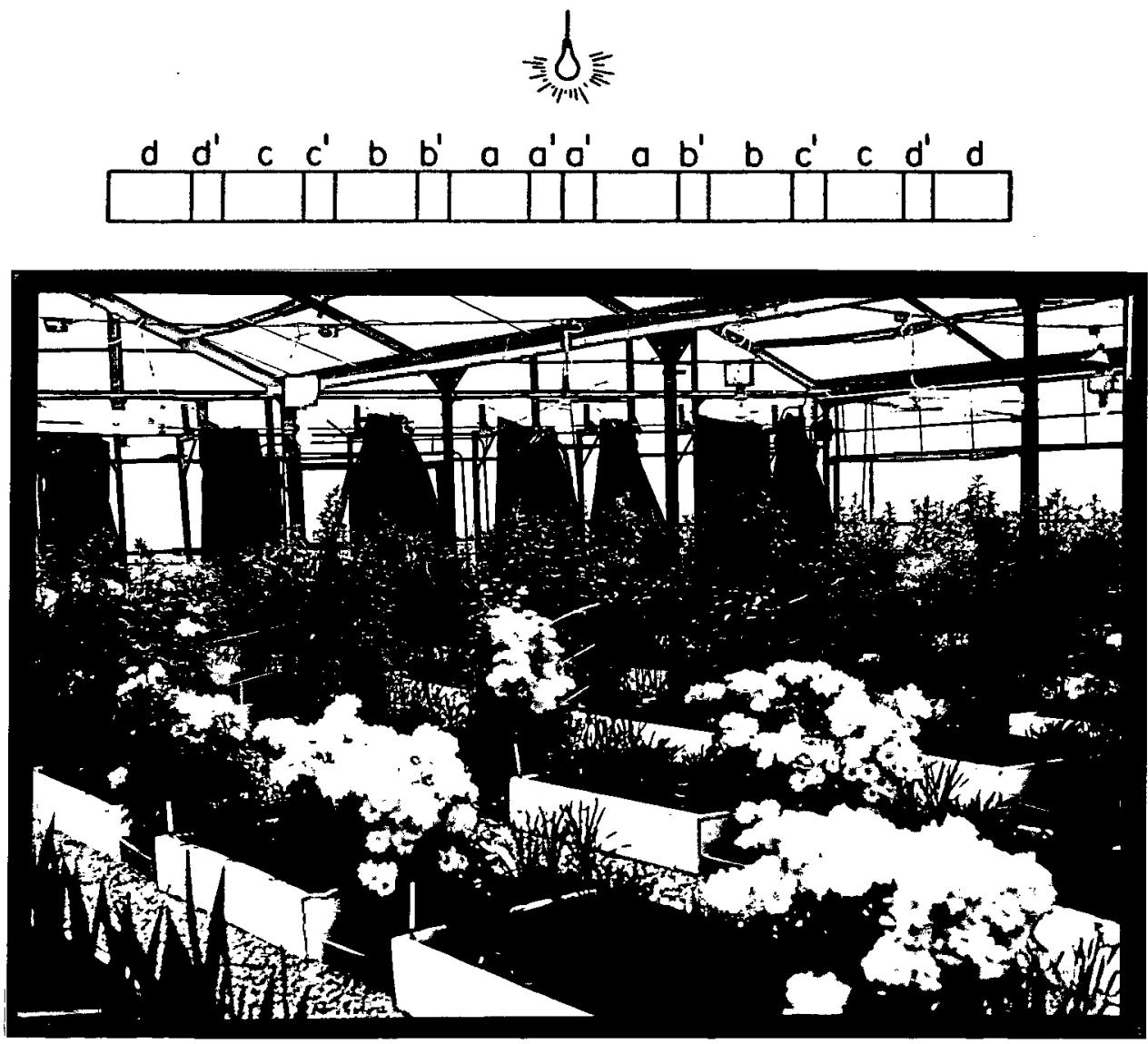
d. Objectives of the original research proposal

Here under is reprinted the abstract of our research proposal, summarizing the research problem, the objective of the research and the expected contributions.

Definition of the research problem. Agricultural application of photoperiodic illumination has recently been extended to many new crops. This has been done in order to induce flowering of cut-flowers for winter export. Different types of lamps, because of their different spectral emission, differ greatly in their relative efficiency, depending on the illumination regime and on night length. To the bestof our knowledge no critical experiments have been conducted to compare the merits of different lamps according to the most efficient application for each type of lamp.

Specific object of the research. An experimental system will be erected to compare the effects of different lamps in different illumination regimes, and to compare the results with those obtained in controlled evironments.

Expected contribution. In Israel, approximately 20 million KWH of electricity is used annually for photoperiodic illumination of Gypsophila and other crops. It is believed that about two-thirds of this energy could be saved. The basic understanding of the different response to different light may also be extended.

Methodology. In Israel, a large greenhouse will be divided, into several elongated compartments, each fitted with a single lamp for night illumination. Timers will be used to * provide different illumination regimes. In the USA the experiments will be conducted in the Biotron. 
e. Efficiency of Different Lamps and Illumination Regimes in Photoperiodic Illuminations of Agricultural Crops

\section{Introduction}

The objective of the research was to compare the photoperiodic and photomorphogenetic effects of the light of different lamps applied at different times, for different durations. In Israel the plants were grown in greenhouses, as much as possible under usual horticultural conditions. In the USA, the plants were grown entirely under artificial light, in a. Phytotrom (Biotron).

The first part of the report is concerned with the experiments carried out in Israel, this is followed by those carried out in the USA.

\section{A. In Israel}

The lamps were situated at the center of the beds and the plants were placed at fixed distances from the lamps, along a light gradient. At night black polyethylene curtains were automatically pulied between the beds.

The main crop plant tested was Gypsophila paniculata, a long-day-plant (LDP), which can flower in winter only when provided with photoperiodic illuminations. Other crop plants were the short-day-plants (SDP) Chrysanthemum morifolium and Kalanchoe blossfeldiana, in which photoperiodic illuminations are used to keep the plants in the vegetative conditions, mainly for the sake of cutting production. and Aster pilosus, a long-short-day plant, for which photoperiodic illuminations are used to induce stem elongation for winter flowering. In addition we tested a large number of photoperiodicaliy sensitive plants, which are commonly used in plant physiology studies of the photoperiodic reaction. The plants used are listed in Table 1.

The experiments will be summarized separately for the different plants. Statistical analysis has been applied to most of the early experiments and to all of the Gypsophila experiments. In the later experiments we have not yet applied statistical analysis, mainly because of personnel problems. Lines in the graphs have been drawn only following statistical analysis. Otherwise, only average data points are presented (except for those graphs presenting the effects of $2 \mathrm{~h}$ irradiations applied at different times in Exps 6 and 7 ). In this report we do not present all the 
experiments, but most will be published in due time. We have chosen the most interesting experiment with each plant,

for presentation herein. The results with Gypsophila has been prepared for publication (two papers have already been published, in Hebrew); Those with Aster pilosus have been presented as a poster; and the kalanchoe results have been published in the Triennual Report of the Scientific Activities of the Institute of Field and Garden Crops (1982-1985).

A Word of thanks. Many thanks are due to the people who helped to carry out this study. Special appreciation is expressed to Mordechai Ron and Meir Gartenhouse who transformed two dilapidated glass greenhouses into an excellent experimental tool, and to our main assistants Dovrat Peiper-Schwab and Meir Gartenhouse, for helping in most of the experiments. To oded Kutner for the renovation of the curtain system, and to Yosi Cohen, Dror Mahala and Amihud Radomiselski we express our appreciation for their help. Special thanks are due to $A$. Genizi of the Dept. of statistics for his constant help and advice throughout the experiments. We also wish to thank Yoran Metal Works, and especially Yuval, for the construction of the curtain system; and to the workers of "Hameshakem" who helped with all the difficult jobs. And last but not least, to Prof. A. Galston and to the Biology Department at Yale University, for allowing me to stay there while writing this report.

Materials and Methods

The research was carried out in two unheated greenhouses, covered with clear polycarbonate roof and polyethylene sides. The central part of each greenhouse was divided each night into eight north-south compartments by means of black polyethylene curtains which were pulled automatically after sunset and rolled back before dawn. The bed situated on the west side of one greenhouse was used for the natural daylength (ND) control and in the other greenhouse a shortday (SD) compartment (1OL/14D) was created using a black polyethylene cover which was automatically pulled over the bed after sunset and rolled back at the proper time after sunrise. This was done in order to avoid shading the neighboring beds and in order to avoid overheating of the plants in the SD compartment in the afternoon. In the beds on the east side five incandescent lamps were hung in a row (these beds were usualiy not included in this report). In all other cases, one or more lamps were hung above the center of each bed. On each side of the lamps four lots of plants were planted in polyurethane boxes $(130 \times 80 \times 17 \mathrm{~cm})$. in the early experiments (Exps. $1-4$ and part of Exp. 5) only: gypsophila plants were grown in these boxes. A gap of 
$50 \mathrm{~cm}$ between the polyurethane boxes was used to grow plants other than gypsophila. Two boxes or two interboxes (plots), which were equi-distant from the lamps, comprised one treatment (position) (Fig. 1). In some cases two compartments (beds) were used for each treatment. In the case of the polyurethane boxes, in several experiments only three of the positions were included in the statistical evaluations, because on the north the fourth box was shaded by the curtains and on the south the plants of the fourth box received more sunlight then the other lots. The experiments were repeated seven times, with variations mainly in the light fluence rates and in the timing and duration of the irradiations (Table 2).

Light sources. Incandescent lamps (INC), 100W, 150W and 300W; Quartz-Iodide, 500W; High-pressure sodium (HPS), 150W; Low-pressure sodiumm, (LPS) 130W; Cool-White Fluorescent (CW), 40W; Gro-Lux Fluorescent (GL), 40W. Blue light was filtered out of $40 \mathrm{~W}$ Blue fluorescent lamps covered with "Blue-" celluloid which did not transmit the FR. Far-Red (FR) light was filtered out of 500W Quartziodide lamps with a combination of "Blue+" (FR

transmitting) blue celluloid, orange celluloid and darkred cellophane (see Kadman-Zahavi \& Ephrat, Israel J. Bot. $25: 11-23,1976$ for details of the Blue-, Bluet and Orange celluloids). Each could be connected to any one of several timers. The combination of lamps and lamp wattage used in the different experiments is summarized in Table 3 and the relative quantum emission of the Inc, HPS, GL and $\mathrm{CW}$ lamps is presented in Figs a1-4 (data received from $\mathrm{T}$. Tibbsitts).

Timing and duration of the irradiations (Table 4 ). The irradiations were applied throughout the night (AN) (12h or $10 \mathrm{~h})$, in the evening(DE) ( $2 \mathrm{~h}, 4 \mathrm{~h}$ or $5 \mathrm{~h})$, or in the middle of the night (NB) (15 min, $2 \mathrm{~h}$ or $4 \mathrm{~h}$ ). In addition, in Exp. 6 and $7,2 \mathrm{~h}$ irradiations were applied in late evening (LE) or early morning (EM). In these two experiments $30 \mathrm{~min}$ End-Of Day (EOD) irradiations with Grolux or FR light were applied immediately after sunset. In several experiments Incandescent light was provided either continuously for the whole irradiation period (cont) or in pulses (cyclic: $2 \mathrm{minL} / 4 \mathrm{minD}$, or $5 \mathrm{minL} / 5 \mathrm{minD}$ ), during the same periods. Light fluence rates in the cyclic treatments were triple or double these of the continuous irradiations, accordingly.

Light Measurements (uMol.m-2.s-1), were carried out with a Li-Cor Quantum sensor connected to a Li-Cor quantum meter (Lambda Instrument Corporation, Lincoln, Nebraska, USA). Two readings were taken at each plot: In the first the light sensor was facing the vertical (VE). For the second reading the sensor was aimed to read the maximum reading possible at each plot (Max). Readings were taken separately 
for the polyuretane boxes ("gypsophila") and for the interbox positions ("chrysanthemum"). In the polyurethane boxes sometime two or even three readings were taken at each box. These measurements were used for gypsophila, whenever different treatments were planted in each box (such as GA sprays and Cold treatments), and at the last experiments when each species was planted at one particular position in the polyurethane boxes. The measurements were usually taken at ground level, before the planting; sometimes a second measurement was taken at the end of the experiment, after the plants were removed. The actual readings were always somewhat variable, even with consecutive readings. We therefore decided to average the readings for each lamp combination and use these average readings instead of the specific reading at each plot. These calculations are presented in Tables 5 and 6 .

Light fluence rates are not presented in this report, but in most graphs and tables the logarithm of the total fluence received per night is presented: Log uMol.mz.night-1 (quanta per square meter per second) $x$ (the duration of the irradiations, in seconds). In gypsophyla, aster and kalanchoe, the calculated average vertical+maximum readings were used. In all other figures only the vertical reading was used, because that is the accepted method used in measuring light fluences, although in our opinion the averaged fluence is a better measurement of the actual light received by the plants. In the tables both measurements are given.

Soil mixes. The polyurethane boxes were filled with volcanic gravel, as is recommended for gypsophila. In the interbox plots the plants were grown in black $7 \times 7 \times 17 \mathrm{~cm}$ polyethylene pots, filled with a mixture of peat and small size volcanic grave $(11: 1)$. Water and fertilizers were applied via drip irrigation once or twice daily, according to weather conditions; the irrigation was always given to an overflow, to prevent salt accumulation.

Data Collection. Each individual plant had its own number, according to its position in the plot. Twice a week the plants were scanned and the dates of stem elongation, and the appearance of visible flower buds, open flowers or any other interesting phenomena were recorded. In addition, in many experiments the plants were collected for measurements of stem length and leaf number, etc., either at the time of opened flowers or at the end of the experiment. In some experiments the apexes of non-flowering plants were dissected to determine their condition. All these data were later transferred to a main-frame or PC computer.

Statistical analysis was done using the SAS statistical program. 
Eig. 1 Schematic plan of a Bed:

$a, b, c, d$ - The polyurethane Boxes. Positions at increased distance from the lamp.

$a^{\prime}, b^{\prime}, c^{\prime}, d^{\prime}-$ Inter-box positions

(As each plant species was planted either in the polyurethane boxes or in an inter-box position, the 'sign is not further used).

$$
\bigcup_{\equiv} \equiv
$$

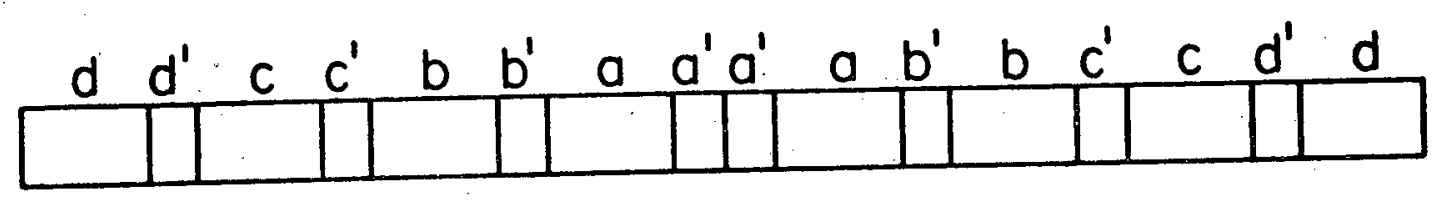


Table 1

Plants used in the seven experiments.

Experiment

\begin{tabular}{|c|c|c|c|c|c|c|c|}
\hline Plant species & 1 & 2 & 3 & 4 & 5 & 6 & 7 \\
\hline Gypsophila paniculata & + & + & + & + & + & - & - \\
\hline Arabidopsis taliana & - & - & - & - & + & - & - \\
\hline Aster pilosus & + & + & + & - & - & - & - \\
\hline Brassica campestris & + & + & - & - & - & - & - \\
\hline Centaurea cyanus & + & - & - & - & + & + & + \\
\hline Chrysanthemum morifolium & + & - & + & - & + & - & - \\
\hline Hordeum vulgare & - & - & - & - & - & - & + \\
\hline Hyoscyamus niger & - & - & - & + & + & + & + \\
\hline Kalanchoe blossfeldiana & - & + & + & + & - & - & - \\
\hline Pharbitis nil & - & - & - & - & - & + & + \\
\hline Setaria italica & - & - & - & - & - & + & - \\
\hline Sinapis alba & - & - & - & - & + & + & + \\
\hline Spinacia oleracea & - & - & + & + & - & - & + \\
\hline Iriticum vulgare & + & - & - & - & - & + & - \\
\hline Xanthium strumarium & - & - & - & + & + & - & + \\
\hline
\end{tabular}


Table 2 The Experiments. Lamps, Timing and Plants used in the different experiments. (For lamps see Table 3; for timing, see Table 4).

Experiment 1. Autumn 1983 - win̈ter 1984

Lamps: Inc HPS CW GL Inc+CW.

Timing: AN(12h) DE(5h) NB(4h)

Duration: Inc - Continuous vs. Cyclic lighting ( 1 min 1 - 2 min d).

Plants

LDP: Gypsophila paniculata. Brassica campestris, Centaurea cyanus, Triticum vulgare.

SDP: Chrysanthemum morifolium.

L-SDP: Aster pilosus.

Experiment 2. Winter - Spring 1984

Lamps: Inc HPS CW GL Inc+CW, Blended-light.

Timing: AN(12h) DE(5h) NB(4h)

Duration: Inc - Continuous or Cyclic ( $5 \mathrm{~min} 1-5 \mathrm{~min} d)$.

Plants: LDP: Gypsophila paniculata, Brassica campestris

SDP: Kalanchoe blossfeldiana.

L-SDP: Aster pilosus (from LD).

Experiment 3. Autumn 1984 - Winter 1985.

Lamps: IncC HPS LPS CW GL FR Blue

Timing: AN(12h) DE(4h) NB(4h) NB (15 min).

Plants: LDP Gypsophila paniculata, Hyoscyamus niger,

Spinacia oleracea.

SDP : Chrysanthemum morifolium. Kalanchoe

blossfeldiana.

L-SDP: Aster pilosus (from LD).

Experiment 4. Winter-Spring 1985.

Lamps: Inc HPS CW GL LPS.FR Blue

Timing: AN(1Oh) DE(4h) NB(4h) NB (15 min).

Duration Inc(AN) - Cont, Cycl ( 5 min $1-5$ mind).

Plants: LDP: Gypsophila paniculata $(2 x)$, Hyoscyamus

niger, Spinacia oleracea.

SDP: Kalanchoe blossfeldiana, Xanthium strumarium. 
Experiment 5. Autumn 1985 - Winter 1986

Lamps: Inc HPS CW GL LPS FR Blue

Timing: $\quad A N(10 h) D E(2 h) \quad N B(2 h)$ NB(15 min)

Plants: LDP Gypsophila paniculata. Centaurea cyanus,

Hyoscyamus niger. Triticum vulgare, Sinapis alba.

strumarium.

SDP: Chrysanthemum morifolium. Xanthium

Experiment 6. Winter-Spring 1986.

Lamps: Inc HPS CW GL LPS FR Blue

Timing: AN(10h) DE(2h) NB(2h) NB(15min) EOD(30min) LE(2h)

Plants: $\quad$ LDP Centaurea cyanus, Hyoscyamus niger, Sinapis

alba

SDP: Pharbitis nil, Setarie italica.

Experiment 7. Autumn 1986 - Winter 1987

Lamps: Inc HPS CW GL LPS FR Blue

Timing: AN(10h) DE(2h) NB(2h) NB(15min) EOD (30min)

$\operatorname{LE}(2 h) \operatorname{EM}(2 h)$

Plants: LDP Centaurea cyanus, Hyoscyamus niger, Sinapis

alba $(2 x)$, Spinacia oleracea $(2 x)$.

SDP : Pharbitis nil, Xanthium strumarium. 
Table 3

Lamps and Lamp Wattage Used in the Different Experiments

Inc - Incandescent or Quartz-iodide ; Inc CYC -

Incandescent - Cyclic lighting; HPS- High Pressure Sodium; LPS - Low Pressure Sodium; CW - CoOl White fluorescent; GL - Grolux fluorescent; FR - Quartz-Iodide with Filters (See Materials and Methods); Blue - Blue fluorescent lamps with "Blue-" Filter (See Materials and Methods)..

Timing.

$\underline{A N}$ - AII Night; $\underline{D E}$ - Day extension - soon after darkness;

NB - Night break - Centered at midnight. EOD - End of day - immediately after sunset. LE - Late evening (1800-2000); EM - Early morning (0300-0500) (see Table 4 for the duration of the irradiations.)

$\underline{\text { INC }}$

Experiment No.

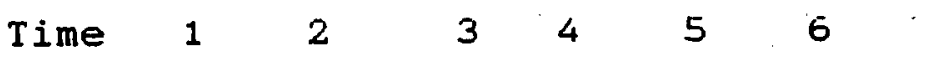

$\begin{array}{llllllll}\text { AN } & 100 & 150 & 150 & 300 & 100 & 100 & 100 \\ \text { DE } & 100 & 150 & 150 & 300 & 300 & 300 & 300 \\ \text { NB } & 100 & 150 & 150 & 300 & 300 & 300 & 300 \\ \text { SNB } & - & - & 300 & 1000 & 1600 & 1600 & 1600 \\ \text { LE } & - & - & - & - & - & 300 & 300 \\ \text { EM } & - & - & - & - & - & 300 & 300\end{array}$

INC CYCLIC

Experiment No.

\begin{tabular}{lccccccc} 
Time & 1 & 2 & 3 & 4 & 5 & 6 & 7 \\
\hline AN & 300 & 300 & - & 600 & - & - & - \\
DE & 300 & 300 & - & - & - & - & - \\
NB & 300 & 300 & - & - & - & - & -
\end{tabular}


CW+INC

\section{Experiment No.}

\begin{tabular}{llllllll} 
Time & 1 & 2 & 3 & 4 & 5 & 6 & 7 \\
\hline AN & 140 & 140 & - & - & - & - & - \\
DE & - & - & - & - & - & - & - \\
NB & 140 & 140 & - & - & - & - & -
\end{tabular}

CW

Experiment No.

\begin{tabular}{lccccccc} 
Time & 1 & 2 & 3 & 4 & 5 & 6 & 7 \\
\hline AN & 40 & 80 & - & - & - & - & - \\
DE & - & 80 & - & - & - & - & - \\
NB & 40 & 80 & 80 & 80 & 80 & - & - \\
SNB & - & - & 160 & 160 & - & - & - \\
\hline
\end{tabular}

GL

Experiment No.

\begin{tabular}{|c|c|c|c|c|c|c|c|}
\hline Time & 1 & 2 & 3 & 4 & 5 & 6 & 7 \\
\hline AN & 40 & - & - & - & - & 40 & 40 \\
\hline$D E$ & 40 & - & - & - & 80 & 80 & 80 \\
\hline NB & 40 & 80 & 80 & 80 & 80 & 80 & 80 \\
\hline $\begin{array}{l}\text { SNB } \\
\text { EOD }\end{array}$ & - & - & $\begin{array}{l}160 \\
-\end{array}$ & $\begin{array}{l}160 \\
-\end{array}$ & $\begin{array}{l}240 \\
-\end{array}$ & $\begin{array}{l}240 \\
240\end{array}$ & $\begin{array}{l}240 \\
240\end{array}$ \\
\hline LE & - & - & - & - & - & 80 & 80 \\
\hline $\mathbf{E M}$ & - & - & - & - & - & 80 & 80 \\
\hline
\end{tabular}


HPS

Experiment No.

\begin{tabular}{lccccccc} 
Time & 1 & 2 & 3 & 4 & 5 & 6 & 7 \\
\hline AN & $150 *$ & 150 & 150 & 300 & 300 & 150 & 150 \\
DE & $150 *$ & 150 & - & - & - & - & - \\
NB & $150 *$ & 150 & - & - & - & - & - \\
\hline
\end{tabular}

LPS

Experiment No.

\begin{tabular}{llllllll} 
Time & 1 & 2 & 3 & 4 & 5 & 6 & 7 \\
\hline AN & - & - & 130 & - & - & - & - \\
DE & - & - & 130 & 130 & - & - & - \\
NB & - & - & 130 & 130 & 130 & - & - \\
\hline
\end{tabular}

\section{BLUE}

Experiment No.

\begin{tabular}{lccccccc} 
Time & 1 & 2 & 3 & 4 & 5 & 6 & 7 \\
\hline AN & - & - & - & 160 & 240 & 240 & 240 \\
NB & - & - & 80 & - & - & - & - \\
& & & &
\end{tabular}

FR

Experiment No.

\begin{tabular}{llllllll} 
Time & 1 & 2 & 3 & 4 & 5 & 6 & 7 \\
\hline AN & - & - & - & 1000 & 1000 & - & - \\
NB & - & - & 1000 & - & - & - & - \\
EOD & - & - & - & - & - & 1000 & 1000
\end{tabular}


Table 4.

Timing and duration of the irradiations.

\begin{tabular}{|c|c|c|c|c|c|c|c|}
\hline Time & 1 & $\frac{\text { Exper }}{2}$ & $\frac{\text { iment }}{3}$ & $\frac{\text { No. }}{4}$ & 5 & 6 & 7 \\
\hline AN & $12 \mathrm{~h}$ & $12 \mathrm{~h}$ & $12 \mathrm{~h}$ & $12 \mathrm{~h}$ & $10 \mathrm{~h}$ & $10 \mathrm{~h}$ & $10 \mathrm{~h}$ \\
\hline$D E$ & $5 h$ & $5 h$ & $4 h$ & $4 h$ & $2 h$ & $2 h$ & $2 \mathrm{~h}$ \\
\hline NB & $4 h$ & $4 h$ & $4 h$ & $4 h$ & $2 h$ & $2 h$ & $2 \mathrm{~h}$ \\
\hline SNB & - & - & $15 \mathrm{~m}$ & $15 m$ & $15 \mathrm{~m}$ & $15 \mathrm{~m}$ & $15 \mathrm{~m}$ \\
\hline EOD & - & & - & & - & $30 \mathrm{~m}$ & $30 \mathrm{~m}$ \\
\hline $\mathbf{E}$ & - & & - & & - & $2 h$ & $2 \mathrm{~h}$ \\
\hline$M$ & - & & - & & - & $2 \mathrm{~h}$ & $2 h$ \\
\hline
\end{tabular}


Table 5

Summary of light measurements over Gypsophila boxes 1985-87

Figures are in umol.m-2.sec-1

Averages of all measurements

VE: Light probe facing up.

AvgVe+Max: Average of two measurements at each spot:

vertical and maximum (maximum reading on the probe when

facing the lamp): (Ve+Max)/2

One or more lamps hanging in the center of the beds.

except 2x: 2 clusters of lamps hanging above Gypsophila boxes over positions a.

Sometimes two measurements were taken in each box:

one closer (I) and the other(II) farther from the lamps.

$\mathrm{n}$ : number of light measurements

\begin{tabular}{|c|c|c|c|c|c|}
\hline Lamp & Wattage & $n$ & Position & AvgVe & AvgVe+Max \\
\hline Inc & 100 & 1 & $\begin{array}{l}a \\
b \\
c \\
d\end{array}$ & $\begin{array}{l}.80 \\
.16 \\
.04 \\
.01\end{array}$ & $\begin{array}{l}.80 \\
.22 \\
.07 \\
.03\end{array}$ \\
\hline Inc & 300 & 4 & $\begin{array}{l}a \\
b \\
c \\
d\end{array}$ & $\begin{array}{r}1.29 \\
.29 \\
.10 \\
.05\end{array}$ & $\begin{array}{r}1.48 \\
.45 \\
.18 \\
.10\end{array}$ \\
\hline Ine & $2 \times 150$ & 2 & $\begin{array}{l}a \\
b \\
c \\
d\end{array}$ & $\begin{array}{r}1.46 \\
.55 \\
.15 \\
.06\end{array}$ & $\begin{array}{r}1.46 \\
.69 \\
.22 \\
.10\end{array}$ \\
\hline Inc & $2 \times 300$ & 2 & $\begin{array}{l}a \\
b \\
c \\
d\end{array}$ & $\begin{array}{r}3.05 \\
1.40 \\
.27 \\
.11\end{array}$ & $\begin{array}{r}3.06 \\
1.70 \\
.47 \\
.21\end{array}$ \\
\hline Inc & $\begin{array}{l}2 \times(500 \\
+300)\end{array}$ & 1 & $\begin{array}{l}a \\
b \\
c \\
d\end{array}$ & $\begin{array}{r}8.90 \\
1.62 \\
.26 \\
.11\end{array}$ & $\begin{array}{l}9.15 \\
2.07 \\
.46 \\
.21\end{array}$ \\
\hline Inc & $5 \times 150 \mathrm{~W}$ & 2 & $a$ & 1.76 & 1.85 \\
\hline $\begin{array}{l}\text { Far-Red } \\
\text { Quartz-I } \\
2 \times 500 \mathrm{~W} \\
\text { without }\end{array}$ & $\begin{array}{l}\text { odine } \\
\text { FR filter }\end{array}$ & I. & $\begin{array}{l}\text { a South } \\
b \\
c \\
d\end{array}$ & $\begin{array}{r}4.50 \\
.40 \\
.11 \\
.08\end{array}$ & $\begin{array}{r}5.25 \\
1.00 \\
.23 \\
.12\end{array}$ \\
\hline & & II. & $\begin{array}{l}\text { a South } \\
b \\
c \\
d\end{array}$ & $\begin{array}{l}4.40 \\
.35 \\
.10 \\
.06\end{array}$ & $\begin{array}{r}4.80 \\
.62 \\
.19 \\
.10\end{array}$ \\
\hline
\end{tabular}




\begin{tabular}{|c|c|c|c|c|c|c|}
\hline \multicolumn{2}{|l|}{ Lamp } & Wattage & $\mathrm{n}$ & Position & AvgVe & AvgVe+Max \\
\hline \multicolumn{2}{|l|}{$C W$} & 80 & 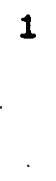 & $\begin{array}{l}a \\
b \\
c \\
d\end{array}$ & $\begin{array}{r}1.53 \\
.30 \\
.09 \\
.05\end{array}$ & $\begin{array}{r}1.78 \\
.44 \\
.14 \\
.08\end{array}$ \\
\hline \multicolumn{2}{|c|}{ GroLux } & 40 & 2 & 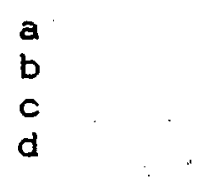 & $\begin{array}{l}.72 \\
.14 \\
.05 \\
.03\end{array}$ & $\begin{array}{l}.81 \\
.22 \\
.09 \\
.05\end{array}$ \\
\hline \multicolumn{2}{|c|}{ GroLux } & 80 & 4 & $\begin{array}{l}a \\
b \\
c \\
d\end{array}$ & $\begin{array}{r}1.34 \\
.24 \\
.07 \\
.03\end{array}$ & $\begin{array}{r}1.52 \\
.38 \\
.14 \\
.07\end{array}$ \\
\hline \multicolumn{2}{|c|}{ Grolux } & $2 \times 120$ & 4 & $\begin{array}{l}a \\
b \\
c \\
d\end{array}$ & $\begin{array}{r}3.68 \\
1.92 \\
.37 \\
.11\end{array}$ & $\begin{array}{r}3.69 \\
2.21 \\
.56 \\
.22\end{array}$ \\
\hline \multicolumn{2}{|l|}{ HPS } & 150 & 1 & $\begin{array}{l}a \\
b \\
c \\
d\end{array}$ & $\begin{array}{r}1.29 \\
.49 \\
.16 \\
.08\end{array}$ & $\begin{array}{r}3.33 \\
1.02 \\
.26 \\
.13\end{array}$ \\
\hline \multicolumn{2}{|l|}{ HPS } & $2 \times 150$ & 1 & $\begin{array}{l}a \\
b \\
c \\
d\end{array}$ & $\begin{array}{r}5.30 \\
3.05 \\
.70 \\
.30\end{array}$ & $\begin{array}{r}5.30 \\
3.62 \\
1.15 \\
.55\end{array}$ \\
\hline \multirow[t]{2}{*}{ LPS } & I. & 130 & 1 & $\begin{array}{l}a \\
b \\
c \\
d\end{array}$ & $\begin{array}{r}3.68 \\
1.20 \\
.30 \\
.10\end{array}$ & $\begin{array}{r}4.01 \\
1.64 \\
.56 \\
.15\end{array}$ \\
\hline & I I. & & 1 & $\begin{array}{l}a \\
b \\
c \\
d\end{array}$ & $\begin{array}{r}2.85 \\
.80 \\
.26 \\
.07\end{array}$ & $\begin{array}{r}3.18 \\
1.25 \\
.42 \\
.12\end{array}$ \\
\hline \multicolumn{2}{|l|}{ Blue } & $2 \times 120$ & 1 & $\begin{array}{l}a \\
b \\
c \\
d\end{array}$ & $\begin{array}{l}.53 \\
.25 \\
.07 \\
.04\end{array}$ & $\begin{array}{l}.53 \\
.30 \\
.10 \\
.06\end{array}$ \\
\hline
\end{tabular}


Table 6

Average Light Fluence Rates at positions between

Gypsophila Boxes.

Summary of light measurements 1983-1987

Figures are in umol.m-2.sec-1 (averages of all measurements)

VE: Light probe facing up.

Avg Ve+Max: Average of two measurements at each spot:

vertical and Maximum (maximum reading on the probe when

facing the lamp): (Ve+Max) $/ 2$

one or more lamps hanging in the center of the beds.

except: $2 x$ - two clusters of lamps hanging above Gypsophila boxes over positions a.

$\mathrm{n}$ : number of light measurements

\begin{tabular}{|c|c|c|c|c|c|}
\hline Lamp & Wattage & $n$ & Position & AvgVe & $A v g V e+\operatorname{Max}$ \\
\hline Inc & 100 & 4 & $\begin{array}{l}a \\
b \\
c \\
d\end{array}$ & $\begin{array}{l}.80 \\
.16 \\
.04 \\
.01\end{array}$ & $\begin{array}{l}.80 \\
.22 \\
.07 \\
.03\end{array}$ \\
\hline Inc & 150 & 3 & $\begin{array}{l}a \\
b \\
c \\
d\end{array}$ & $\begin{array}{r}1.24 \\
.30 \\
.09 \\
.03\end{array}$ & $\begin{array}{r}1.26 \\
.39 \\
.14 \\
.07\end{array}$ \\
\hline Inc & 300 & 10 & $\begin{array}{l}a \\
b \\
c \\
d\end{array}$ & $\begin{array}{r}2.21 \\
.59 \\
.15 \\
.06\end{array}$ & $\begin{array}{r}2.22 \\
.75 \\
.26 \\
.13\end{array}$ \\
\hline Inc & $2 \times 150$ & 4 & $\begin{array}{l}a \\
b \\
c \\
d\end{array}$ & $\begin{array}{r}.76 \\
1.34 \\
.24 \\
.08\end{array}$ & $\begin{array}{r}.76 \\
1.39 \\
.35 \\
.13\end{array}$ \\
\hline Inc & $2 \times 300$ & 2 & $\begin{array}{l}a \\
b \\
c \\
d\end{array}$ & $\begin{array}{r}1.69 \\
2.73 \\
.58 \\
.15\end{array}$ & $\begin{array}{r}1.69 \\
2.86 \\
.83 \\
.27\end{array}$ \\
\hline Inc & $\begin{array}{l}2 \times(500 \\
+300)\end{array}$ & 2 & $\begin{array}{l}a \\
b \\
c \\
d\end{array}$ & $\begin{array}{r}3.30 \\
8.65 \\
.55 \\
.15\end{array}$ & $\begin{array}{r}3.36 \\
8.81 \\
.80 \\
.29\end{array}$ \\
\hline Inc & $5 \times 150 \mathrm{~W}$ & 1 & a & 1.76 & 1.85 \\
\hline
\end{tabular}




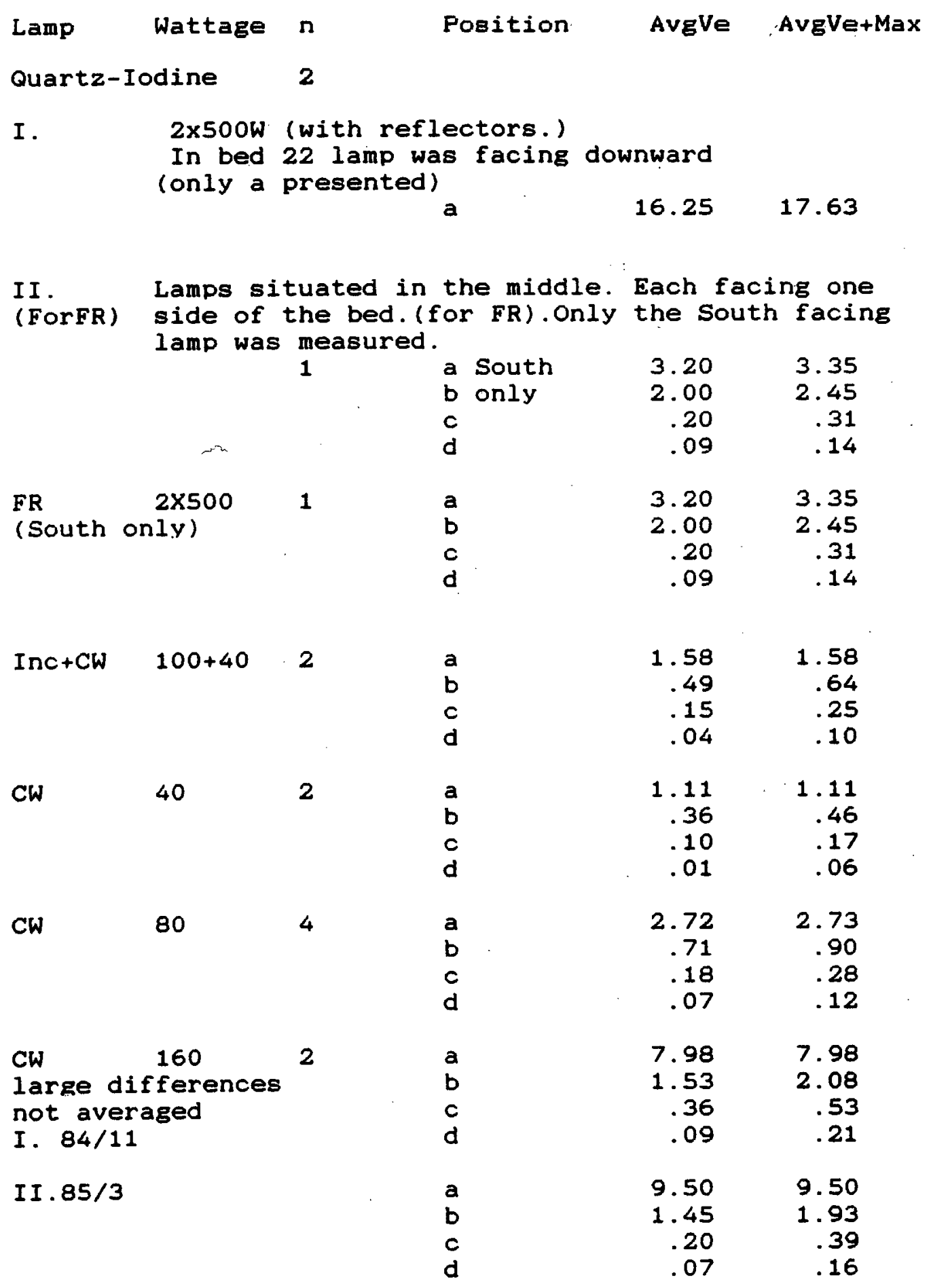




\begin{tabular}{|c|c|c|c|c|c|}
\hline Lamp & Wattage & $n$ & Position & AvgVe & AvgVe+ \\
\hline GroLux & 40 & 4 & $\begin{array}{l}a \\
b \\
c \\
d\end{array}$ & $\begin{array}{r}1.14 \\
.30 \\
.08 \\
.02\end{array}$ & $\begin{array}{r}1.14 \\
.39 \\
.13 \\
.06\end{array}$ \\
\hline GroLux & 80 & 4 & $\begin{array}{l}a \\
b \\
c \\
d\end{array}$ & $\begin{array}{r}2.39 \\
.53 \\
.13 \\
.05\end{array}$ & $\begin{array}{r}2.39 \\
.72 \\
.22 \\
.09\end{array}$ \\
\hline $\begin{array}{l}\text { Grolux } \\
\text { Large di } \\
\text { not aver } \\
\text { I. } 84 / 4\end{array}$ & $\begin{array}{l}160 \\
\text { fferences } \\
\text { aged }\end{array}$ & 2 & $\begin{array}{l}a \\
b \\
c \\
d\end{array}$ & $\begin{array}{r}3.32 \\
1.22 \\
.34 \\
.12\end{array}$ & $\begin{array}{r}3.32 \\
1.38 \\
.47 \\
.18\end{array}$ \\
\hline II . $85 / 3$ & & & $\begin{array}{l}a \\
b \\
c \\
d\end{array}$ & $\begin{array}{r}4.65 \\
.95 \\
.18 \\
.07\end{array}$ & $\begin{array}{r}4.65 \\
1.30 \\
.31 \\
.14\end{array}$ \\
\hline GroLux & $2 \times 120$ & 4 & $\begin{array}{l}a \\
b \\
c \\
d\end{array}$ & $\begin{array}{r}2.36 \\
3.53 \\
.72 \\
.18\end{array}$ & $\begin{array}{r}2.38 \\
3.58 \\
.94 \\
.32\end{array}$ \\
\hline $\begin{array}{l}\text { HPS } \\
\text { I. "With } \\
\text { Ref I }\end{array}$ & $\begin{array}{l}150 * \\
\text { out } \\
\text { ectors }\end{array}$ & 3 & $\begin{array}{l}a \\
b \\
c \\
d\end{array}$ & $\begin{array}{l}.89 \\
.97 \\
.29 \\
.12\end{array}$ & $\begin{array}{r}.89 \\
1.25 \\
.53 \\
.27\end{array}$ \\
\hline II. With $\begin{array}{l}\text { Ref } 1\end{array}$ & ectors & 3 & $\begin{array}{l}a \\
b \\
c \\
d\end{array}$ & $\begin{array}{r}4.64 \\
1.63 \\
.46 \\
.16\end{array}$ & $\begin{array}{r}4.64 \\
2.01 \\
.73 \\
.32\end{array}$ \\
\hline $\begin{array}{l}\text { III. } 86 / \\
\text { Much low } \\
\text { Readings } \\
\text { not incl } \\
\text { in avera }\end{array}$ & $\begin{array}{l}10 \\
\text { er } \\
\text { uded } \\
\text { ge }\end{array}$ & 1 & $\begin{array}{l}a \\
b \\
c \\
d\end{array}$ & $\begin{array}{r}3.88 \\
.73 \\
.18 \\
.08\end{array}$ & $\begin{array}{r}4.36 \\
1.07 \\
.36 \\
.21\end{array}$ \\
\hline LPS & 130 & 5 & $\begin{array}{l}a \\
b \\
c \\
d\end{array}$ & $\begin{array}{r}5.18 \\
1.94 \\
.66 \\
.17\end{array}$ & $\begin{array}{r}5.23 \\
2.57 \\
1.06 \\
.32\end{array}$ \\
\hline
\end{tabular}

Blue Blue Fluorescent lamps covered with Blue- Celluloid

\begin{tabular}{|c|c|c|c|c|}
\hline 160 & 1 & $\begin{array}{l}a \\
b \\
c \\
d\end{array}$ & $\begin{array}{l}.67 \\
.15 \\
.05 \\
.02\end{array}$ & $\begin{array}{l}.69 \\
.20 \\
.07 \\
.04\end{array}$ \\
\hline $2 \times 120$ & 1 & $\begin{array}{l}a \\
b \\
c \\
d\end{array}$ & $\begin{array}{l}.35 \\
.48 \\
.10 \\
.07\end{array}$ & $\begin{array}{l}.35 \\
.50 \\
.14 \\
.08\end{array}$ \\
\hline
\end{tabular}


Cool-pite

(ci)

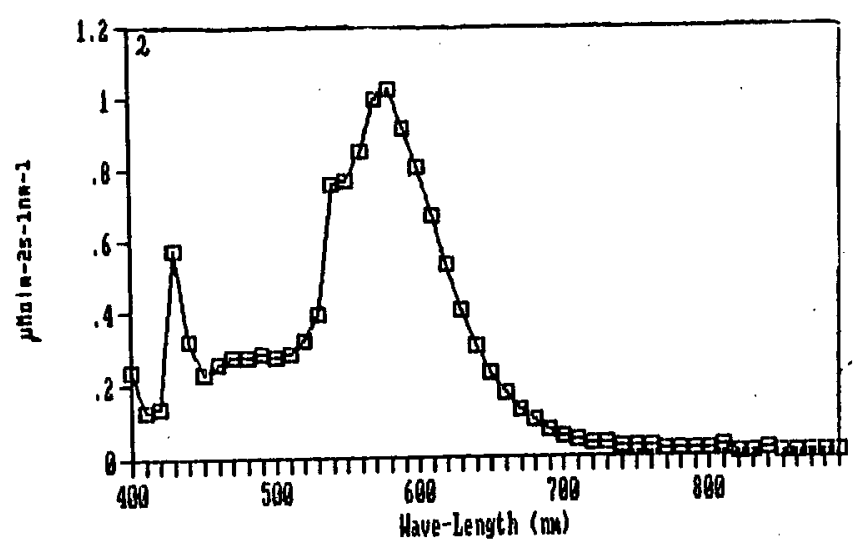

High-Pressure Sodiun

(HIS)

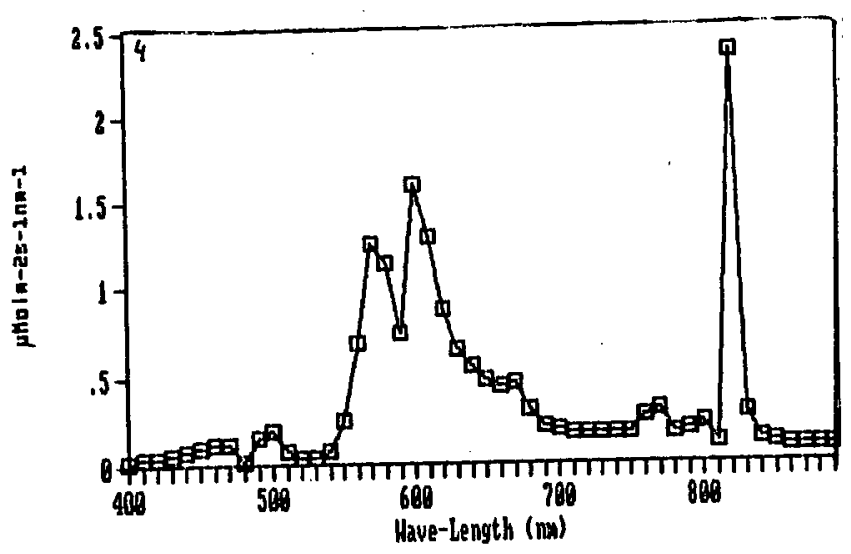

Gro-lux

(CL)

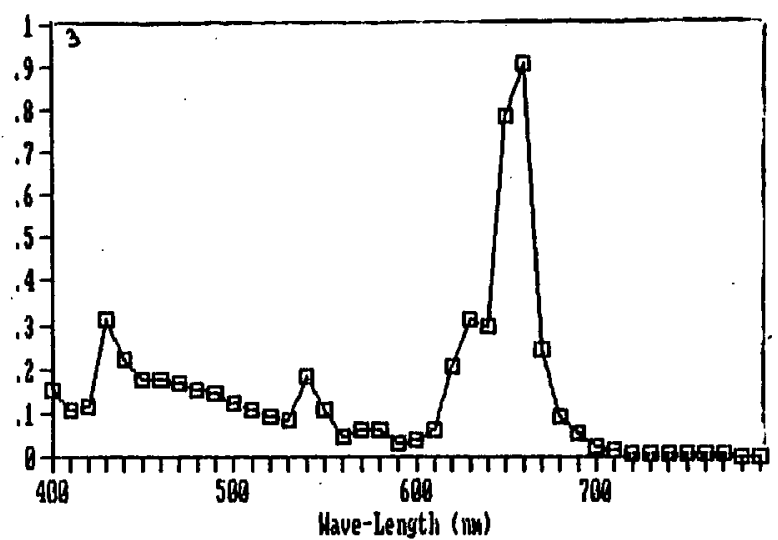

Incandescent

(Iiik)

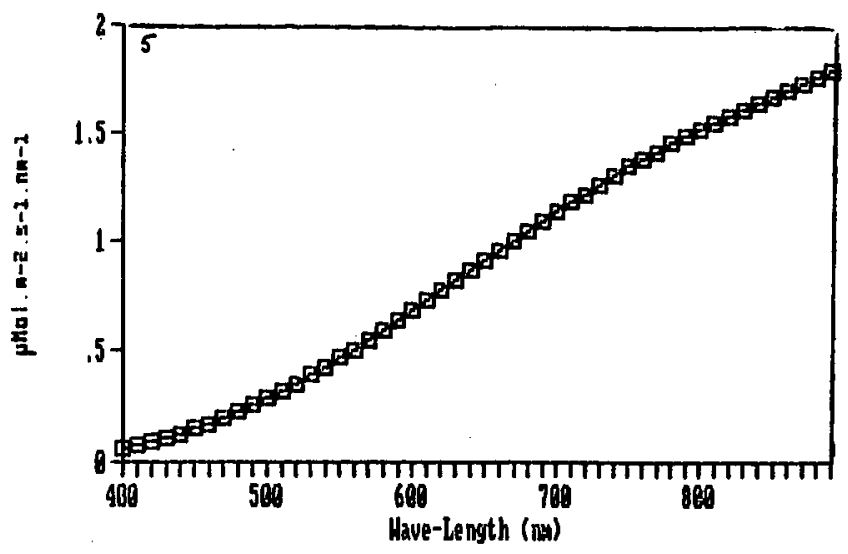

Figs. $2-5$ Relative fluence rates (umol.m-2.s-1) emitted by CW, GL, HPS and Inc lamps. 
Legend for all the Figures

(Except for Aster pilosus. Kalanchoe blossfeldiana and Fig 1 in Chrysanthemum morifolium)

Lamp: Inc - Incandescent or Quartz-iodide ; Inc Cyc Incandescent - Cyclic lighting; HPS- High Pressure Sodium; LPS - Low Pressure Sodium; CW - Cool White fluorescent; GL Grolux fluorescent: FR - Quartz-Iodide with Filtres (See Materials \& Methods); BLUE - Blue fluorescent lamps with Blue-Filter (See Materials \& Methods).

Iiming: AN - All Night; DE - Day extention - soon after darkness: NB - Night break - Centered at midnight. SI Short irradiation, $15 \mathrm{~min} \mathrm{NB}$ or $30 \mathrm{~min}$ EOD (End of Day)

Timing

\begin{tabular}{|c|c|c|c|c|}
\hline Lamp: & AN & $\overline{D E}$ & NB & $\mathrm{SI}$ \\
\hline Inc & 0 & 0 & $\odot$ & (2) \\
\hline Inc Cycl & 0 & $\theta$ & (2) & \\
\hline$G L$ & $\triangle$ & $\triangle$ & $\Delta$ & $\Delta$ \\
\hline $\mathrm{CW}$ & 圆 & $\square$ & $\square$ & 回 \\
\hline HPS\&LPS & 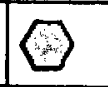 & 0 & $\odot$ & \\
\hline FR & $\#$ & & & $\#$ \\
\hline Blue & $\diamond$ & & & \\
\hline ND & $x$ & & & \\
\hline
\end{tabular}


Lighting in Gypsophila: Spectra, Fluence, Duration and Timing of Application

Abstract

The effectiveness of different lamps and illumination regimes were tested over a wide range of light fluences, thus providing a basis for comparison for economical calculations of the optimal illumination regime for winter flowering in Gypsophyla. It was found that lamps emitting light in the 550-770 nm range were almost equally suitable. Flowering date was directly related to the logarithm of the total light fluence between 1-100 mMolm-2night-1. The most economical application was to illuminate the plants throughout the night. Cyclic lightig could not provide any saving of energy.

\section{Introduction}

The long-day plant LDP Gypsophila paniculata is one of Israel's major cut flower crops. Winter flowering is induced by the use of photoperiodic irradiations.

Incandescent (Inc) lamps are usualiy recommended for the irradiation of LDP because they emit mixed Red and FR light, believed to be needed to induce flowering in LDP), but the radiant efficiency (the conversion of electric energy to light energy) of these lamps is low. Discharge lamps have a high radiant efficiency, but their spectral emittence is, in most cases, deficient in the $660 \mathrm{~nm}$ (Red)$720 \mathrm{~nm}$ (FR) range, which is the most effective for eliciting the photoperiodic reaction. Shillo and Halevy report that Cool-White (CW) fluorescent lamps were not effective in inducing flowering in gypsophila. However, Shlomo has shown that mixed $\mathrm{CW}$ and Inc lamps were very effective.

Irradiation early in the evening (day extensions) was less effective than irradiation applied later in the dark period (Shillo and Halevy, 1982). In several LDP the spectral response of the photoperiodic reaction changes in the course of the night: light with a high content of FR being most effective for extending the photoperiod, and light with a high content of Red being most effective in the middle of the night. In addition, it has been suggested that light applied intermittentiy (cyclic lighting) is more efficient than when the same total light energy is applied continuously. Cyclic illumination regimes have been worked out in detail and are widely in use for Gypsophila in Israel. Currently, about $12 \mathrm{KWHm}^{-2}$ of electricity is used annually to force two winter flowering flushes. 
The aim of the present research was to compare the efficiency of different light sources, applied at different periods of the night, in order to provide the basis for economicl calculations of the optimal illumination regime for Gypsophila. In this paper we report the effects of the illuminations on the advancement of flowering. The interaction of light, gibberellic acid and vernalization on the timing and quality of Gypsophyla flowering will be reported in a separate paper.

Materials and Methods.

The plants. Virus-free Gypsophila paniculata L. plants (var. Bristol Fairy, Selection: Romano 4) were received courtesy of the Yesod and Dan nurseries. Planting was usually in mid to late october, except for Exp. 5, which was planted in February. The winter experiments were usually terminated in February or early March. The plants were pruned down to the ground and then allowed to regenerate, to start a new, spring experiment. In summer all the plants were removed. Conventional commercial growing conditions were employed with the plants placed in volcanic gravel, and irrigated and fertilized daily via a drip irrigation system.

Data collection. Data on the date of appearance of flower buds (Day-Bud) and the date of the opening of the first flower (Day-Flower) were collected for every plant. Flowering plants were cut and collected for measurements when "commercially ripe" (i.e. about one-third of the flowers in the inflorescence were open). The following measurements were taken: total weight, length of the main branch, and the number of internodes, counted from the base up to the first triangulate node.

In Table 1. Lamps Used, Lamp Wattage, Timing and Duration of Illuminations, and Dates of the Different Experiments are summerized. Times of application are: $A N=A l l$ night; $\mathrm{DE}=$ Day extension; $\mathrm{NB}=\mathrm{Night}$ breaks. Lamps: Blue=Blue fluorescent with filter; CW=Cool white fluorescent; FR=Quarz-iodine with filter; GL=Grolux fluorescent; HPS=High-pressure sodium; INC=Incandescent ; LPS=Lowpressure sodium.

Results and Discussion

a. Light Fluence. Soon after the start of the first experiment it became evident that in most treatments light fluence was too low to allow flowering for such a late planting date. The only treatments attaining $100 \%$ flowering were those receiving the highest fluences: Position ' $a$ ' of the AN compartments of the HPS or INC+CW lamps (see data in Table 4, Exp. 1). The wattage of the lamps was therefore 


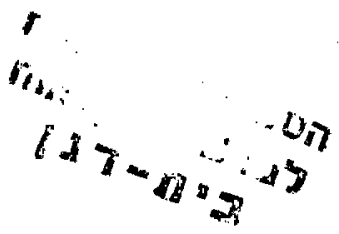

increased (Table 1, Exp. 2) and on Feb. 12, 1984 all the plants were pruned and allowed to regenerate. In this spring, experiment all the plants, including the natural daylength control, eventualiy flowered. In all the compartments the plants in positions $\underline{a}, \underline{b}$ and $c$ flowered before the natural daylength controls. The acceleration of flowering was directly related to the logarithm of light fluence (Fig. 1 ). In another spring experiment (Exp. 4) it was possible to calculate the threshold fluence below which flowering date was not affected by light (Fig. 2).

Furthermore, it was found that this threshold was higher in winter than in spring (Table 2): This was probably due both to the longer natural background photoperiod and the increased total PAR light and higher temperatures in spring.

b. Spectral responses

In Fig. 1a the fluence response curves fall clearly into two parallel straight lines, one representing treatments illuminated with incandescent lamps and the other

representing the discharge lamps (HPS, CW and GL). This figure shows that when light is measured in the 400-700nm (PAR) wavelength band, apparently more light quanta were needed to accelerate flowering with discharge lamps than with incandescent lamps. However, a large proportion of the light emitted by the incandescent lamps falls in the wavelength bands longer than 700 nm and are therefore not measured by our instrument. In Exp. 4 (Fig. 2) we found that FR light (i.e., wave, bands longer than $700 \mathrm{~nm}$ ) was effective in inducing flowering in Gypsophila. On the other hand, a large proportion of the light emitted by the fluorescent lamps used by us (CW and $G L$ ) falls in the blue region. In Exp. 4 it was found also that blue light had no effect on the flowering of Gypsophila (Fig. 2). All this shows that light measurements in the 400-700nm range, as measured with the Li-Cor Quantum-meter, does not represent the real photoperiodic effectiveness of the different lamps. However, since no other ready-made instrument was available, we calculated the missing light quanta in the incandescent light using tables provided by Prof. T. Tibbits (Table 3 ).

When these correction factors were applied, the light of all the lamps used in Exp. 2 fell on a single line (Fig. 1b) i.e. when light fluence is measured between 550 and 770 nm. then light emitted by all these lamps is almost equaliy effective. (Note: The correction factors are used for Gypsophila only).

In fig $1 \mathrm{~b}$ the HPS points are all aligned on one side of the graph. Calculations showed that in this experiment HPS light was not significantly different from that of the rest of the lamps, but in three consecutive experiments 
(Exp. 4, $5 \& 6$ ), HPS and LPS light was found to be slightly but significantiy less efficient than Inc and CW light (Fig 3). In Fig. 3 it can also be seen that FR light was also slightly less effective than the light emitted by Inc or $\mathrm{CW}$ lamps. We do not claim that our experiments provide very precise spectral response curves, but they suggest that the entire range between 550 and $770 \mathrm{~nm}$ is effective in the photoperiodic reaction of Gypsophila. If Phytrochrome is the active photosystem, then light absorbed both by $P_{r}$ and by $\mathrm{Per}$ is effective. On the other hand, there is no need for a mixed light reaction since LPS light, which is almost pure 590nm light without any FR, as well as FR light without any mixture of red below $700 \mathrm{~nm}$, were effective. The fact that during the day our plants grew in high intensity sunlight might have compensated for the lack of FR in the photoperiodic illuminations.

c. Lamp efficiency The fact that the 1 i $g h t$ emitted by the Inc lamps was more effective than that emitted by the HPS or LPS lamps does not mean that HPS and LPS 1 a $m p s$ are less effective. In Table 4 the effectiveness of these lamps at an equal wattage of $130-150 \mathrm{~W}$ is compared. It can be seen that the sodium lamps were effective over a greater distance than the Inc lamps; this is due to their higher radiant efficiency.

\section{d. Timing of the irradiation}

In Exp, 2, light applied at any time during the night seemed to be equally effective. In Exp. 4, on the other hand, $4 \mathrm{~h}$ night-break (NB) were found to be significantly more effective than $4 \mathrm{~h}$ day extensions (DE). This was true for both Inc and LPS lamps (Fig. 4 ).

e. Continuous vs cyclic lighting

The cyclic lighting regime is very common in commercial application in Israel. In three experiments we could not find any differences in the response of Gypsophila plants to one mode of application over the other, provided that the same total fluence was applied over the same period (Figs. 1 and 3 ).

\section{f. Morphogenetic effects}

In another paper (in preparation) we show that flower quality was directly related to flowering date, at least in winter and spring: the earlier the flowering, the higher the quality. The correlation between the date of flowering (Week-Flowering) and stem length is presented in Fig. 5. Stem length increased with earliness but was also dependent on light spectra: when plants flowering on the same date were compared, those grown in incandescent light with a high mixture of FR had longer stems than comparable plants 
illuminated with $\mathrm{CW}$ or sodium lamps, low in FR (Fig. 6). This could be seen as an indication against the use of HPL, light but in fact the stems produced in HPS were long enough. It was also found that the application of gibberellic acid could further increase stem length if necessary.

\section{g. Conclusions}

It was found that it is not possible to save energy by reducing the light fluence needed to induce winter flowering in Gypsophila. However, the total amount of light per crop, as well as other costs, may be drastically reduced by applying high fluence rates over prolonged irradiation periods - thus advancing flowering and shortening turnover time by one or more months. Any lamp emitting light in the 550-770nm range is suitable, the economic consideration depending on the price of electricity on the one hand and on the price of the installations on the other hand. Continuous irradiations should are preferable to cyclic lighting regimes, because in the former the same total fluence may be applied with lamps of a lower wattage. 
Legends for Figures.

(Simbols are Lamp simbols only, except for Fig 4, where Timing is also included)

Eig. 1. Relationship between log-light fluence(Log umol $\mathrm{m}^{-}$ ${ }^{\text {night-1) }}$ ) and average flowering-day in Exp. 2 (see Table 1 for details of treatments). 1a. Light fluence as measured with a LiCor Quantum meter in the 400-700nm range. $1 \mathrm{~b}$. Corrected log light fluence in the 550-770nm range. See text and Table 3 for details.

Fig. 2. Relationship between log light fluence (corrected) and flowering day in Exp. 4. (see Table 1 for details of treatments).

Fig. 3. Comparing the effectiveness of the different lamps in experiments 4 and 5 in the effective range (above log-light 3.7). Average flowering day: Number of days from pruning (Exp.4) or from planting (Exp. 5) to opening of the first flower per plant.

Fig. 4. Comparing the effectiveness of $4 \mathrm{~h}$ day extensions (DE) or $4 \mathrm{~h}$ Night-breaks (NB) with LPS and Inc lamps in the effective light range (above log-light 3.7) (Exp. 4. see table 1 for details).

Eig. 5. The correlation between flowering date and stem length (Exp. 2).

Fig. 6. Stem-length of plants grown under HPS and Inc light, at different light fluences (Exp.6). 
Table 1. Gypsophila paniculata. Lamps Used, Lamp Wattage, Timing and Duration of Illuminations, and Dates of the Experiments.

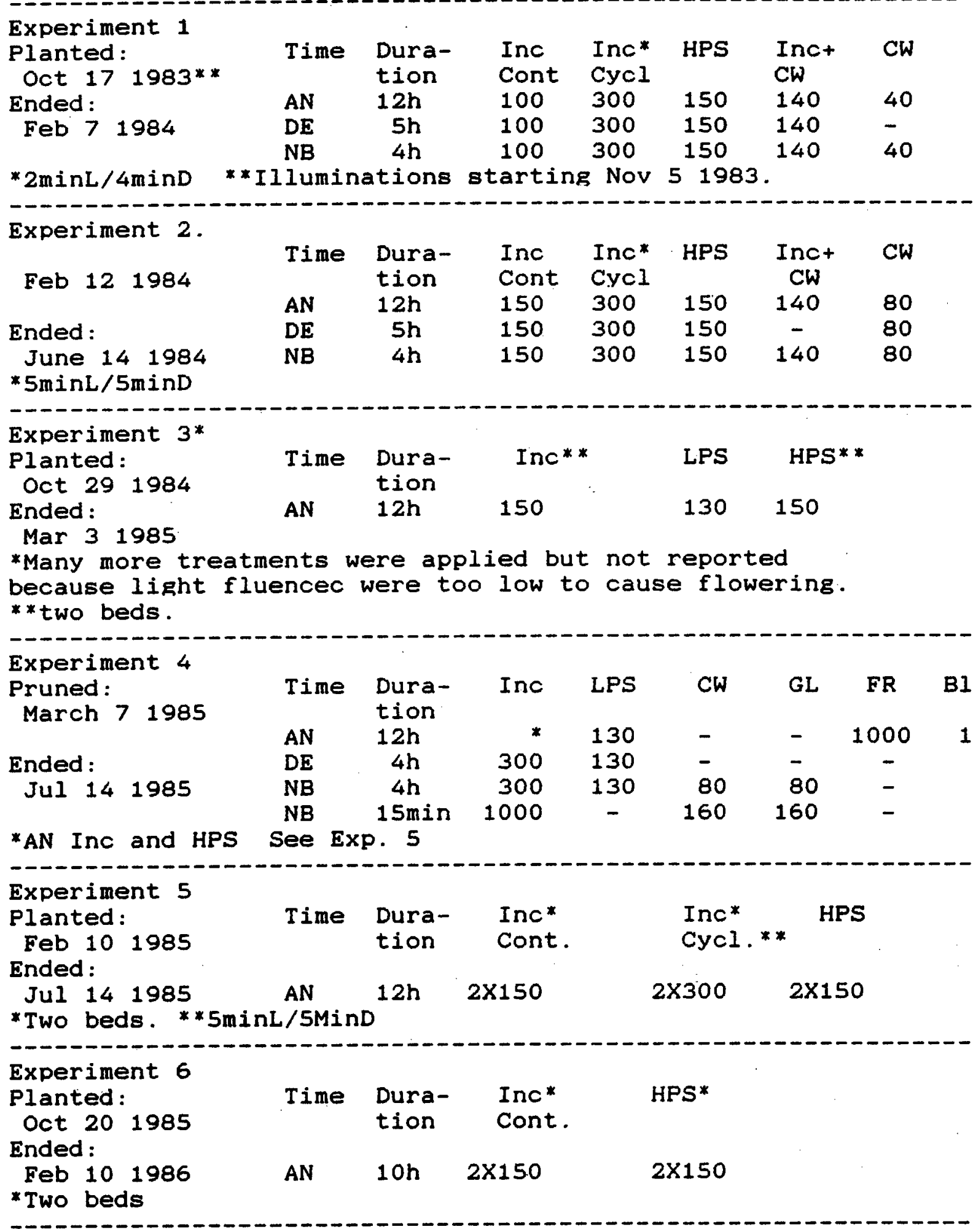


Table 2. Gypsophila paniculata

Threshold fluences of light effectiveness: The figures are

the highest fluences which do not differ from the ND controls.

(Log light: Log umol.cm2.night 550-750nm)
a. Spring experiments .
b. Winter experiments.*

$\operatorname{Exp}$

Log light

Exp. Log light

$\begin{array}{llll}2 & 3.2 & 1 & 4.1 \\ 4 & 3.7 & 3 & 4.3 \\ 5 & 3.67 & 6 & 4.4\end{array}$

* These experiments were terminated before the flowering of the ND controls

Table 3 Gypsophila paniculata

Relative quantum content of the light of the different lamps in the 400-700nm band*; Correction factors for the Li-Cor quantum meter readings for Gypsophila and Phytochrome photoequilibria*

\begin{tabular}{|c|c|c|c|c|c|}
\hline Lamp & $\begin{array}{c}\% \text { of } \\
\text { Blue } \\
400-550\end{array}$ & $\begin{array}{l}\text { Total }(40 \\
\text { Red } \\
550-700\end{array}$ & $\begin{array}{c}0-770)^{*} \\
\text { FR } \\
700-770\end{array}$ & $\begin{array}{c}\text { Correction } \\
\text { factor } \\
550-770 / 400-700\end{array}$ & $\begin{array}{l}\text { Phyto } \\
\text { photoequi }\end{array}$ \\
\hline nc & 15 & 44 & 41 & 1.44 & \\
\hline PS & 10 & 78 & 21 & 1.01 & \\
\hline PS & 0 & 100 & 0 & 1.00 & 8 \\
\hline WF & 42 & 54 & 2 & .59 & $7:$ \\
\hline$F$ & 41 & 54 & 1 & .56 & \\
\hline
\end{tabular}

* Data courtesy of T. Tibbitts.

Table 4. Gypsophila paniculata

Compareing the effectiveness of HPS, LPS and INC lamps in AN

illuminations at 130-150W. Figures are percentage reproductive plants. ( 12 plants per treatment).

$\begin{array}{lllll}\text { position Exp. } 1 & \text { Exp. } 3 & \text { Exp. } 5 & \text { Exp. } 6\end{array}$

$\begin{array}{lrrrrrrrrr} & \text { HPS } & \text { INC +CW } & \text { HPS } & \text { INC } & \text { LPS } & \text { HPS } & \text { INC } & \text { HPS } & \text { INC } \\ \text { a } & 100 & 100 & 78 & 87 & 43 & 100 & 100 & 100 & 87 \\ \text { b } & 42 & 17 & 8 & 0 & 25 & 100 & 100 & 86 & 75 \\ \text { c } & 25 & 0 & 0 & 0 & 28 & 100 & 53 & 38 & 0 \\ \text { d } & 0 & 0 & 0 & 0 & 0 & 100 & 6 & 25 & 0\end{array}$


gYPGophILA Bpring 1984

31
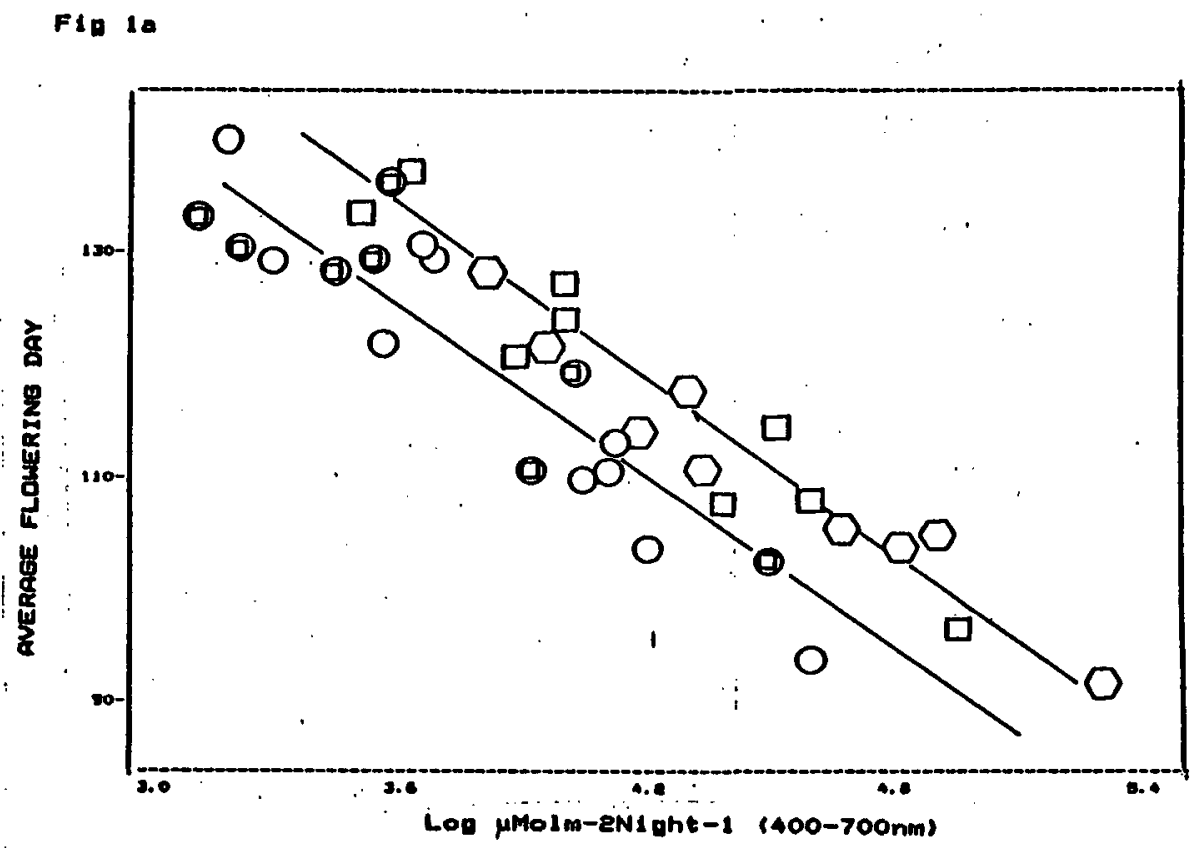

OYPGOPHILA Epring 1984

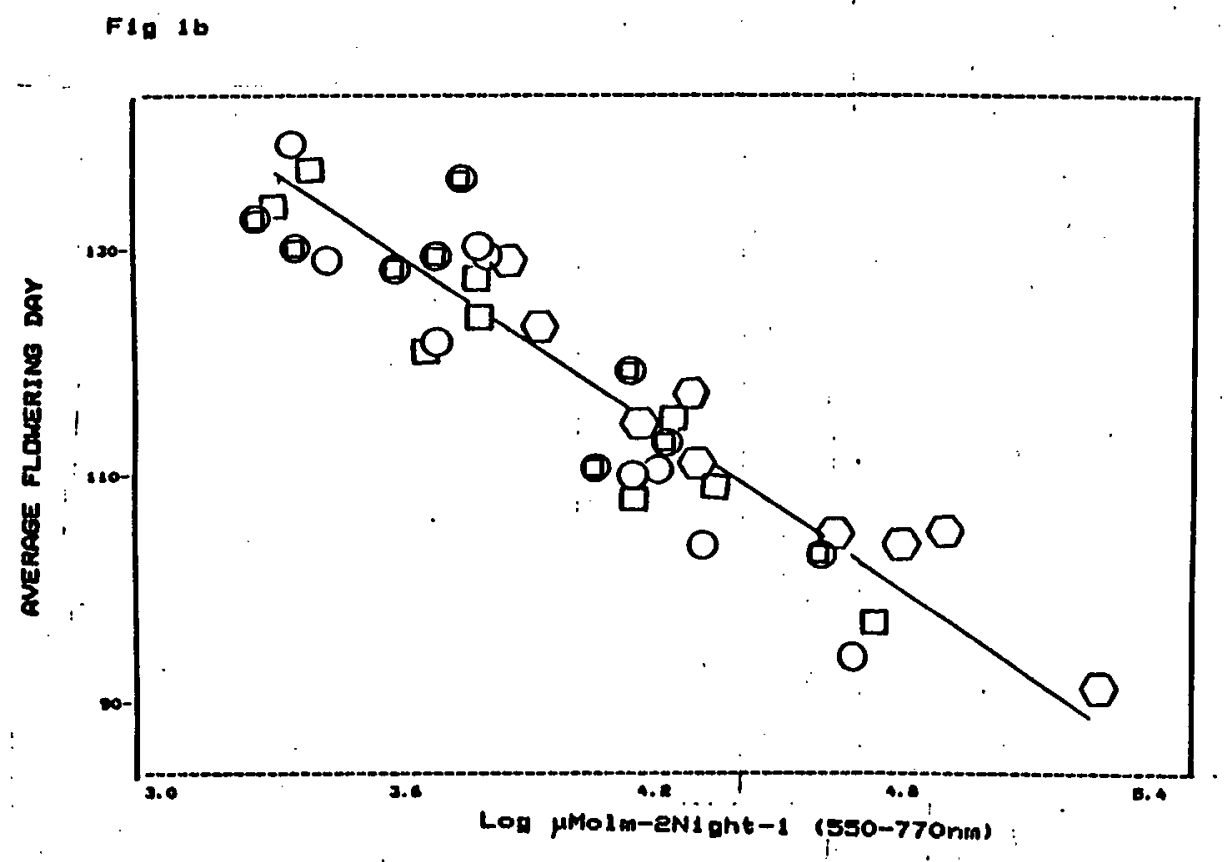


Fig. 2

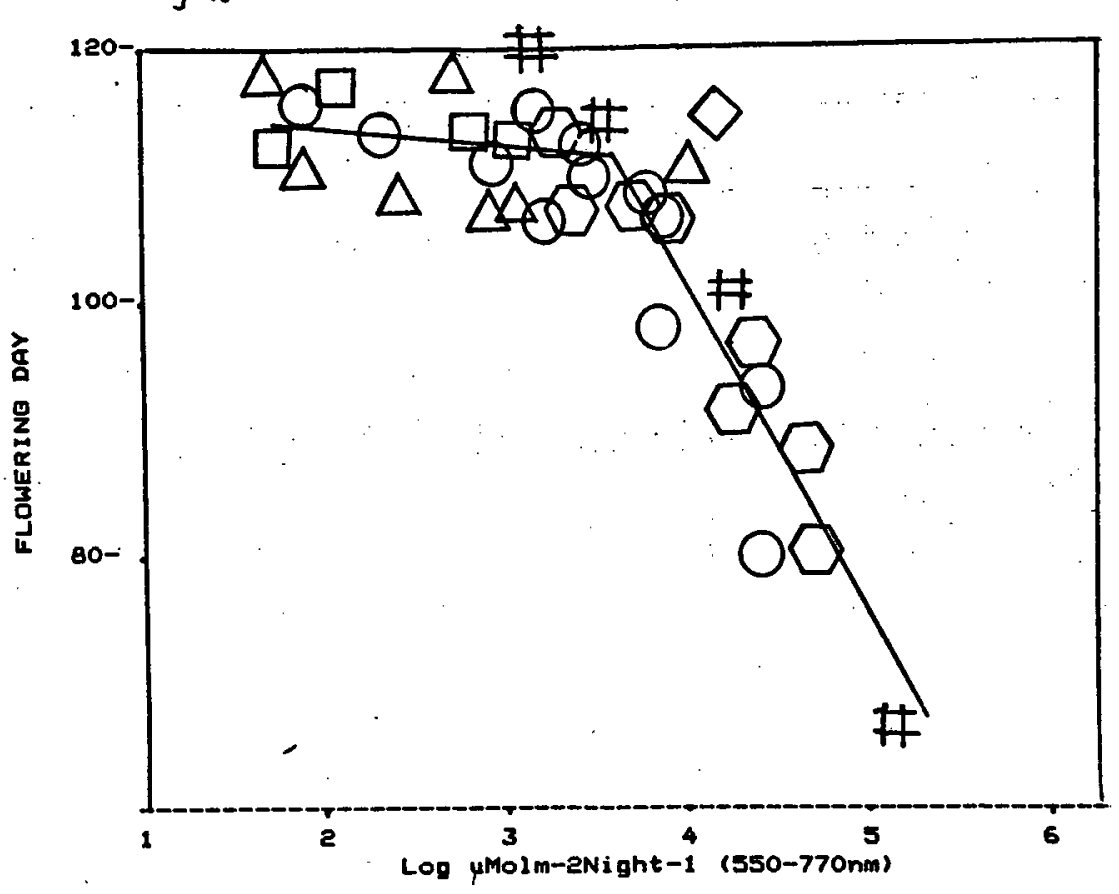

GYFSOPHILA FII 3

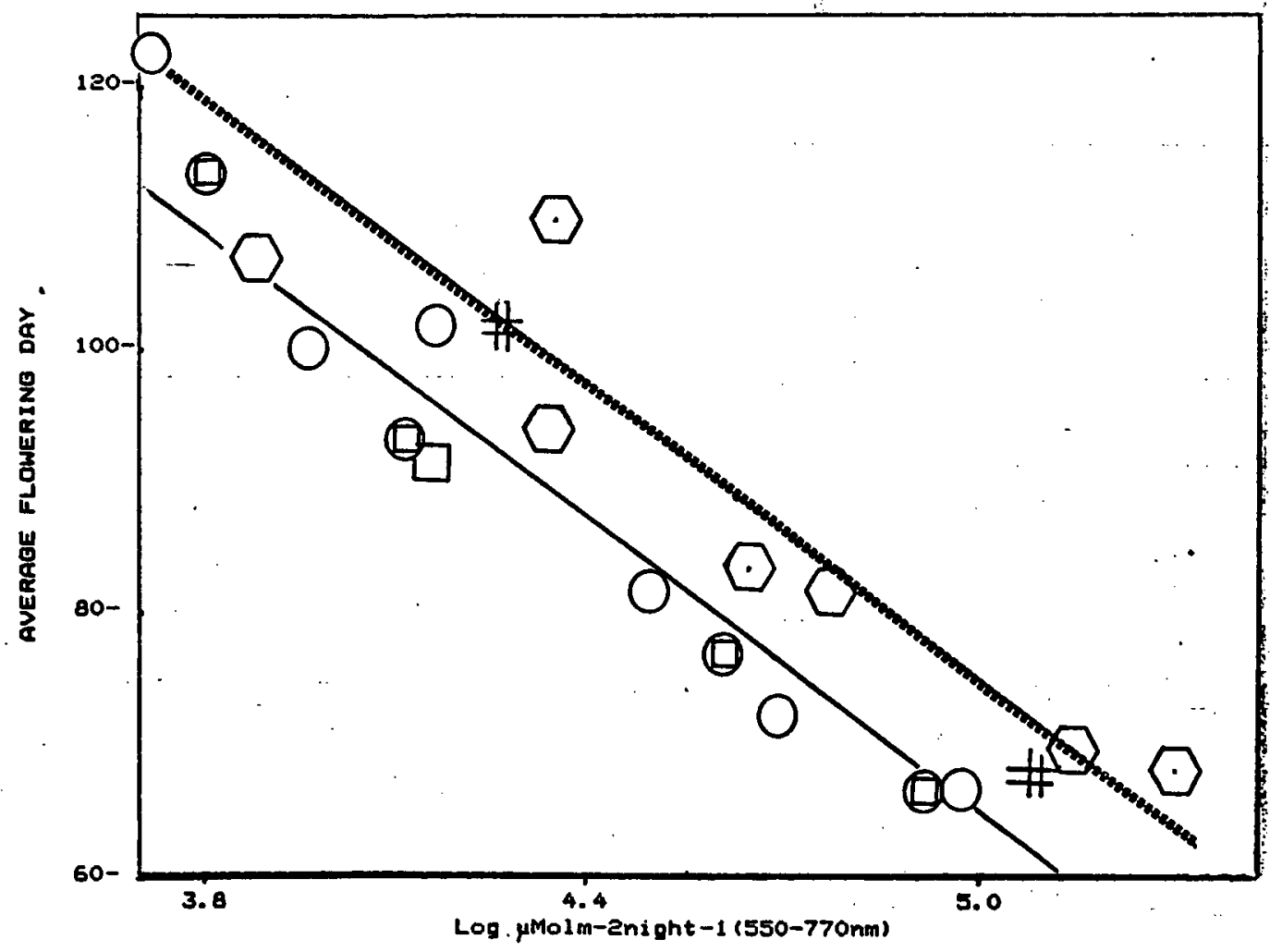


GYPSOPH'LA Fig 4

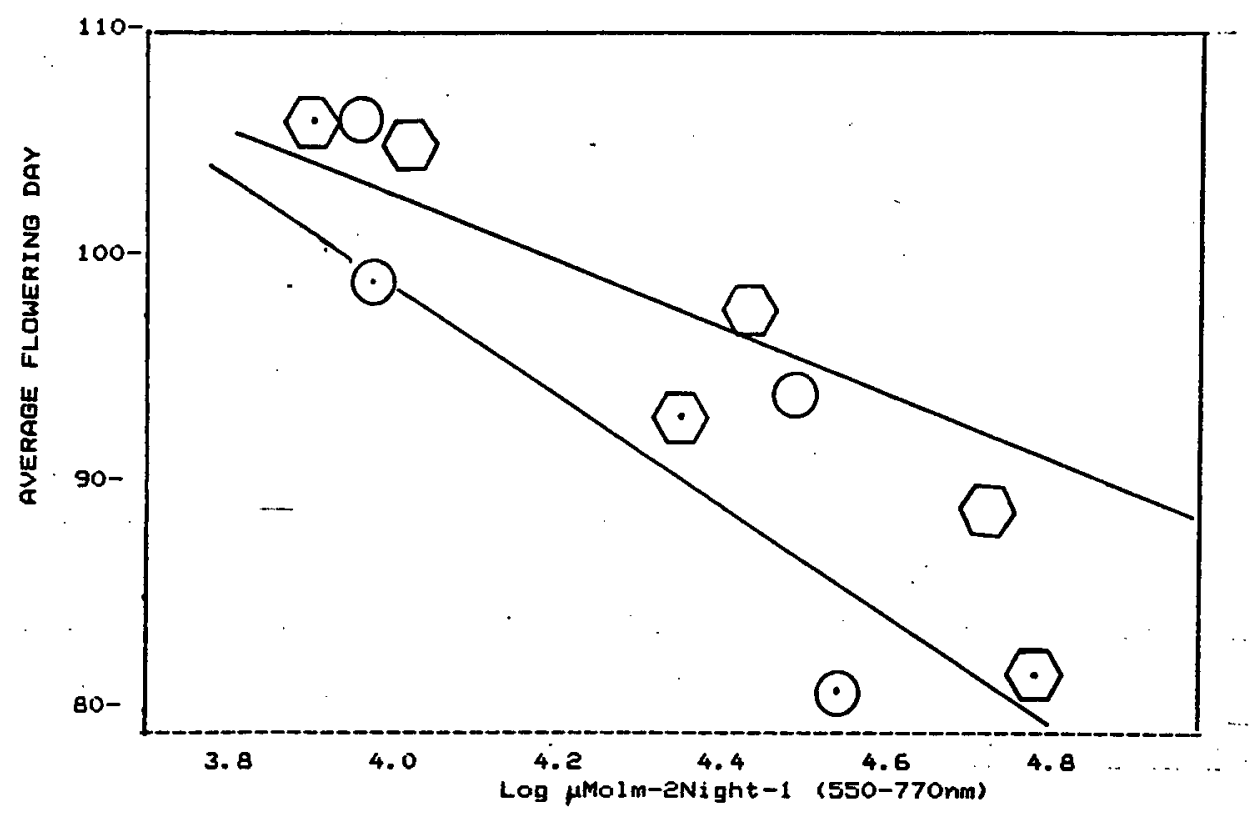

Timing

\begin{tabular}{|l|cccc|}
\hline Lomp: & AN & DE & NB & SI \\
\hline Inc & 0 & 0 & 0 & 0 \\
\hline Inc Cycl & 0 & 0 & 0 & \\
\hline GL & $\Delta$ & $\Delta$ & $\Delta$ & $\Delta$ \\
\hline CW & $\square$ & $\square$ & 0 & ⿴囗口 \\
\hline HPSsLPS & 0 & 0 & 0 & \\
\hline FR & $\#$ & & & $\#$ \\
\hline Blue & 0 & & & \\
\hline ND & $X$ & & & \\
\hline
\end{tabular}




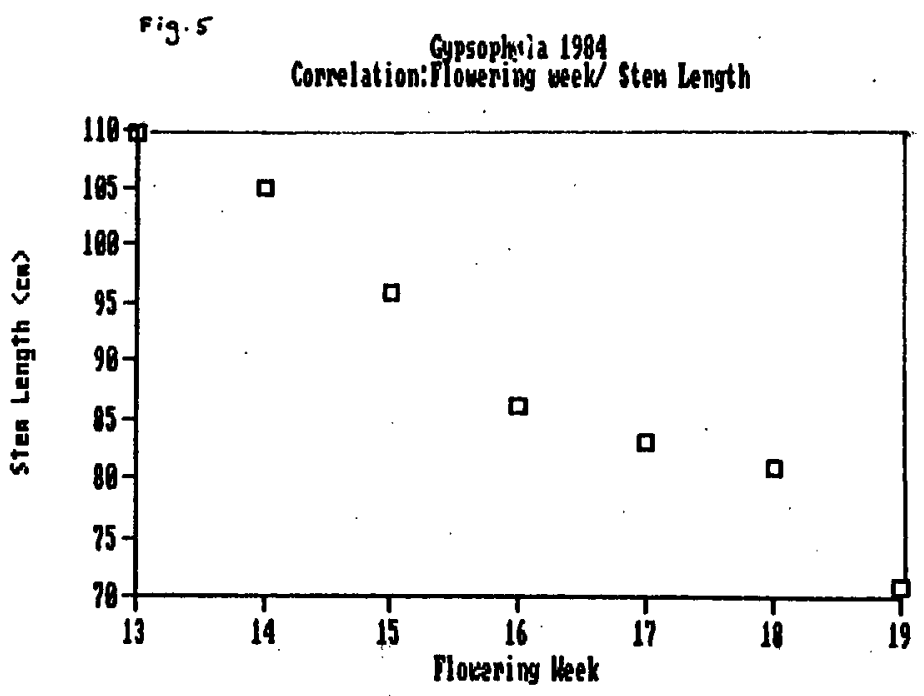

Fig 6

Gypsoph: 12 1985

Stem length of plants irradiated with HPS or INC

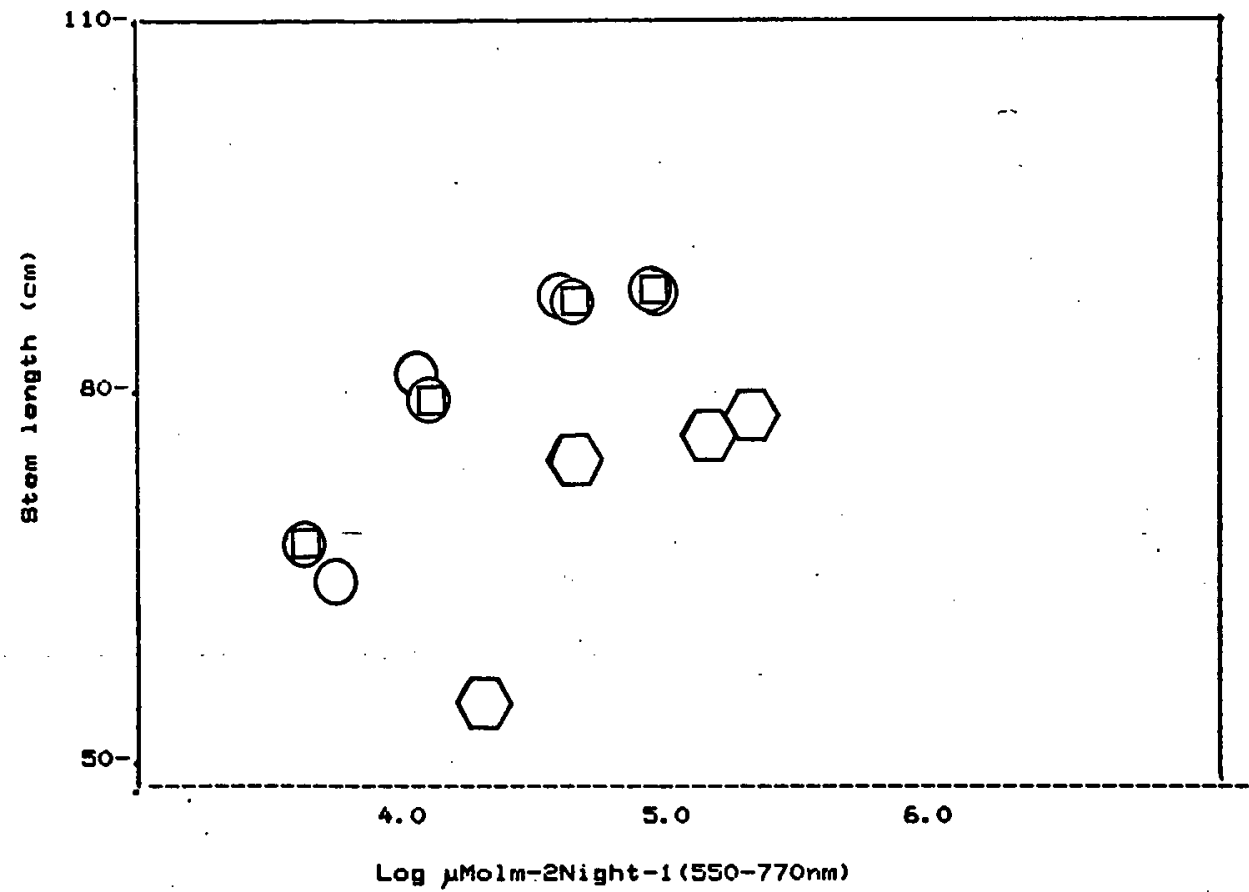




\begin{abstract}
Effects of lamp-type and timing of the
photoperiodic irradiations on flower-inhibition

in Kalanchoe blossfeldiana.
\end{abstract}

Kalanchoe blossfeldiana is a short-day flowering plant

(SDP). Photoperiodic illuminations are used to keep the plants in the vegetative condition needed for cutting production.

On October 27,1985 , cuttings of $K$. blossfeldiana (cv. Stromboli), rooted under constant LD conditions, were planted in pots and placed under the chosen experimental conditions. The plants were checked frequently and the time of appearance of visible flower buds on the main stem or on side branches was recorded. At the end of the experiment the plants were collected and the number of leaves on the main stem was determined. Flowering scores were assigned to the different conditions: 3 - Flowering on the main stem ; 2 - Flowering on side branches only; 1 - Vegetative. The first flowers opened in February 1985. A sigmoidal type of response curve was found between the logarithm of light fluence (log umol.m-2.night-1) and the different types of flowering responses.

Very consistent differences were found according to the position of the plants: more light was needed to inhibit the flowering of plants situated in the southern half of each bed as compared with plants receiving the same amount of photoperiodic irradiations during the night, but situated in the northern side of the same beds (Fig. i). This difference must, most probably, be ascribed to difference in the amount of photosynthetic light received by the plants, as already shown by Schwabe for kalanchoe. similar differences were found in the flowering responses of two other short-day plants: Chrysanthemum morifolium and Aster pilosus. In order to be able to apply statistical analysis to the effects of the lamps and the timing of the illuminations it was necessary to compensate for this difference. This was done by adding the amount of log umol $\mathrm{m}^{-2}$.night-1 $=0.29$ to the plants in the southern plots (Figs. $2-5$ ).

Light fluences which were below $10 g$ umol.m-2.night-1 $=2.8$ had no effect on any aspect of flowering (Figs. 2,3). Higher fluences increased the number of leaves on the main stem (Fig 2) and delayed flowering (Fig 3). Light fluences greater than log umol.m- night-i $=3.5$, inhibited flower differentiation on the main stem but allowed flowering to occur on one. or more side branches (Figs. 3 and 4 ). Fluences above $10 \mathrm{~g}$ umol. $\mathrm{m}^{-2}$. night-1 $=3.7$ completely suppressed flowering in some of the plants, and above log umol. $m^{-2}$.night-1 $=4.6$ there was no flowering in any treatment except the FR. Statistical analysis was carried out on the linear segments of the sigmoidal curves. In this way it was found that CW or GL light (Figs. 3 and 4, Iine 
A) was more effective than Inc (Figs. 3 and 4, 1ine B) the sodium lamps being intermediate in effectiveness. Very short NB with GL and $C W$ light was highly effective. In this experiment there was no consistent difference between $4 \mathrm{~h}$ $\mathrm{NB}$ and $4 \mathrm{~h}$ day extensions.

We wish to thank Dan nurseries for the plants and Mr. A. Genisi for his help and advise in carrying out the statistical analysis.

Legends for the figures

Fig. 1

Flowering scores of kalanchoe plants growing in southern plots (S) or northern plots $(N)$. Flowering score: 1 Vegetative; 2 - flowers on side branches only; 3 -flowers or flower buds on the main stem.

Fig. 2

Number of leaves on the main stem (for plants flowering on the main stem) vs log light fluence (light fluence corrected for southern plots of kalanchoe plants).

Fig. 3

Flowering scores vs log light fluence (light fluence corrected for southern plots). A - Regression line for HPS, LPS, GL and CW; B - Regression line for Inc. Flowering score: 1 - vegetative: 2 - flowers on side branches only; 3- flowers or flower buds on the main stem of kalanchoe plants.

Fig. 4

Percent flowering vs log light fluence (light fluence corrected for southern plots of kalanchoe plants). A Regression line for HPS, LPS, GL and CW; B - Regression line for Inc. Flowering score: 1 - vegetative; 2 - flowers on side branches only; 3 - flowers or flower buds on the main stem of kalanchoe plants. 
Fig. 1

Kalanchoe blossfeldiana

Northern us Southern plots

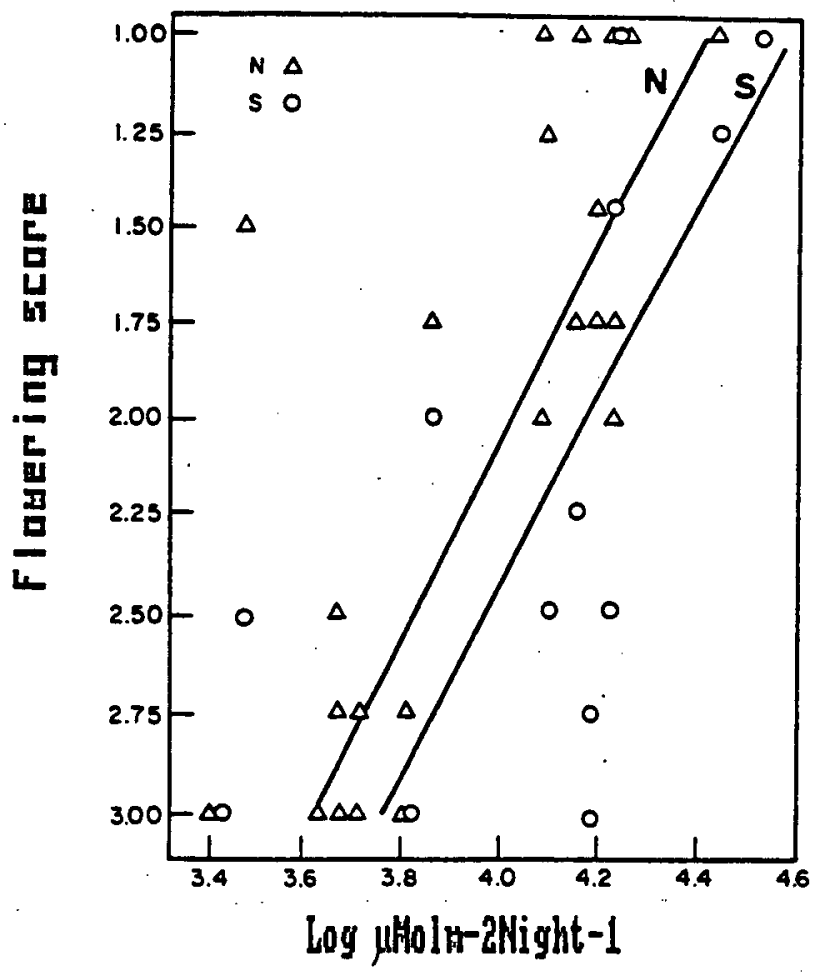

Fig. 2

- Ralanchoe blossteldiana

No of Leaves

\begin{tabular}{|c|c|c|c|c|}
\hline & $\begin{array}{c}\text { All } \\
\text { Mlght }\end{array}$ & $\begin{array}{c}\text { Day } \\
\text { Extension }\end{array}$ & & ont \\
\hline LAMP & $12 \mathrm{~h}$ & $4 h$ & $4 h$ & $1 / 4 h$ \\
\hline INC & 0 & - & 0 & 0 \\
\hline LPS & 0 & 0 & & \\
\hline HPS & $\Delta$ & & & \\
\hline CW & & & ㅁ & 可 \\
\hline$\overline{\mathbf{G L}}$ & & & $\nabla$ & $\nabla$ \\
\hline FA & & & 0 & \\
\hline
\end{tabular}

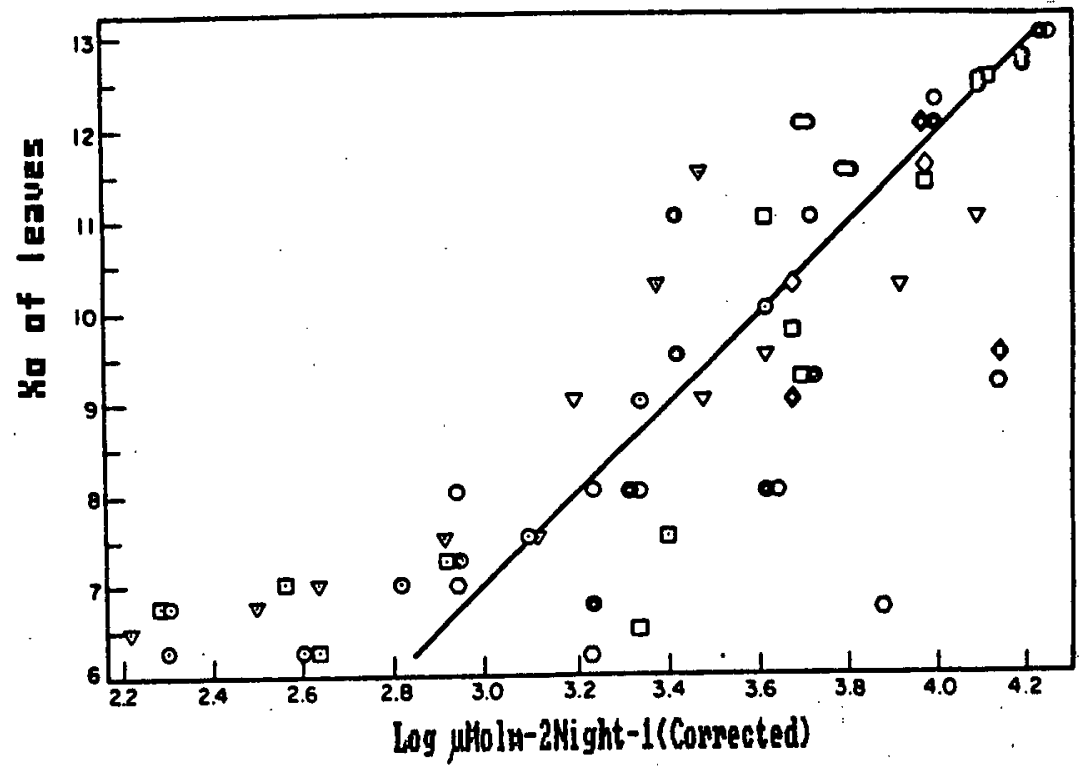


Fig. 3

\section{Kalanchoe blossfeldiana}

Imeandescent us Dischange Lasps

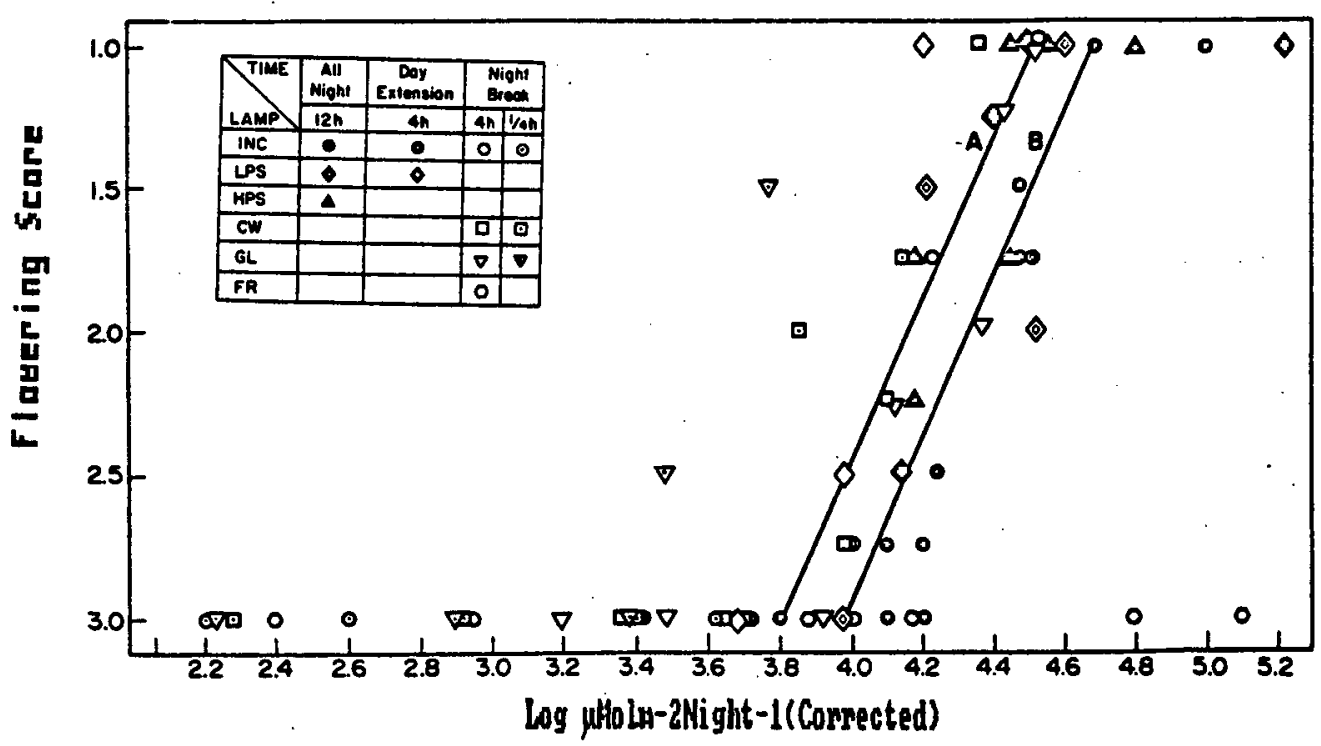

rig. 4

Yal anchoe blossfeldian Incandescent us Disclaange Laups

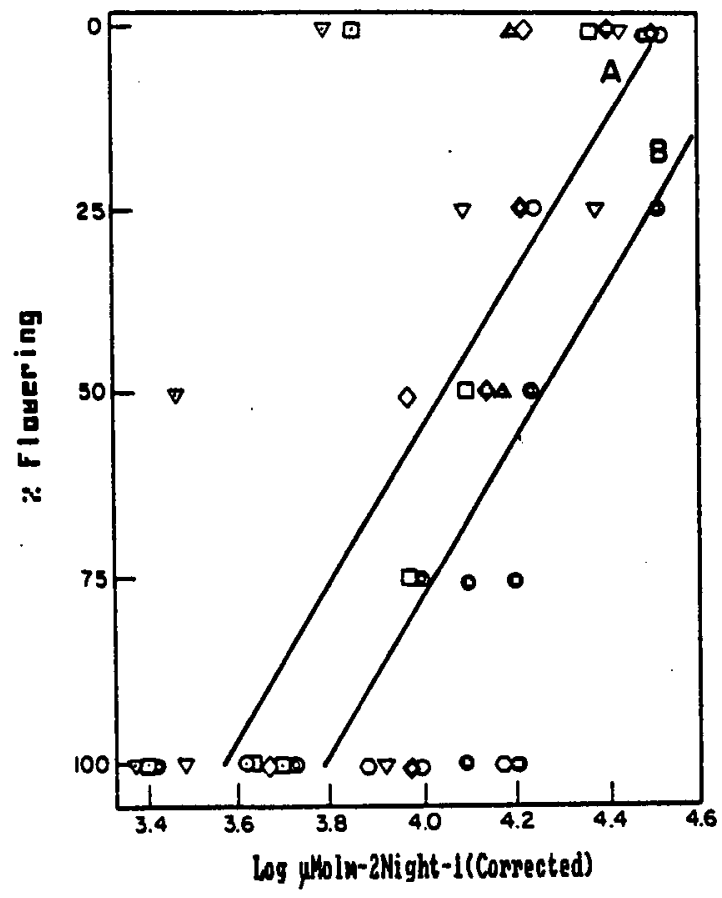


Aster pilosus: Effects of lamp type and timing of the irradiations on stem elongation (a long-day response) and on flowering (a short-day response).

Aster pilosus is a long-short day plant. In winter the plants grow in rosettes. Long days induce stem elongation, which is a prerequisite for flowering, but flower induction takes place only under short-day conditions. This plant has lately been introduced in Israel as a winter flowering cut-flower for export. The aim of the research was to define the lighting regime needed to create long-day conditions and to determine whether the long-day conditions that promote stem elongation are identical to those that inhibit flowering.

Three experiments were conducted. In the first we tested the effects of photoperiodic irradiations on the elongation of rosette plants. and the second and third experiments were concerned with flowering.

Experiment 1 . Young plants were placed in the different treatments on oct. 19, 1983. Stem elongation became apparent 5 weeks later, the first stems appearing in the plots nearest to the lamps in the All Night irradiated beds (Fig A). By the end of the experiment (Jan. 12, 1984) most of the plants were elongating, with the exception of the control plants under natural daylength and some of the plots receiving very low light fluences (Fig. B). Light fluences causing stem elongation in $50 \%$ of the plants on different dates are presented in Table 1.

It is clear from Table 1 that higher light fluences were needed when the light was applied in the evenings as day extensions rather then as night-breaks or throughout the night.

In most cases the plants in the northern plots of the same positions elongated earlier then those of the southern plots. We ascribe this difference to the greater amount of sunlight in the southern plots, this light increasing the inhibitory effects of the basic short-day conditions. More photoperiodically active irradiations were therefore needed in order to overcome this inhibition. 
Stem length. A. pilosus stems usually reach a final length which in most cases does not exceed $1 \mathrm{~m}$. Final stem length may therefore not be a reliable measure of the effectiveness of the lighting regime. The results of exp. 1 are therefore presented in two figures. In Fig. A the early stages of stem elongation are depicted. At that time elongation was evident only in plants receiving light fluences above log umol $\mathrm{m}^{-2}$ night-1 $=3.25$ (Fig. A and Table 1). Above that fluence there was a direct relation between stem length and the logarithm of light fluence, without consistent differences between the lamps. Great variability in growth rate within each treatment prevents any closer analysis. In Fig. B the differential effects at the low light fluences are evident. It is apparent that, without exception, $4 \mathrm{~h}$ NB was more effective than $5 \mathrm{~h} D E$, despite a certain overlap in the timing of the illuminations (see table 1 ). There was no consistent difference in the effects of Inc lamps whether the light was applied continuously or intermittently, except for the two lowest intensities in the All-night illuminations which we suspect might have been due to local conditions other than light.

The number of side branches was also directly related to the light fluence, but it was found that the effects of the light on the number of side branches were circumstantial: branching started as soon as the stems reached a certain length and was therefore directly related to stem length.

In Experiments 2 and 3. , Highly branched plants were moved from Long-Day conditions to the different treatments. Experiment 2 was started on April 6, which proved to be too late, because ambient daylength was already somewhat inhibitory. Experiment 3 was therefore started on Jan. 9, the results are presented in Figs. C and D.

Flower initiation. As already stated, Long-day conditions prevent flower initiation. In the present experiment it was found that very high fluences were needed to prevent flowering completely (Fig. C); at lower fluences, flowering was delayed but not prevented. In Table 1 The minimum light fluences (Log uMol.M-2.night-1) causing stem elongation (Exp. 1) or a delay in flowering (Exps. 2 and 3) are compared.

Light applied in the evenings (DE) was always less effective than NB. Also, less light was needed to cause stem elongation then that needed for the dalay of flowering. In experiment 3, at similar fluences, very short night-breaks ( $15 \mathrm{~min}$ GL or $\mathrm{CW}$ ) were found to be more effective than longer irradiation periods. In flowering, as in stem elongation, no consistent differences were 
found among Inc, CW. HPS or GL lamps. Blue and FR had

almost no effect on the flowering of Aster pilosus.

* Figs A, B, C and D were presented as a Poster at the University of Nottingham Easter School on the Manipulation of Flowering, April 1986.

\section{Legend for Figures}

Fig. A Effect of different lamps and timing of the illumination the early stages of stem elongation (stemlength on Dec. 11, 1983).

Fig B The late stages of stem elongation of Aster pilosus (stem length on Jan. 12, 1984).

Figs. C and D

C. Percent flowering of $(75 \%-0 \%)$.

D. Delay in flowering of : Days after the flowering of the Natural daylength control (80-100\% flowering). 
Table 1 Aster pilosus

The smallest amounts of light causing stem elongation or a delay in flowering in. The light was applied in the evening (DE) or in the middle of the night (NB)

$\begin{array}{lll}\text { Type of } & \text { Date* } & \text { Log uMol.m-2.night-1 } \\ \text { effect } & \text { DE } & \text { NB }\end{array}$

effect

Stem elongation

Delay in flowering Delay in flowering
Jan. 12,1984

Jan. 9. 1985

Apr .6, 1984
3.35

4. 90

3.76
2.79

3.48

3.27

* Dates of observation for stem elongation or date of the start of the experimental treatments (flowering) 
Aster pilosus 1983-4

(A) Dec. 11, 1983 (B) Jan. 12, 1984
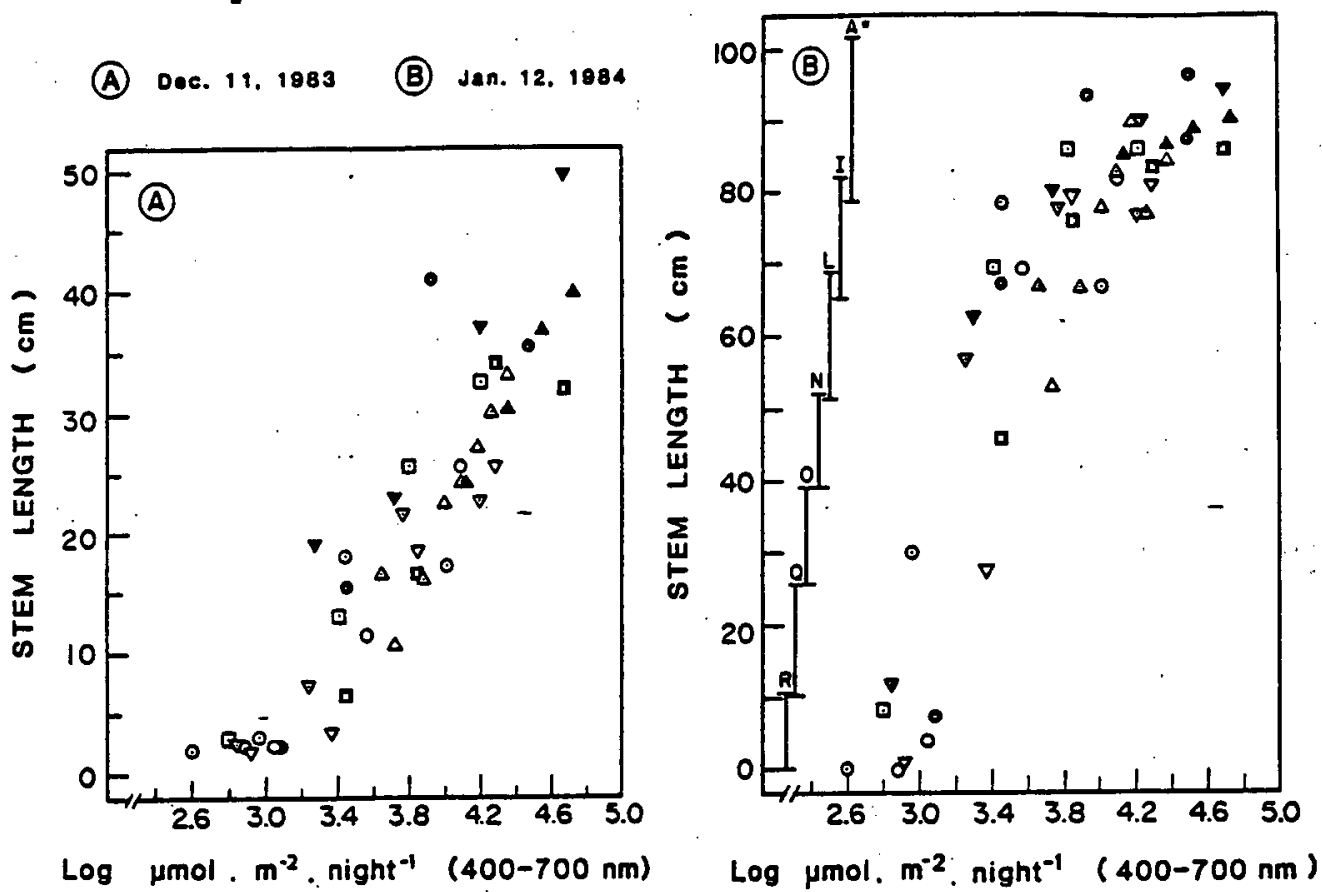

\section{Aster pilosus 1984-5}

(C) Flowering

(D) Delay in tlowering (daye alter the natural daylength control 85-100\% Howering)

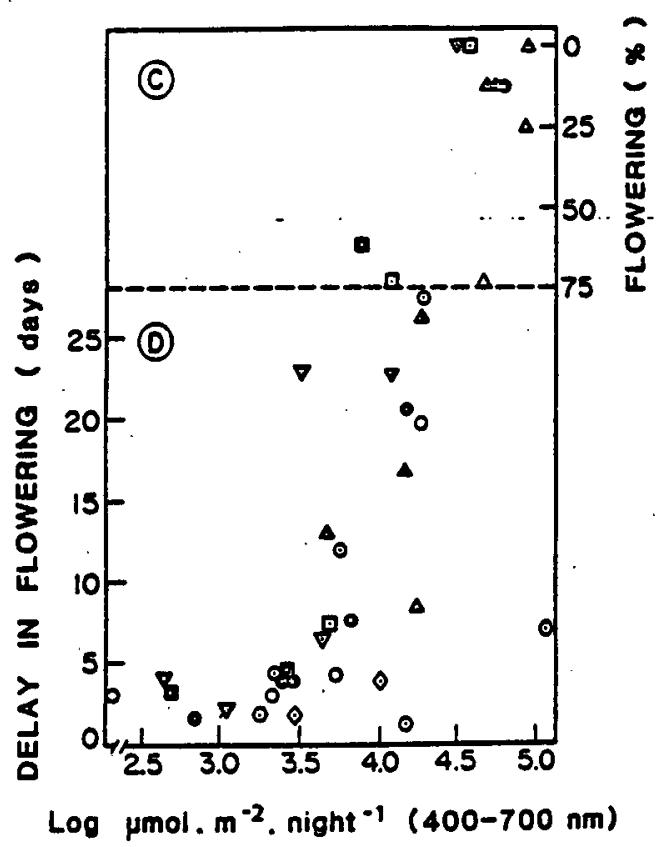

- Duncan grouping

ane Nlues

\begin{tabular}{|c|c|c|c|c|}
\hline \multirow{2}{*}{ Lamol } & \multirow{2}{*}{$\frac{\text { All night }}{12 \mathrm{~h}}$} & Doy extension & \multicolumn{2}{|c|}{ Night breat } \\
\hline & & 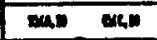 & an & $13 \mathrm{~min}^{2}$ \\
\hline INC. & 0 & 0 & 0 & 0 \\
\hline $\mathbf{G}$ & $\nabla$ & $\nabla$ & $\nabla$ & $\nabla$ \\
\hline$c w$ & & 0 & - & 口 \\
\hline HPS & $\Delta$ & $\Delta$ & $\Delta$ & \\
\hline Blue & $\cdot$ & $\therefore$ & $0^{4}$ & \\
\hline$\overline{F R}$ & & & $0^{7}$ & \\
\hline
\end{tabular}

4n 


\section{Centaurea cyanus}

Centaurea cyanus is another Long-Day flowering plant, forming a rosette in short days. We studied its responses to photoperiodic irradiations on several previous occasions.

In the present project this plant was included in exp. 1 , 5,6 and 7 . And the results of exp. 5 and 7 are presented in detail herein.

Experiment 5. Seeds of the var. 'Blue-Boy' were sown in the polyurethane boxes on oct. 10, 1985. The irradiation treatments were started on Oct. 27 . On Nov. 7 stem elongation was evident in plants in positions "a" in AN GL and Inc, and on Nov. 28 the first flowers opened in AN GL. Flowering plants were recorded and removed two or three times weekly. There were 17-30 plants per position. The experiment was terminated on Feb. 12, with $60 \%$ flowering in the natural day-length control. The results are presented as the number of days from the start of the irradiations to $50 \%$ flowering in each treatment. In Fig. 1 the timing of 2 $h$ irradiations with $G L$ and Inc is compared. It is evident that NB were far more effective then DE. Both with NB or $D E$ there was no difference between GL and Inc light.

In Fig. 2 the effects of $2 \mathrm{~h}$ NB with different light are compared. No differences could be detected among GL, Inc or LPS light. CW may have been slightly less effective than the other types of light. In fig. 3 the effects of $10 \mathrm{~h} \mathrm{AN}$ irradiations are compared. Blue was somewhat effective at the high fluence levels while FR was entirely ineffective in inducing flowering in Centaurea cyanus. There was no difference between Inc and GL light. The effects of the duration of the irradiations are compared in Figs. 4 (GL) and 5 (Inc). There was no clear difference in GL, while in Inc the very short irradiations seem to have been a little less effective (such a difference was found again in Exp. 7).

Experiment 7. Seeds were sown in the polyurethane boxes on Sep. 15, 1986, and the irradiation treatments were started on the same day. The first flowers opened in AN HPS on Oct. 26 and in AN GL and Inc on Oct. 30. In the Natural daylength control the first flowers opened on Jan. 8, 1987. The experiment was terminated on April 8 . by which date almost all the plants had already flowered. Flowering plants were recorded and removed as in Exp. 5. Their total stem length, position of the first elongating internode, and total leaf number were recorded (not presented here). The effects of the timing of $2 \mathrm{~h}$ irradiations with GL or Inc light are presented in Figs. 1 and 2 , respectively. In GL light differences in effectiveness can be seen only at the lowest light fluences tested, with NB being the most effective and LE the least. With Inc light DE was clearly less effective, followed by EM. In Fig. 3 the effects of 30 min End of Day irradiations with GL or FR light are 
compared with those of 2 h day-extensions with GL or Inc light. EOD irradiations had no clear-cut effect. As already mentioned $2 h$ DE was effective with Centaurea cyanus, but again there was no difference in effectiveness between GL and Inc light.

In 1 Oh AN irradiations ( Fig. 4) Blue was somewhat effective, but its effectiveness did not increase with the increase in light fluence. Inc, GL and HPS seem to be equally effective. With GL light there was again no difference whether the light was applied for $10 \mathrm{~h}, 2 \mathrm{~h}$ or 15 min (Fig. 5), but, as already mentioned, with Inc light 15 min irradiations were somewhat less effective than $2 \mathrm{~h}$ or $10 \mathrm{~h}$ irradiations (Fig 6).

In both experiments the fluence needed to induce flowering was rather low. This may be because flower inhibition by the ambient photoperiod was not very strong, as is evident from the flowering of the control plants. 
Centaurea cyanus. Legend for figures

$y$ axis: Days to $50 \%$ Flowering.

$x$ axis: Log light fluence per night.

Figs. 1-5 Exp. 5, $1985 / 6$.

Fig. 1 Comparing the effect of $2 h D E$ and $2 h$ NB with Inc and GL light.

Fig. 2 Effects of $2 \mathrm{~h}$ NB with CW, GL, Inc or LPS light.

Fig. 3 Effects of $10 \mathrm{~h}$ irradiations with Blue, FR, GL, or Inc light.

Figs. 4, 5 Effects of irradiations around midnight with 15 min, $2 \mathrm{~h}$ or $10 \mathrm{~h}$ of $\mathrm{GL}$ (Fig. 4) or Inc (Fig. 5) light.

Figs.6-11 Exp. 7, 1986/7

Fig. 6, 7 Effects of the timing of $2 \mathrm{~h}$ irradiations with GL (Fig. 6) and Inc (Fig. 7).

Fig. 8 Effects of irradiations in the evenings: $30 \mathrm{~min}$ EOD FR or GL or $2 \mathrm{~h} \mathrm{DE}$ GL or InC.

Fig. 9 Effects of $10 \mathrm{~h}$ irradiations with Blue, GL, Inc or HPS light.

Figs. 10,11 Effects of irradiations around midnight with 15 min, $2 \mathrm{~h}$ or $10 \mathrm{~h}$ of GL (Fig. 10) or Inc (Fig. 11) light. 
Contaurea 1985-6

Days to $50 \%$ flowering (DEarB)

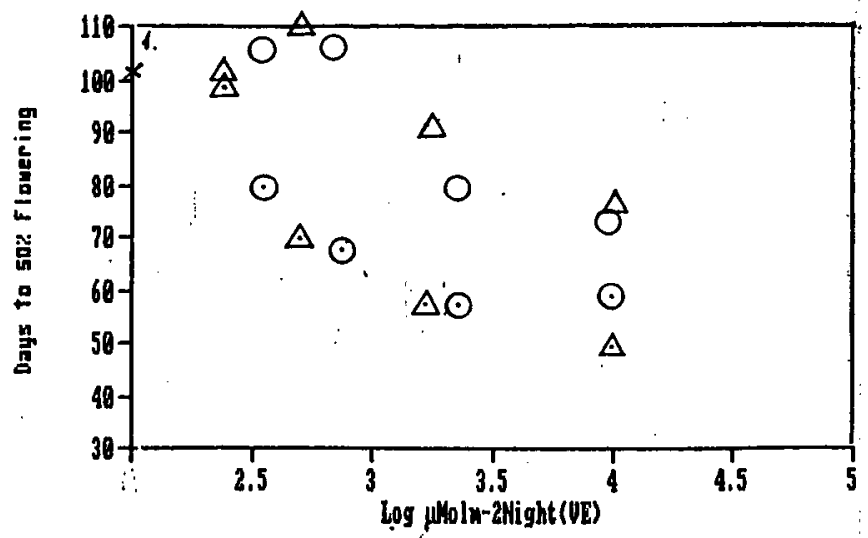

Centaurea 1985-6

Ail Days to 58\% Tlowering

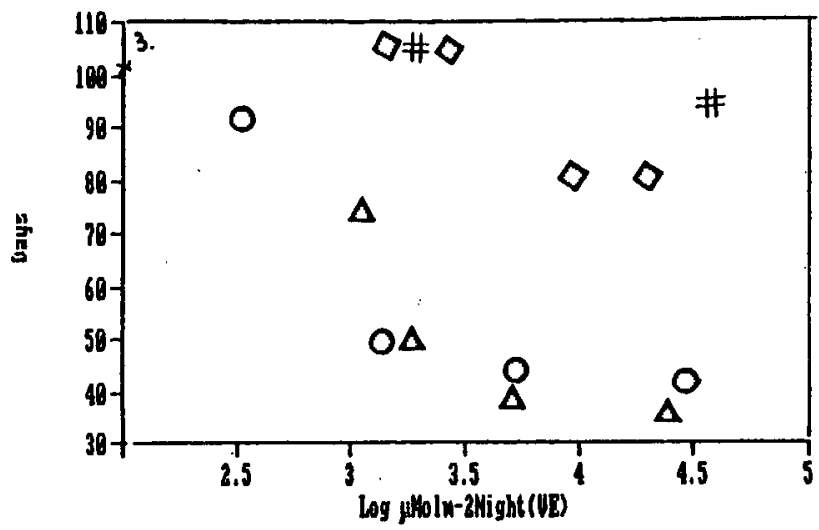

Centaurea 1985-6

Grolux Days to 50\% Hlowering

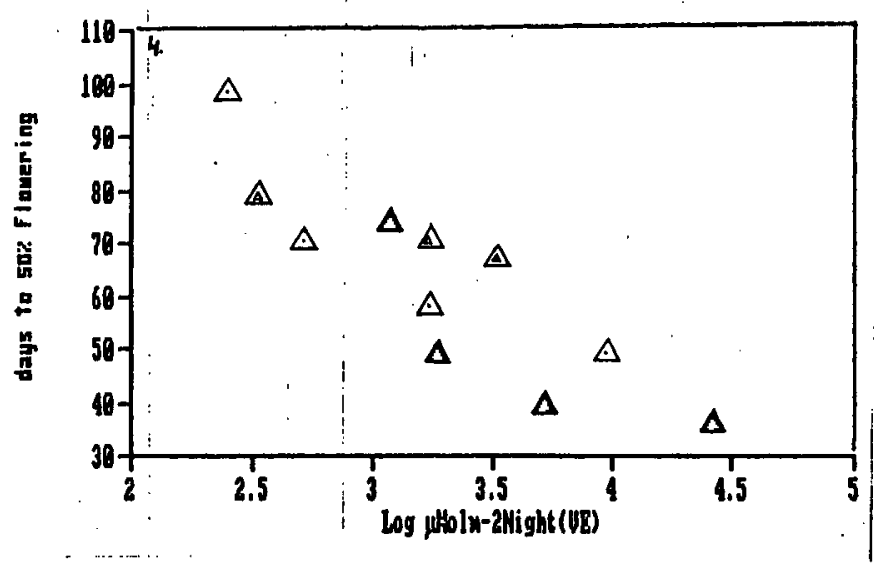

Centaurea 1985-6

Days to 5 bu flowering (2WWB)

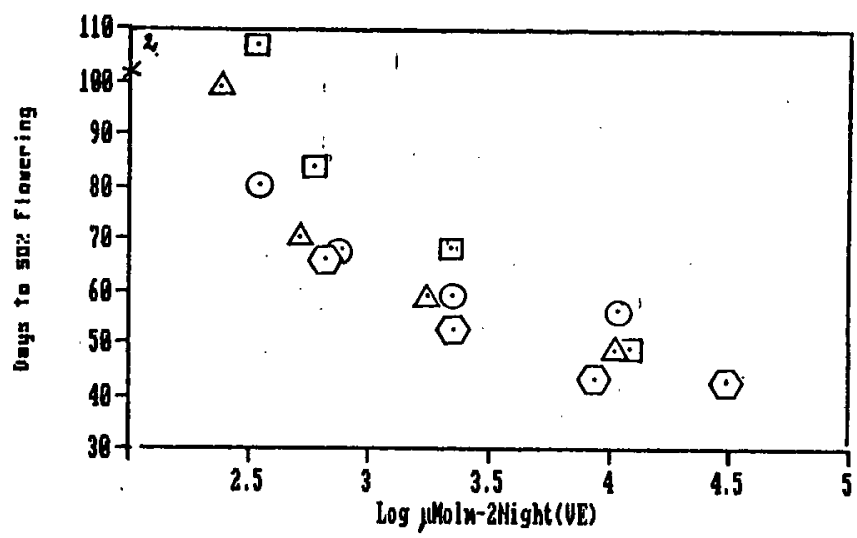

Timing

\begin{tabular}{|c|c|c|c|c|}
\hline Lomp: & AN & $\mathrm{DE}$ & NB & SI \\
\hline Inc & 0 & $\mathrm{O}$ & $\odot$ & () \\
\hline Inc Cycl & 0 & 0 & O & \\
\hline$G L$ & $\Delta$ & $\Delta$ & $\Delta$ & $\Delta$ \\
\hline $\mathrm{CW}$ & $\square$ & $\square$ & Q & 回 \\
\hline HPS\&LPS & 0 & 0 & C & \\
\hline FR & $\#$ & & & $\#$ \\
\hline Blue & 0 & & & \\
\hline ND & $x$ & & & \\
\hline
\end{tabular}

Centaurea 1985-6

IIKC Days to $50 \%$ flowering

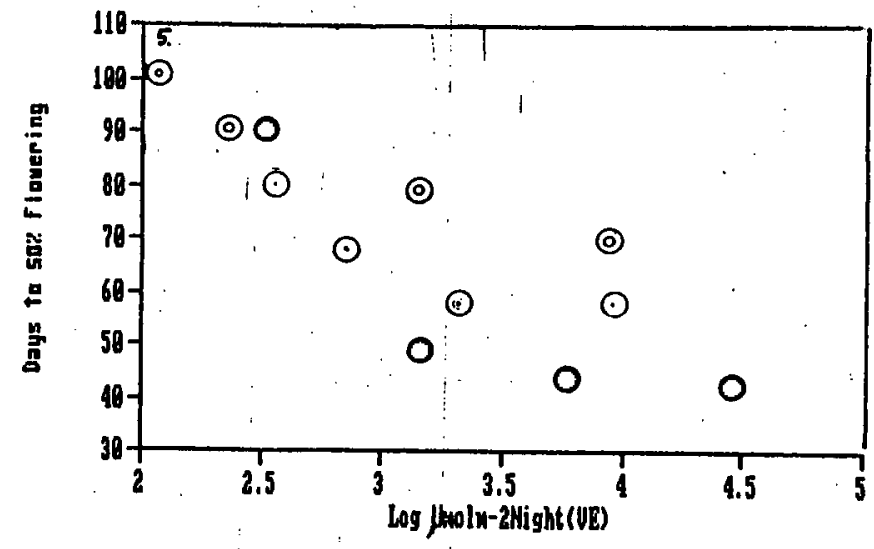


Centaumea 1986-7

2h light per night(a)

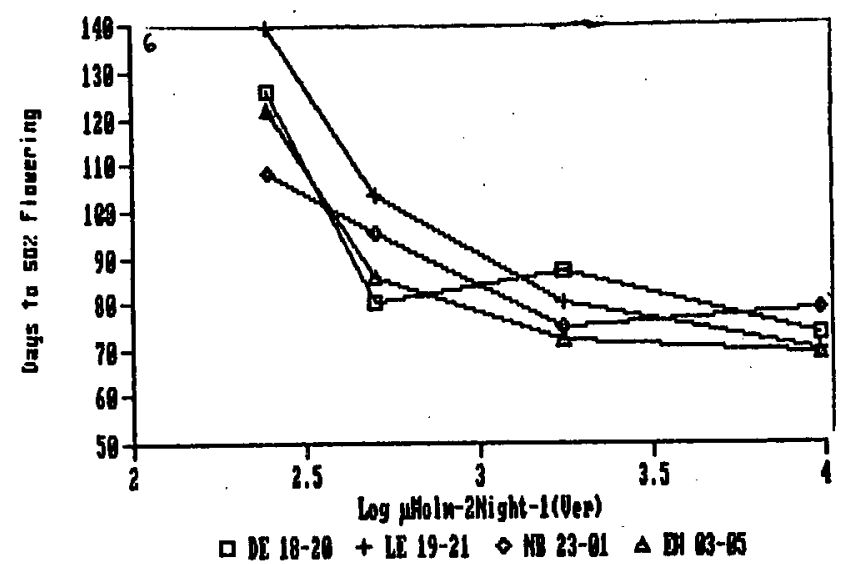

Centaurea 1986-7

Find of day + Day Extension

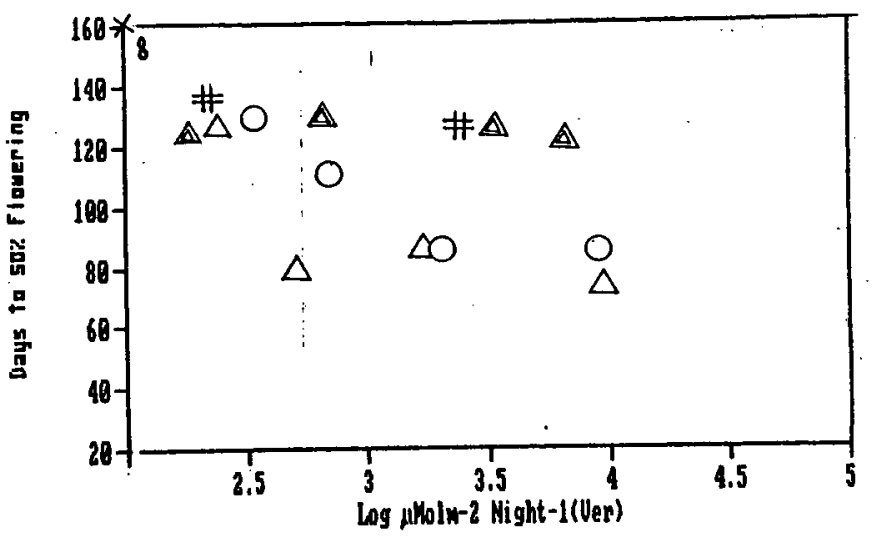

Cent86-7

If bays to $50 \%$ blos 6

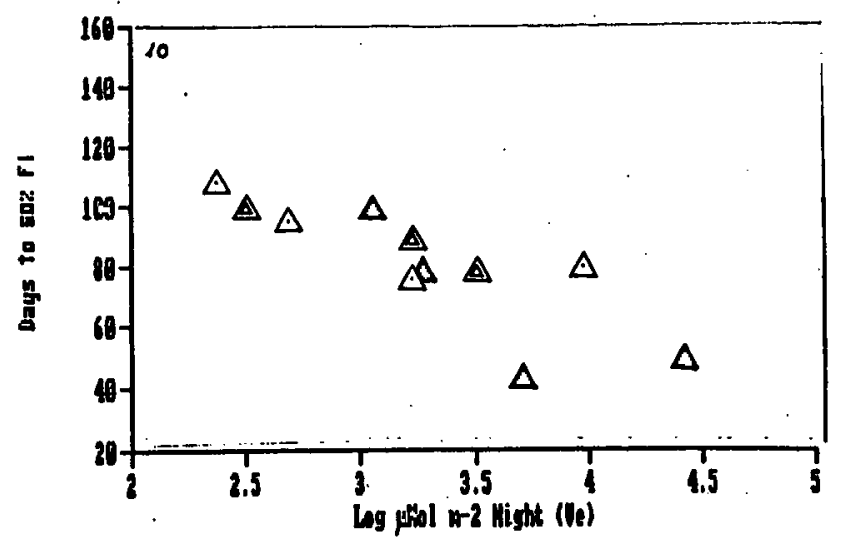

Contauma 1986-7

th light pep night (Ite)

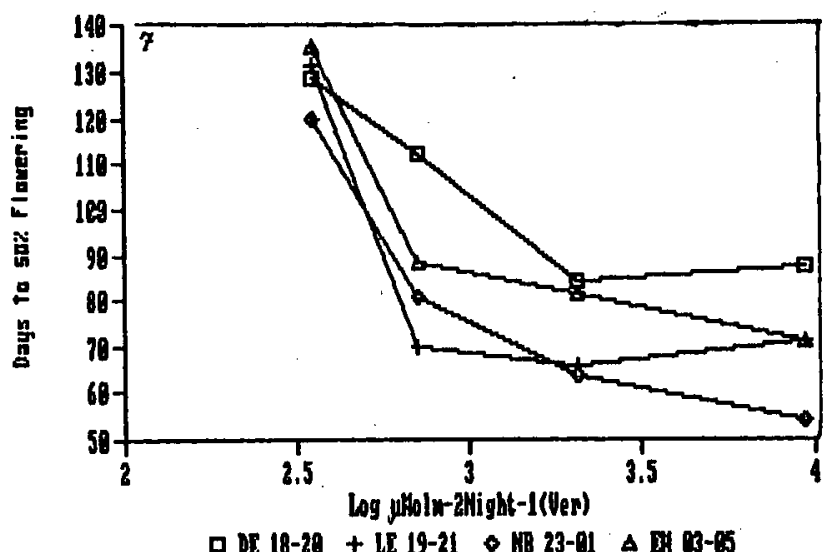

Centaune 1986-7

Days to $50 \%$ flowering (AN)

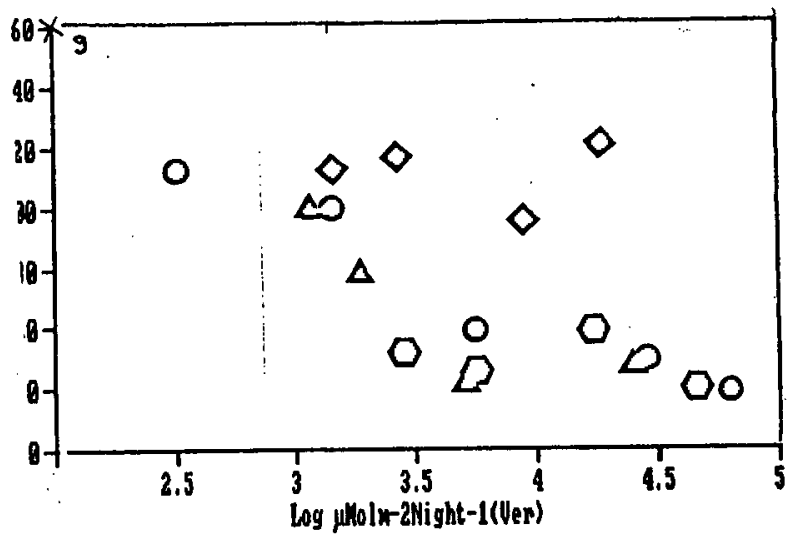

Cent86-7

Ho Days to $50 \%$ Flou (Ime)

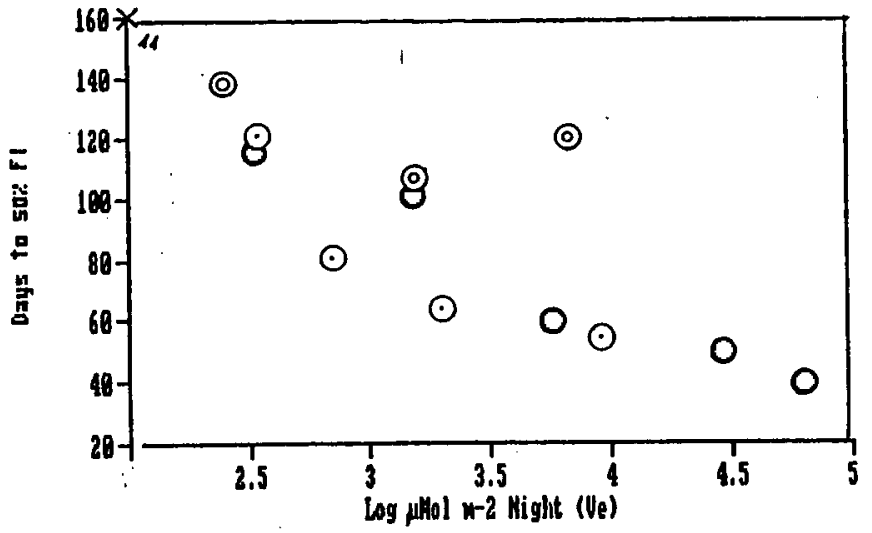




\section{Chrysanthemum morifolium}

Chrysnthemum morifolium is a short-day flowering plant. Photoperiodic illuminations are widely used to control flowering time, as well as to maintain vegetative plants for cutting production. Most of the applied studies of the photoperiodic reactions have been conducted with these plants, as well as a large body of basic research. Cycling lighting was first introduced for the control of flowering in chrysanthemum. We conducted three experiments with $\mathrm{C}$. morifolium (Exps. 1,3 and 5 , see Materials and Methods), two of which are reported herein.

\section{Experiment 1}

Rooted cuttings (var Tal) were potted on Oct. $23,1983$. one week later the plants were pruned down to the seventh leaf. The plants were kept under $4 \mathrm{~h}$ NB illuminations until Nov. 6 and then transferred to the experimental illuminations (see Materials and Methods), eight plants in each position (four plants per plot). Twice a week the plants were checked for the appearance of flower buds. The first flowers opened in the Natural Daylength (ND) control treatment on Jan 1 1984. On Jan. 20 all the plants were collected and langth, leaf number, number of flowering side branches, etc. were recorded. The apical buds of the uppermost branches were measured and assigned numerical values according to size: Vegetative, 1 ; barely visible buds. 2: crown-buds, 3; larger buds, 4-5; color showing, 6 and open flowers, 7 . The apexes of vegetative plants were dissected to ascertain their condition and the number of additional leaf primordia. Here we present only the data on flowering stage (Fig. 1 - note different legend).

Three main points are evident from Fig. 1:

a. 5 h Day Extensions (DE, 1730-2230 hours) were much less effective than $4 \mathrm{~h}$ Night Breaks (NB, 2200-0200 hours), despite the slight overlap in the illumination periods. $12 \mathrm{~h}$ All Night illuminations (AN, 17300530hours). were also slightly less effective than NB, but the regression lines for AN and NB were parallel, whereas that for the DE was very different. The difference between the NB and AN may be due to the fact that the $12 \mathrm{~h}$ AN treatment included the - photoperiodically inefficient early hours of the evening and morning.

$b$. In all three illumination periods (DE, NB and $A N$ ) there was no difference in the effects of the incandescent lamps whether the light was applied continuously (100 W lamps) or in cycles in which the light was applied for one-third of the time ( $300 \mathrm{~W}$ lamps).

$c$. in each illumination period there was no difference in the effects of incandescent light as compared with any of 
the other light combinations. Only Inc, Hps and GL are presented in Fig. 1, but the same was true for the $C W$ and the mixed $\mathrm{CW}+$ Inc that were also included in this experiment (See Materials and Methods, Table 2).

The second experiment with chrysanthemum presented here was conducted in autumn 1985 (Exp. 5). On October 27, rooted cuttings of the var. Golden Polaris were planted in pots and placed directly in the experimental treatments. 16 plants in each position (eight plants per plot). The plants were not pruned. The first flowers opened on Dec. 26,1985 . The plants were collected for measurements on Feb. 2, 1986. Flowering scores of the plants in the different treatments are presented in Figures 2-6. Note that the legend is different then that of Fig 1 and that the score is ascending instead of descending. The score values are also somewhat different: vegetative, 1 ; crown buds, 3 and opened flowers, 5 .

In Fig. 2 the flowering scores of plants receiving $10 \mathrm{~h}$ AN illuminations are presented. Blue and FR had no effect on Flowering score. However, the two highest intensities of Blue, but not of FR, were found to delay flowering date by about 10 days and produced two to four additional leaves on the main stem (not shown). The differences between Inc and GL are probably not significant.

In Fig. 3 it is evident that $2 \mathrm{~h} D E$ were almost entirely ineffective. Only at the highest intensities were some delaying effects evident. This is in sharp contrast to the very highly effective NB irradiations.

In Fig. 4 there were no differences in the effects of $2 \mathrm{~h}$ NB irradiations with Inc, GL, and CW light. LPS was also included in this experiment. Unfortunately over one weekend the lamp burned out and was replaced only after two or three nights. Subsequently, flower buds developed in all the plants, reaching stage 3.5 for the position farthest from the lamp (position d) and stage 3 for all other positions. The buds first became visible on day 62 in position d (day 32 in the ND control), on day 79 in position $c$ and on day 82 for positions $b$ and $a$. This is taken as proof that, when the lamp burned out at least the plants in positions $a$ and $b$ were still entirely vegetative.

With GroLux light ( $\mathrm{Fig} .5$ ), very short irradiations (15 minm) seem to be more effective than $2 \mathrm{~h}$ or $10 \mathrm{~h}$ irradiations. This was not the case for Inc light (Fig. 6), where flowering was directly related to the amount of light quanta provided during the central part of the dark period. There was no difference whether the light was provided over a short period at high fluence rate, or at a somewhat lower fluence rate over $2 \mathrm{~h}$ periods, or for $10 \mathrm{~h}$ at much lower fluence rates. 
Chrysanthemum morifolium. Legend for figures.

Fig. 1 Exp. $11983 / 4$ (note different legend)

Effects of the timing of the irradiations: Regression lines

for NB

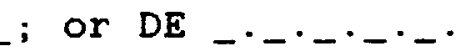

$y$ axis: Flowering stage.

x axis: Log light fluence per night.

Figs. 2-6 Exp. $51985 / 6$

$\mathrm{Y}$ axis: Flowering score.

x axis: Log light fluence per night.

Fig. 2 Comparing the effect of $2 \mathrm{~h}$ DE and $2 \mathrm{~h}$ NB with Inc and GL light.

Fig. 3 Effects of $10 \mathrm{~h}$ irradiations with Blue, FR, GL, or Inc light.

Fig. 4 Effects of $2 \mathrm{~h} N \mathrm{NB}$ with CW, GL, or Inc light.

Figs. 5,6 Effects of irradiations around midnight with 15 min, $2 \mathrm{~h}$ or $10 \mathrm{~h}$ of GL (Fig. 5) or Inc (Fig. 6) light. 

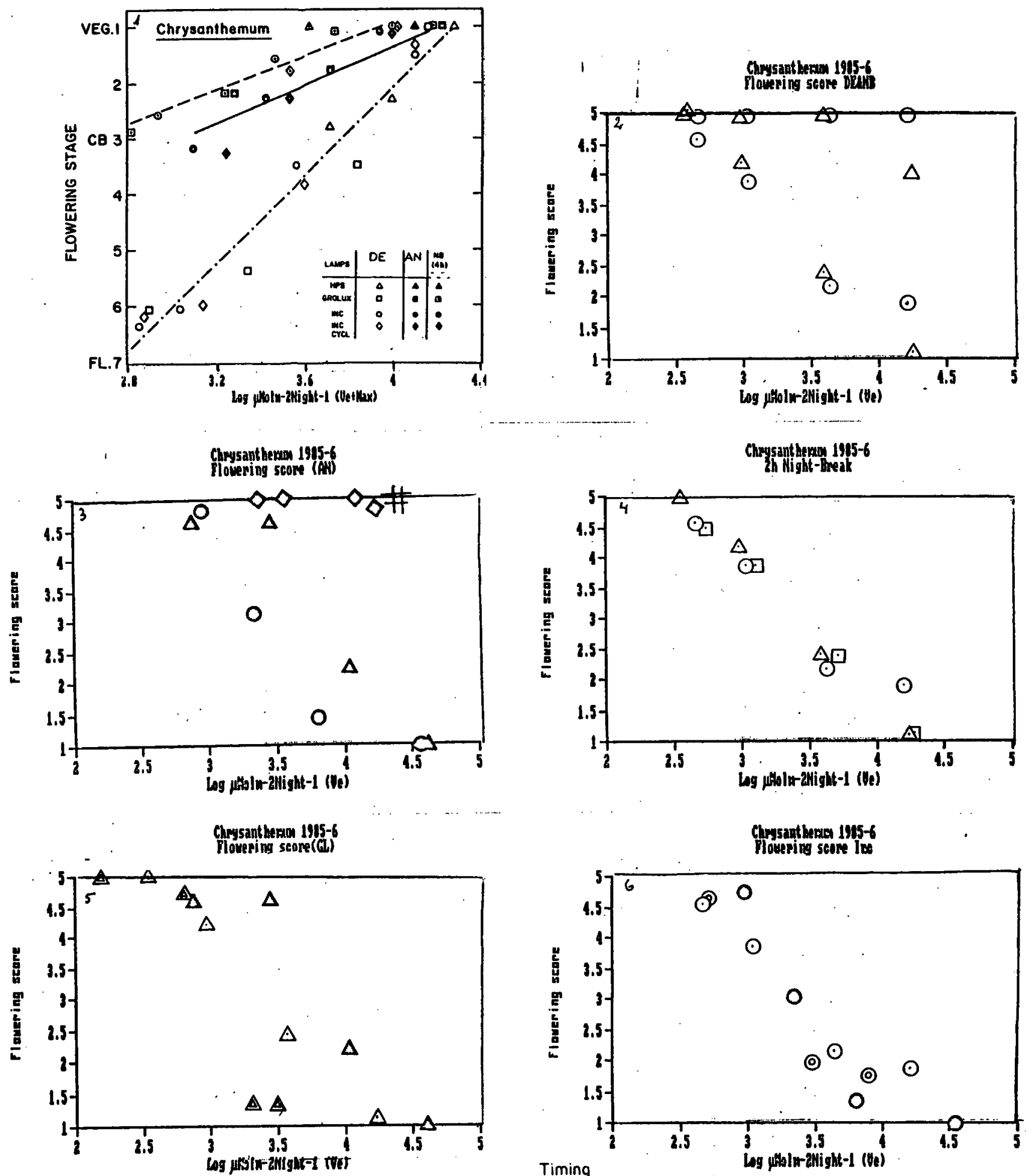

\begin{tabular}{|c|c|c|c|c|}
\hline Lomp: & AN & $D E$ & $\mathrm{NB}$ & SI \\
\hline Inc & 0 & 0 & $\odot$ & (อ) \\
\hline Inc Cycl & 0 & 0 & 0 & \\
\hline$G$ & $\Delta$ & $\Delta$ & $\bar{\Delta}$ & $\Delta$ \\
\hline $\mathrm{CW}$ & 口 & 口 & $\square$ & 回 \\
\hline HPSALPS & 0 & 0 & 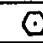 & \\
\hline$\overline{F R}$ & \# & & & \# \\
\hline Blue & 0 & & & \\
\hline ND & $x$ & & & \\
\hline
\end{tabular}




\section{Hyoscyamus niger}

Hyoscyamus niger is one of the most thoroughly studied long-day plants, as regards the physiology of and especially the effects of light of different spectra on, its flowering. We used the annual var. 'Pallidus', originally used by Melchers and Lang (seeds cordially provided by Prof.W. Rau). Four experiments were conducted (Exps. 4-7), of which we report in detail the results on the average number of days to flowering in Exp. $5(1985 / 6)$ and number of days to $50 \%$ flowering in Exp. $7(1986 / 7)$. (See Table 2 For the treatments).

Experiment 5 . Seeds were sown on Oct. 101985 . under natural day length conditions. The irradiation treatments were started oct. 27 . On Nov. 14 stem elongation was evident in the "a" positions in AN Inc and GL, and the first flowers opened in both treatments on Dec. 2, 1985. The experiment ended May 4, 190 days after the start of the irradiations. By that date $50 \%$ of the control plants in Natural Daylength were flowering. Average flowering day was calculated as the sum of the number of days from the start of the irradiations to the opening of the first flower in each plant, divided by the number of plants. Plants that did not flower by May 4 were presumed to have flowered within 10 days after the end of the experiment (day 200) because all the plant had started elongating before the experiment was terminated. The results are presented in Figs . 1-5.

The effects of the timing of the irradiation are presented in Fig 1 As with the SD plants, the effects of a $2 \mathrm{~h}$ irradiation were strongly dependent on the timing of the application, being rather ineffective in the early hours of the night. The slight difference in effect between DE GL and Inc was not found in Exp. 7.

The effects of $2 \mathrm{~h}$ night-breaks with different lamps are compared in Fig 2 . No difference was noted between Inc, GL, CW and LPS light.

The effects of $10 \mathrm{~h}$ irradiations are presented in Fig. 3. Blue was completely ineffective. Again no difference can be seen between Inc and GL, and FR was also effective. The effects of the duration of the irradiations presented around the middle of the night are presented in Fig. 4 (GL) and Fig 5 (Inc and FR). In Fig. 4 the same fluence seems to be more effective when presented over a shorter period then when provided over $10 \mathrm{~h}$. Similar results (although smaller in magnitude), were also obtained in Exp. 7. With Inc light no such difference could be seen, all the durations of the irradiations being equally effective. Here it is again evident that FR was slightly less effective than Inc. 
Experiment 7. The seeds were sown on Sept. 15 and the irradiation treatments were started on the same day. The first flowers opened in AN - HPS on Oct. 30 , in GL on Nov. 19 and in Inc on Nov. 23. The experiment was terminated on Apr. 26,1987 , by which time $87 \%$ of the ND control plants were flowering. The results are presented in Table 1 and Figs. 1-6.

The effects of the timing of the irradiations are presented in Fig. 1 (GL) and Fig. 2 (Inc). Unfortunately, the plants in DE GL positions b-d in and in NB GL position d were deteriorated. For this reason we present the effects of the timing of the irradiations in a more comprehensive manner in Table 1 . It is evident that with both GL and Inc, NB irradiations were most effective, while DE was probably the least effective - with no clear differences between late evening or early morning irradiations.

In Fig. $330 \mathrm{~min}$. End-of-Day irradiation with GL of FR light is compared with $2 \mathrm{~h}$ DE. Only the highest fluence of DE had any effect.

The effects of $10 \mathrm{~h}$ AN irradiations are presented in Fig. 4. Again Blue had no effect. There was no difference in effectiveness between GL and Inc, and HPS was most effective.

In Fig.5 (Inc) and Fig.6 (GL) the effects of the duration of the irradiation periods are compared. With Inc light the duration had no effect: flowering was directly related to the total light fluence received per night. In GL we again find thet $10 \mathrm{~h}$ irradiations were somewhat less effective than $2 \mathrm{~h}$ irradiations, but in contrast to the previous year, 15 min irradiations did not differ from $10 \mathrm{~h}$ irradiations.

Discussion. The fact that in our greenhouse experiment no difference in effectiveness could be found between GL and Inc light contrast greatly with the growth room experiments reported in results of the experiments in the Biotron ( $p$. .), where Inc light was far superiour to $C W$ and GL light in the induction of stem elongation and flowering in $H$. niger. Unfortunately, the experimental treatments varied in more than one component: The very high sunlight intensity during the day time and the high amounts of FR in the greenhouse (in sunlight), as compared with the $11 \mathrm{~h}$ main-light periods with CWF light in the growth room. The lack of effect by blue light is interesting, because in Growth-room experiments Blue light was of ten found to enhance flowering in $H$. niger. The fact that FR was somewhat effective in AN irradiations is in line with Downs's finding that FR could enhance stem elongation in $H$. niger. Owing to this effect of FR, it is of interest that Inc light was not more effective than GL, because, in these experiments the FR content of the Inc lamps was not measured and was of course not included in the calculations of light fluences (see chapter on Gypsophila). 
Table 1 Hyoscyamus niger

$2 h$ Light per night. (* Plants lost)

\begin{tabular}{|c|c|c|c|c|c|c|c|c|c|}
\hline $\begin{array}{l}\text { Treat } \\
\text { Time }\end{array}$ & & $\begin{array}{c}D E \\
18-20\end{array}$ & $\begin{array}{c}L E \\
19-21\end{array}$ & $\begin{array}{c}\text { NB } \\
23-01\end{array}$ & $\begin{array}{c}E M \\
03-05\end{array}$ & $\begin{array}{c}D E \\
18-20\end{array}$ & $\begin{array}{c}L E \\
19-21\end{array}$ & $\begin{array}{c}\text { NB } \\
23-01\end{array}$ & $\begin{array}{c}E M \\
03-05\end{array}$ \\
\hline & a & Perce & ent Flor & vering & & b. & Days to & $50 \% \mathrm{FI}$ & owering \\
\hline Inc. & a & 100 & 94 & 100 & 100 & 103 & 93 & 76 & 82 \\
\hline & b & 90 & 86 & 100 & 100 & 213 & 96 & 121 & 82 \\
\hline & c & 44 & 84 & 74 & 20 & 220 & 207 & 203 & 220 \\
\hline & d & 69 & 54 & 39 & 41 & 215 & 218 & 220 & 220 \\
\hline Grolux & a & 100 & 100 & 100 & 97 & 84 & 85 & 82 & 88 \\
\hline & $\mathrm{b}$ & * & 89 & 100 & 78 & * & 193 & 96 & 203 \\
\hline & c & * & 89 & 100 & 40 & * & 203 & 190 & 220 \\
\hline & 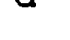 & 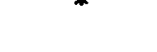 & 78 & 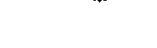 & 22 & 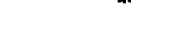 & 203 & 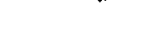 & 220 \\
\hline Control & & 87 & & & & 213 & & & \\
\hline & $c$ & Days & to $1 \mathrm{st}$ & Stem & & & Log & $\begin{array}{l}\text { uMolm- } \\
\text { Ve }\end{array}$ & $\begin{array}{l}\text { 2night }-1 \\
\text { AvgVe }+M\end{array}$ \\
\hline Inc & $\mathbf{a}$ & 42 & 35 & 39 & 42 & Inc & a & 3.97 & 4.03 \\
\hline & $b$ & 52 & 35 & 63 & 46 & & b & 3.31 & 3.51 \\
\hline & $c$ & 177 & 99 & 70 & 145 & & c & 2.85 & 3.11 \\
\hline & $d$ & 187 & 169 & 145 & 183 & & d & 2.55 & 2.84 \\
\hline GroLux & $\mathbf{a}$ & 49 & 39 & 39 & 35 & Grolux & a & 3.99 & 4.04 \\
\hline & $b$ & * & 99 & 52 & 46 & & b & 3.24 & 3.44 \\
\hline & c & * & 88 & 138 & 148 & & c & 2.70 & 2.99 \\
\hline & $d$ & * & 200 & * & 200 & & d & 2.39 & 2.70 \\
\hline
\end{tabular}


Hyoscyamus niger. Legend for Figures.

Figs.1-5. Exp. 5 1985/6.

$y$ axis: Average Flowering day

$\underline{x}$ axis: Log light fluence per night.

Fig. 1 Comparing the effects of $2 \mathrm{~h} \mathrm{DE}$ and $2 \mathrm{~h} \mathrm{NB}$ with Inc or GL light.

Fig. 2 Effects of $2 \mathrm{~h}$ NB with CW, GL, Inc or LPS light.

Fig. 3 Effects of $10 \mathrm{~h}$ irradiations with Blue, FR, GL, or Inc light.

Figs. 4, 5 Effects of irradiations around midnight with 15 min, $2 \mathrm{~h}$ or $10 \mathrm{~h}$ of Inc or FR (Fig. 4) or GL (Fig. 5) light.

Figs. 6-11 Exp. 7, 1986/7

$y$ axis: Number of Days to $50 \%$ Flowering.

x axis: Log light fluence per night.

Fig. 6, 7 Effects of the timing of $2 \mathrm{~h}$ irradiations with GL (Fig. 6) and Inc (Fig. 7)

Fig. 8 Effects of irradiations in the evenings: 30 min EOD FR or GL or $2 \mathrm{~h}$ DE GL or Inc.

Fig. 9 Effects of $10 \mathrm{~h}$ irradiations with Blue, GL, HPS or Inc light.

Figs. 10,11 Effects of irradiations around midnight with $15 \mathrm{~min}, 2 \mathrm{~h}$ or $10 \mathrm{~h}$ of GL (Fig. 10 ) or Inc (Fig. 11) light. 

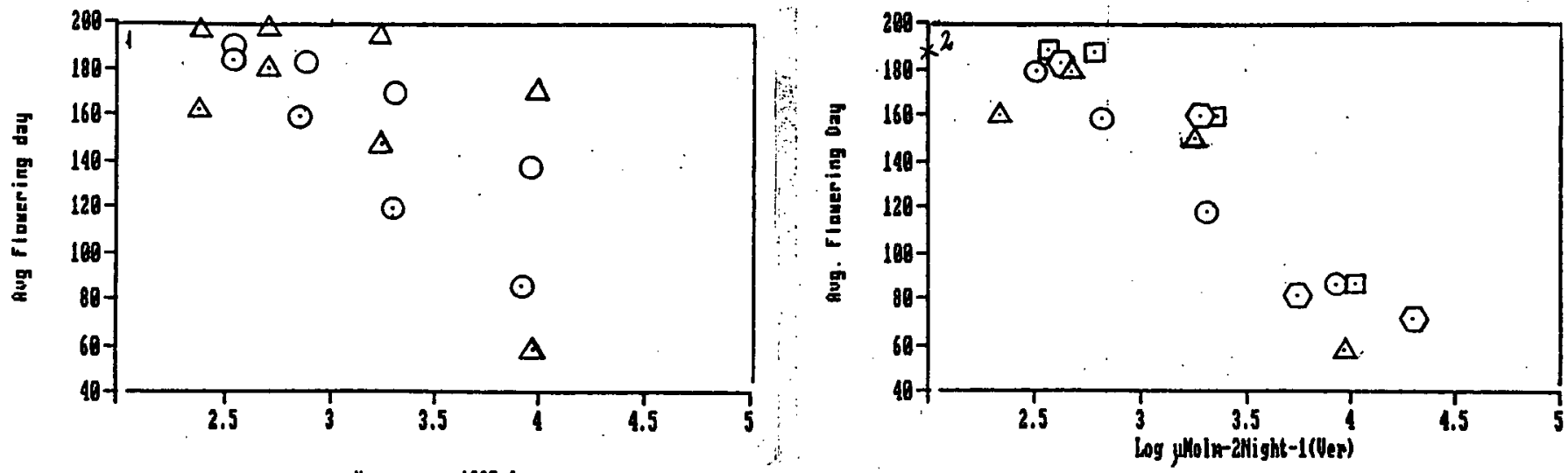

Hyoscyamus 1985-6

Ioh irradiations
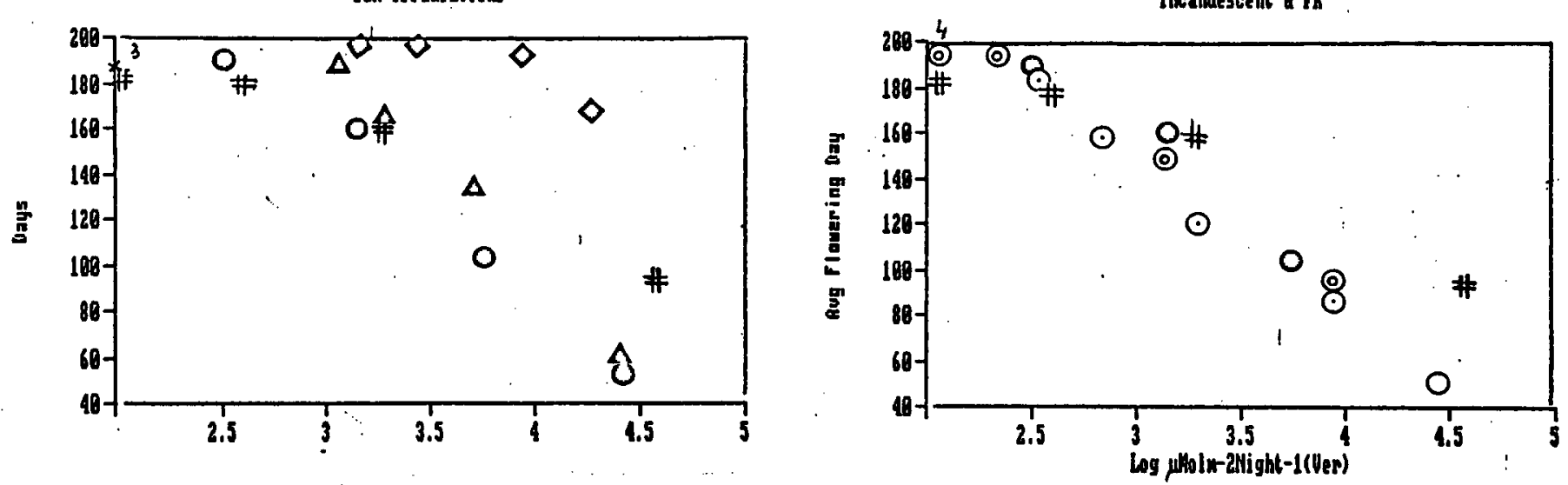

GL AiV I

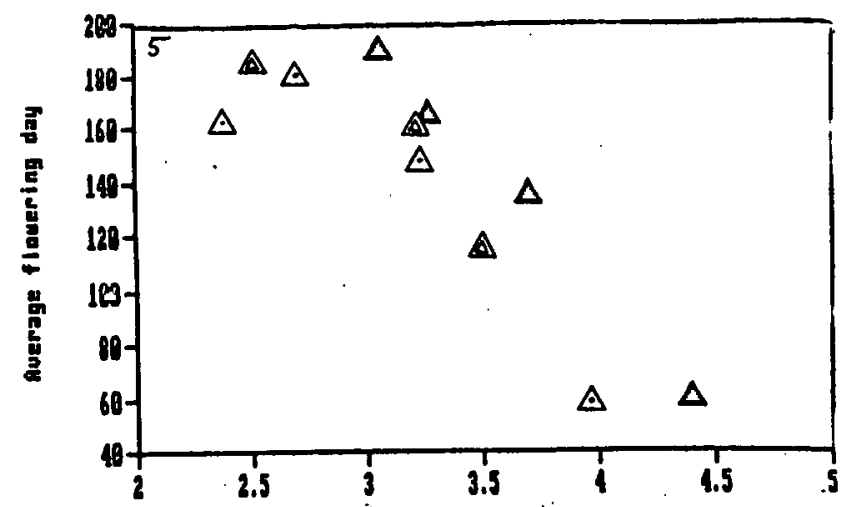

\begin{tabular}{|c|c|c|c|c|}
\hline & \multicolumn{4}{|c|}{ Timing } \\
\hline Lamp: & $A N$ & $\mathrm{DE}$ & NB & SI \\
\hline Inc & 0 & 0 & 0 & (2) \\
\hline Inc $\mathrm{Cycl}$ & 0 & 0 & 0 & \\
\hline$G L$ & $\Delta$ & $\Delta$ & $\Delta$ & $\Delta$ \\
\hline $\mathrm{CW}$ & 0 & D & $\square$ & 回 \\
\hline HPSELPS & 0 & 0 & $\odot$ & \\
\hline$F R$ & \# & & & $\#$ \\
\hline Blue & 0 & & & \\
\hline ND & $x$ & & & \\
\hline
\end{tabular}


Hyoseyapas $1986-7$

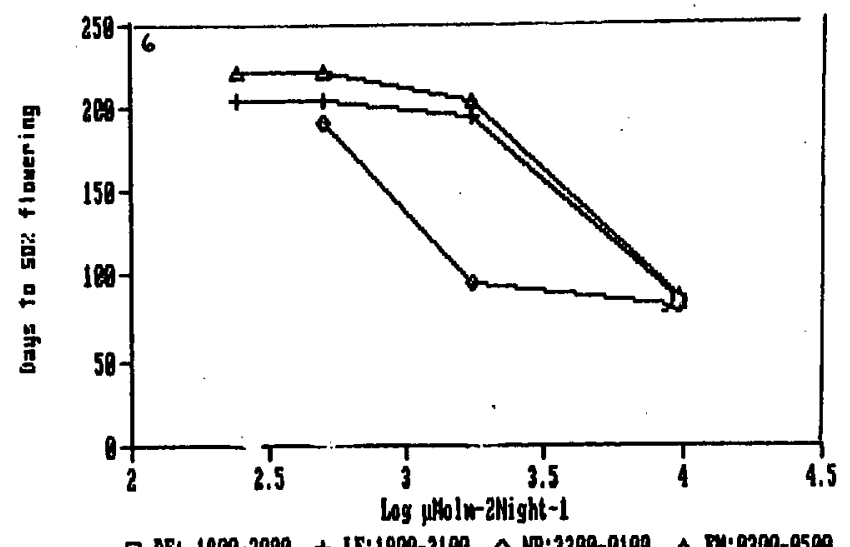

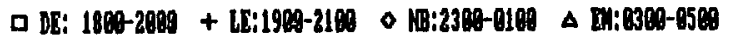

Hyoscyames niger 1986-?

End-of-bay And Day Extensions

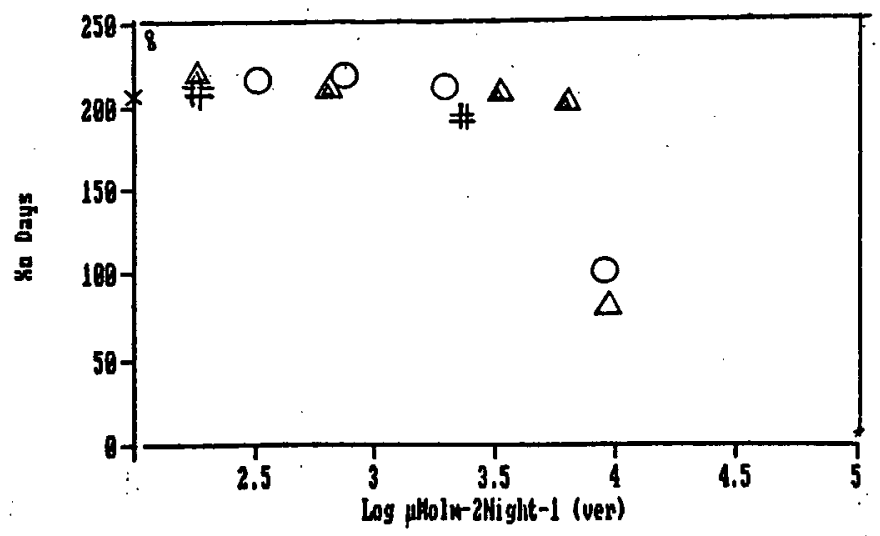

Hyoseyaurs 1986-7

All-Hight and Ni GL

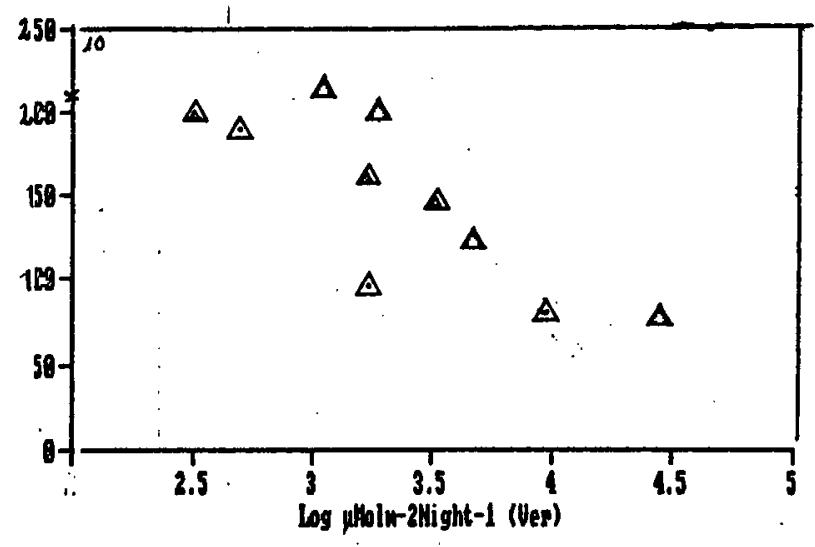

Hyoscyaws 1986-7

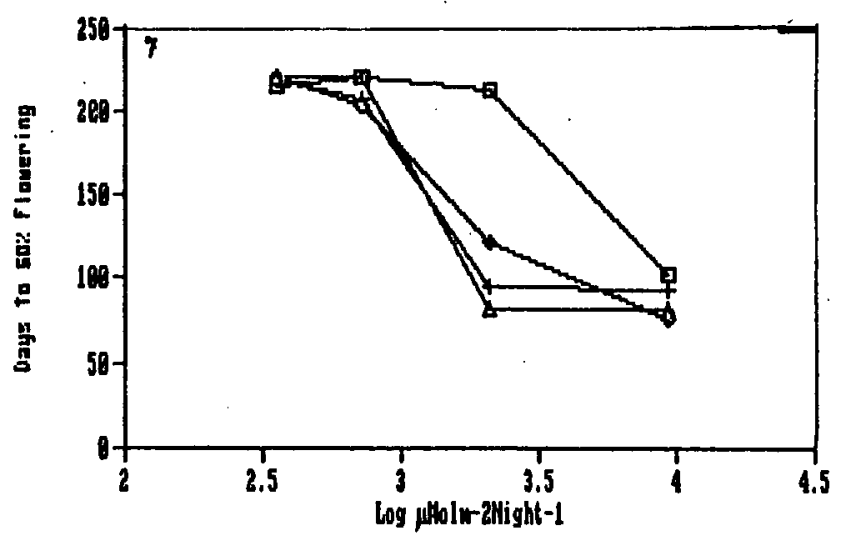

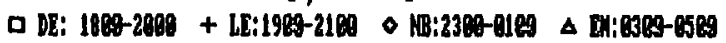

Hyoscyawis 1986-7

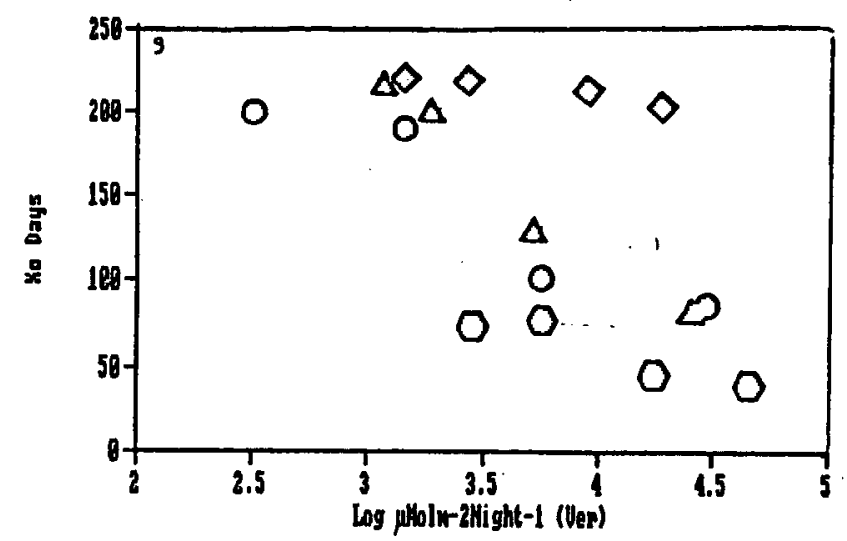

Allyoscyame 1986-9

All-Hight and HB IHC

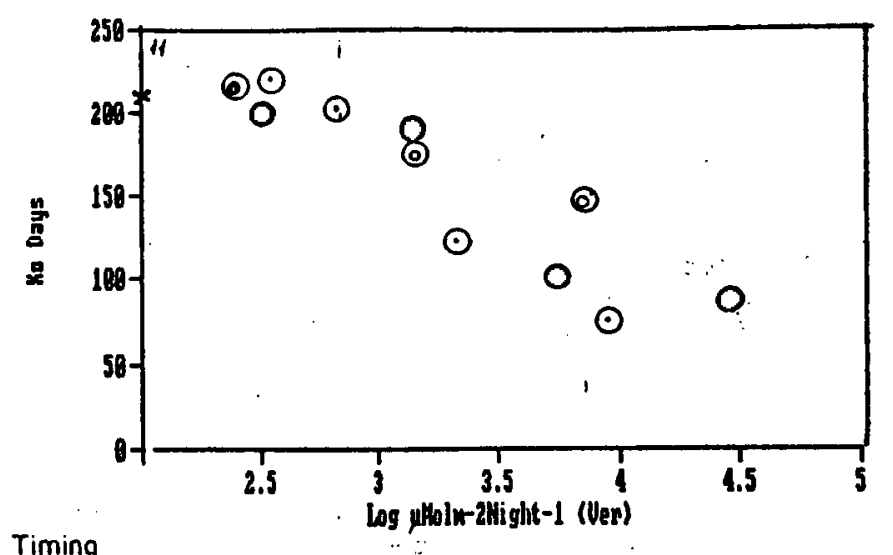

\begin{tabular}{|c|c|c|c|c|}
\hline Lamp: & AN & $D E$ & NB & SI \\
\hline Inc & to & 0 & 0 & (๑) \\
\hline Inc $C_{y c l}$ & 0 & 0 & 0 & \\
\hline$\overline{G L}$ & $\Delta$ & $\Delta$ & $\Delta$ & $\Delta$ \\
\hline CW & a & 口 & $\square$ & 回 \\
\hline HPS\&LPS & 0 & 0 & $\odot$ & \\
\hline FR & $\#$ & & & $\#$ \\
\hline Blue & 0 & & & \\
\hline ND & $x$ & & & \\
\hline
\end{tabular}




\section{Pharbitis nil}

Pharbitis nil is a short-day flowering plant widely used in the study of the physiology of flowering. Under proper conditions it may be induced to flower already in the cotyledon stage. It may be induced to flower by a single dark period longer than $13 \mathrm{~h}$. It is a summer-growing plant, and can grow and flower only at relatively high temperatures.

Ph. nil is a climbing plant, with very long branches. We were therefore reluctant to use it because of its shading effects on adjacent plants. It was included only in the two last experiments (Exps. 6,7), when gypsophila was no longer used. The plants were allowed to grow for one month only. After the end of the first part of Exp. 7, the plants were pruned above the cotyledons and new branches were allowed to develop. Here we report the results of Exp. 6 .

On March 3, 1986, seeds of Ph. nil (var. 'Violet' obtained from Japan) were treated with concentrated sulfuric acid, washed and placed in germination trays for 2 days. Germinated seeds were sown, two per pot, directly in the experimental plots, four pots per plot ( 16 plants per position). As fewer seeds than expected germinated, the positions closest to the lamps (position a) as well as the EOD GL or FR, were not included in the experiment (see table 2 in Materials and Methods, for the treatments). The plants were collected one month later. Stem length, number of leaves and the position of the first and following flowers were recorded.

In growth-room experiments flower buds often develop on the first node and a terminal flower bud is formed after six or seven leaves. In our experiment the first flowers developed on the eightth node, both in the natural daylength control as well as in the Short-Day treatment, and terminal flowers developed only in some of the plants in SD. This was most probably due to the low night temperatures prevailing in March. Flower formation was of ten not continuous, but there were one or more flowerless nodes between the flowering nodes. We could therefore not use the number of the first flowering node for the assessment of flowering. Usually in the upper part of the branches there were no such gaps. The fact that there was no terminal flower, and minute flower buds might be present at the base of every leaf primordium up to the apex, made it impossible to count the actual flower buds present. We therefore assumed that every plant had 20 nodes. The number of flowers was calculated as : 20 minus the flowerless nodes. The results are presented in Figs. 1-5. 
The differences in effectiveness of $2 \mathrm{~h}$ irradiations according to the time of application are shown in Fig. 1 (GL) and Fig. 2 (Inc). From Fig. 1 it is evident that irradiations early in the evening (1800-2000 as well as 1900-2100 hours) with Grolux light were very inefficient in influencing the flowering of $\mathrm{Ph}$. nil. The same amount of light was very effective when applied in the middle of the night, and also somewhat effective when applied just before sunrise (EM, 0300-0500 hours).

The effects of Incandescent light (Fig. 2) were also strongly influenced by the time of application, being very effective in the middle of the night and very ineffective in the evenings. Inc light applied later in the evenings (1900-2100 hours) was somewhat more effective than GL light.

In Fig. 3 the effects of $10 \mathrm{~h}$ AN irradiations are compared. Blue was effective only at the highest fluence tested, whereas flowering was completely suppressed by HPS already at the lowest fluence. There was no difference between the effects of Inc. and Grolux light, both being somewhat less effective than HPS.

Figure 4 shows the effects of different durations of irradiation, centered around the middle of the night. The effectiveness of Inc and GroLux lamps is again very similar. The effect is related only to the logarithm of total light quanta applied per night. The light quanta may be provided for $10 \mathrm{~h}$ using a low fluence rate (from $40 \mathrm{~W} \mathrm{GL}$ or loow Inc lamp, see Table 3 ), or by 15 min irradiations, using much higher fluence rates (240W GL or $1600 \mathrm{~W}$ incandescent lamps).

\section{Discussion}

The high effectiveness of most of the light treatments was probably due to ambient conditions unfavorable for flowering: low night temperatures and relatively long days. In Exp. 7 flowering was again found to be strongly inhibited by relatively low light fluences. but after pruning in October, flower buds developed in most of the plants and was inhibited entirely only at the highest light fluences (not shown). The fact that there was no difference in the effectiveness of Inc and Grolux light is more difficult to explain. The light of both lamps contains very similar amounts of Red light quanta, but the Inc light also contains high amounts of Far-Red quanta (which was not included in the light measurements, see chapter on Gypsophila). Far-Red light as well as Red light have been shown to inhibit flowering in Pharbitis nil. The fact that Inc light was not more effective than GroLux light (or HPS), may suggest that under our conditions the Far-red was not effective, or that the inhibitory and the Redreversing effects of the Far-Red just cancel each other. 
Pharbitis nil. Legends for figures.

Exp. 6, Spring 1986 .

$y$ axis: Flowers per plant.

$x$ axis: Log light fluence per night.

Fig. 1,2 Effects of the timing of $2 \mathrm{~h}$ irradiations with GL (Fig. 1) and Inc (Fig. 2)

Fig. 3 Effects of $10 \mathrm{~h}$ irradiations with Blue, GL, HPS or Inc light.

Eigs. 4 Effects of irradiations around midnight with 15 min, $2 \mathrm{~h}$ or $10 \mathrm{~h}$ of GL or Inc light. 

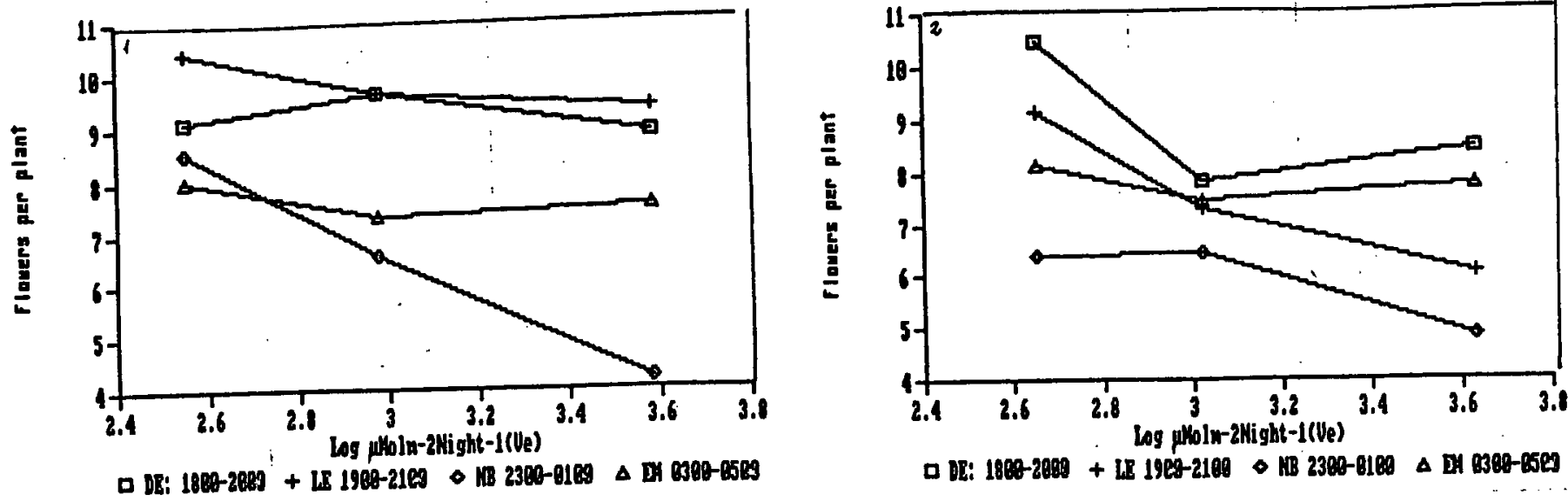

Pharbitis App 1986
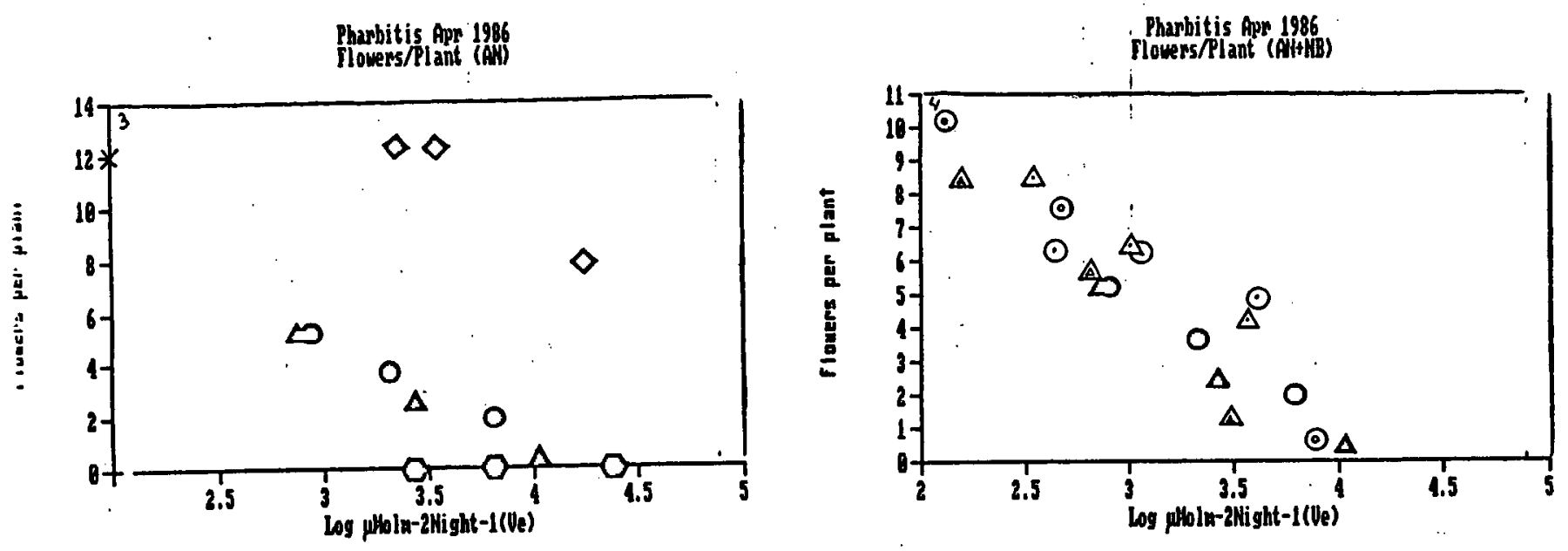

Timing

\begin{tabular}{|c|c|c|c|c|}
\hline Lomp: & AN & $\mathrm{DE}$ & NB & SI \\
\hline $\ln c$ & 0 & 0 & $\odot$ & (2) \\
\hline Inc Cycl & 0 & 0 & $\boldsymbol{O}$ & \\
\hline$G L$ & $\Delta$ & $\Delta$ & $\Delta$ & $\Delta$ \\
\hline $\mathrm{CW}$ & $\square$ & $\square$ & 口 & 回 \\
\hline HPSELPS & 0 & 0 & Q & \\
\hline FR & \# & & & \# \\
\hline Blue & 10 & & & \\
\hline ND & $x$ & & & \\
\hline
\end{tabular}


Setaria italica

Setaria italica is a short-day flowering grass. In a previous set of experiments we found that End-of-Day GL as well as GL Night-breaks (NB) delayed its flowering. This plant was used in Experiment 6 .

Setaria seeds of an unknown var, received from ARO's dept. of Seed research, were sown on March 10, 1986. (See Table 2 for treatments). On April 3 microscopic spike primordia were found in plants from the Natural Daylength (ND) control. On April 22, five plants were collected from each plot (ten plants per position). These plants were checked under a dissecting microscope. Spike primordia were found in most of the plants, but they differed greatly as to the number of elongating internodes. The number of elongating internodes was chosen to represent the effectiveness of the light treatments (Figs. 1-6)

In Fig. 1 (GL) and Fig. 2 (InC) the effects of $2 \mathrm{~h}$ irradiations are presented. Light applied in the middle of the night was the most effective, and early in the evening or early morning least effective, and almost equally so for Inc and $G L$. However, with Inc light late evening was almost more effective than NB. This has to be repeated in order to verify whether this effect is real. In Fig. 3 The effects of End-of-Day GL or FR light are compared with DE GL and INC. Only the two highest fluences of EOD GL had any effect, as has been found previously.

In Figs 4,5 and 6 the effects of light treatments around the middle of the night are compared (note the different scale on the $Y$ axis). In $10 \mathrm{~h}$ irradiations (Fig. 4) Blue was completely ineffective, and HPS was the most effective, followed by GL. Both in GL (Fig. 5) and in Inc (Fig. 6) 10 $h$ irradiations seem to be more effective than shorter irradiations. The lower effectiveness of Inc light in delaying flowering of setaria may derive from the fact that Far-Red light is known to enhance flowering in this plant, and thus the FR included in the Inc light may counteract the flower inhibiting effects of the Red component of that light. 
Setaria italica. Exp. 6. Spring 1986. Legend for figures $y$ axis: Number of elongating internodes.

x axis: Log light fluence per night.

Fig. 1. 2 Effects of the timing of $2 \mathrm{~h}$ irradiations with GL (Fig. 1) and Inc (Fig. 2)

Fig. 3 Effects of irradiations in the evenings: $30 \mathrm{~min}$ EOD FR or GL or $2 \mathrm{~h} \mathrm{DE} \mathrm{GL}$ or Inc.

Fig. 4 Effects of $10 \mathrm{~h}$ irradiations with Blue, GL, HPS or Inc light.

Figs. 5, 6 Effects of irradiations around midnight with 15 min, $2 \mathrm{~h}$ or $10 \mathrm{~h}$ of GL (Fig. 5) or Inc (Fig. 6) light. 
Setapia ifalica

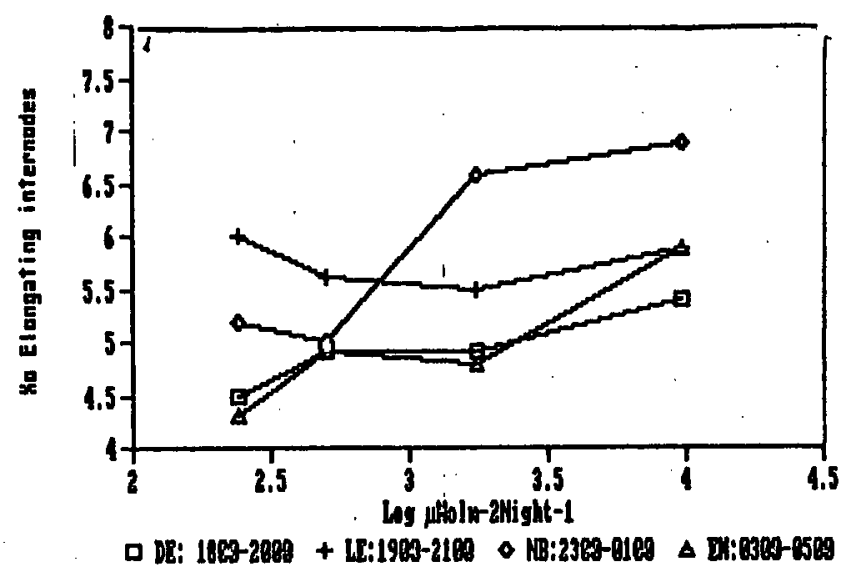

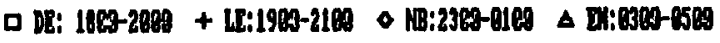

Setayis Aps 1906

Eons and of

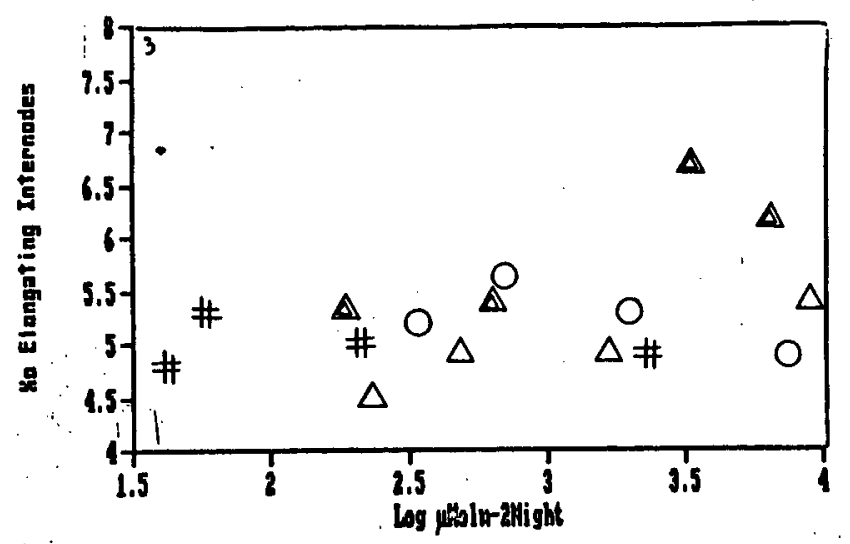

Setaria fops. 1986

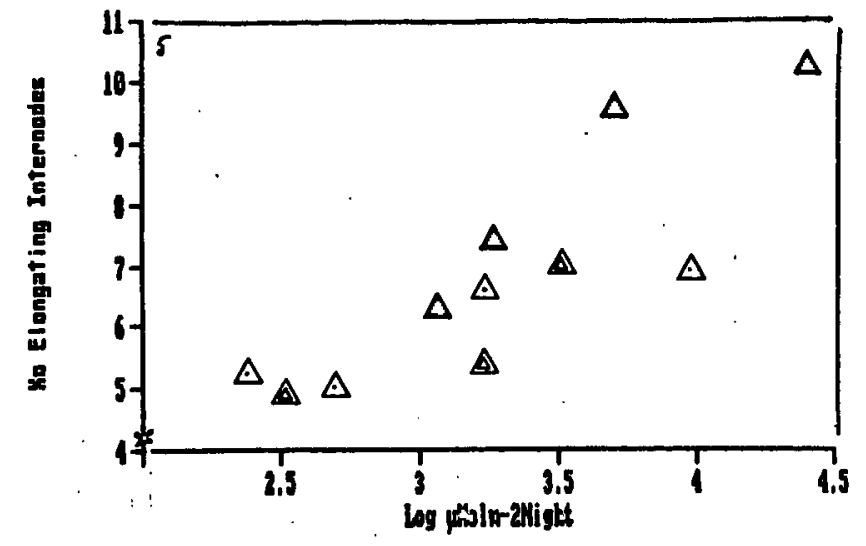

Seturia italica

is ine

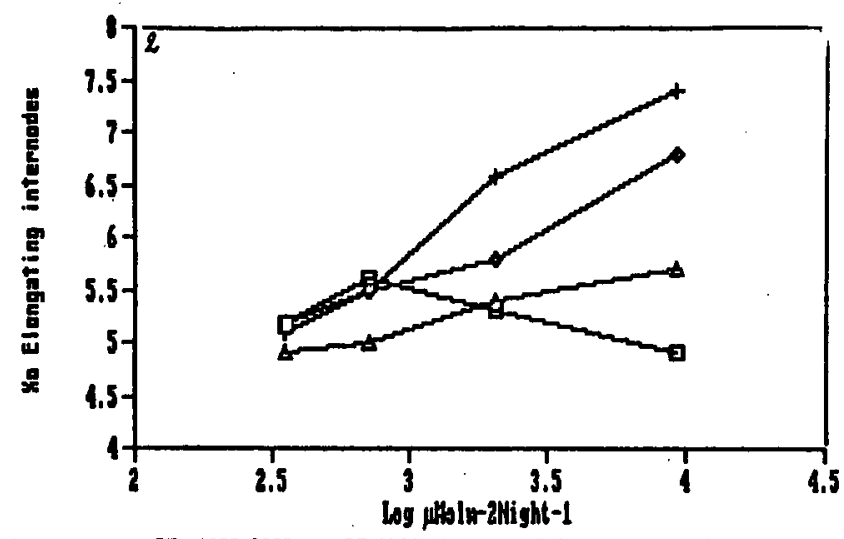

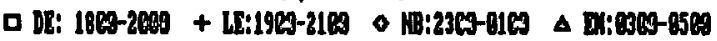

Setaria App.1986

AN. No of Elongating Internodes

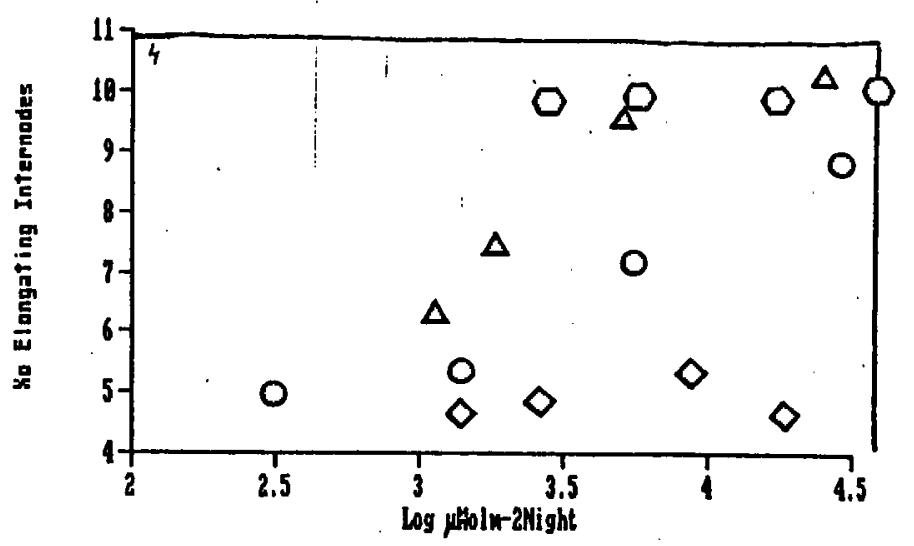

Setwia Aprduns

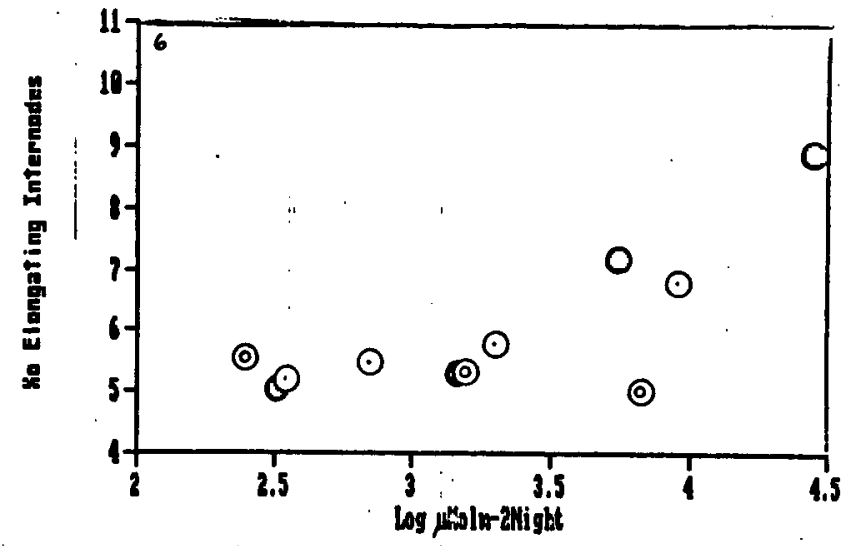


Sinapis alba

Sinapis alba is a long-day flowering crucifer, which has been widely used in photoperiodic and photomorphogenetic studies. We included it in several of our experiments, along with two other cruciferes: Brassica campestris and Arabidopsis thaliana, and never obtained clear response to the light treatments.

In Exp. 5 On Dec. 24, 1985 Sinapis seeds were sown in the polvurethane boxes. Up to 25 plants developed per plot (50 per position). The first flowers opened on Feb. 24 in the " $a$ " positions in LPS ( $2 \mathrm{~h} \mathrm{NB})$. The experiment was terminated on April 12,1986. Most of the plants having flowered by that date.

In Fig. 1 the effects of different irradiations with discharge lamps are shown. Only the highest fluences of GL ( $2 \mathrm{~h}$ and $10 \mathrm{~h}$ irradiations) and LPS ( $2 \mathrm{~h}$ irradiations) materialy advanced flowering before that of the natural day-length control. Incandescent, FR and Blue (not shown) had no such effect even at the highest fluences tested (Fig. 2). In Fig 3 it can be seen that DE with Inc or GL light also did not advance flowering.

In Experiment 7 seeds of the (Webbs 'Fine White'), sown on Sept. 141986 , showed no response to the light treatments. Flowering date was influenced more by the position of the plants as regards sunlight then as regards the light gradient during the night. As is evident from Table 1 , plants grown in the east and west beds and those in positions "d" in the southern plots of the different beds (peripheral plots). flowered in advance of those grown in more central plots. In the central plots there was no difference among plants irradiated with Inc, GL or Blue light. 
Table 1 Effect of position in the greenhouse on Flowering of Sinapis alba (Webs Fine white) plants sown on sept. 14,1986

Flowering assessed on Nov. 6, 1986

Position

Peripheral

sub-Peripheral

Central:

INC

GL

BLUE
\% Flowering

$$
15.62
$$

3.57

1.70

1.79

1.79 
Sinapis alba. Exp. 5, 1985/6. Legend for figures

$y$ axis: Average Flowering day

$x$ axis: Log light fluence per night.

Figs. 1,2 Effects of irradiations around midnight with 15 min, $2 \mathrm{~h}$ or $10 \mathrm{~h}$ of GL, or $2 \mathrm{~h}$ with CW or LPS (Fig. 1); or $15 \mathrm{~min}, 2 \mathrm{~h}$ or $10 \mathrm{~h}$ Inc or $10 \mathrm{~h}$ FR (Fig. 2) light.

Fig. 3 Effects of the timing of $2 \mathrm{~h}$ irradiations with GL and Inc. 
Simapis 1985-6

fuerage flotering $\mathrm{Daz}_{\mathrm{Cl}} \mathrm{Cl}, \mathrm{Cl}$, LPS

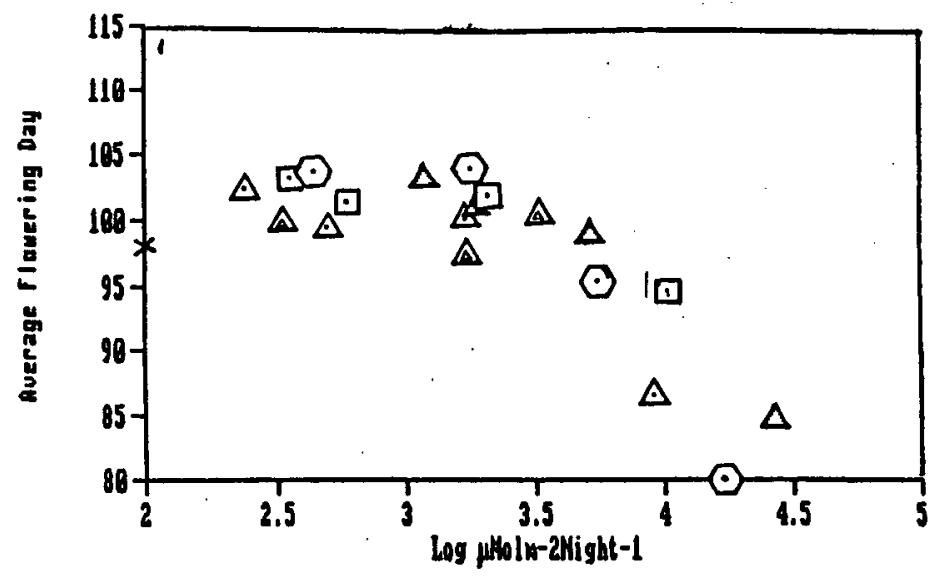

Simapis 1985-6

Average flouering Day IncdrR

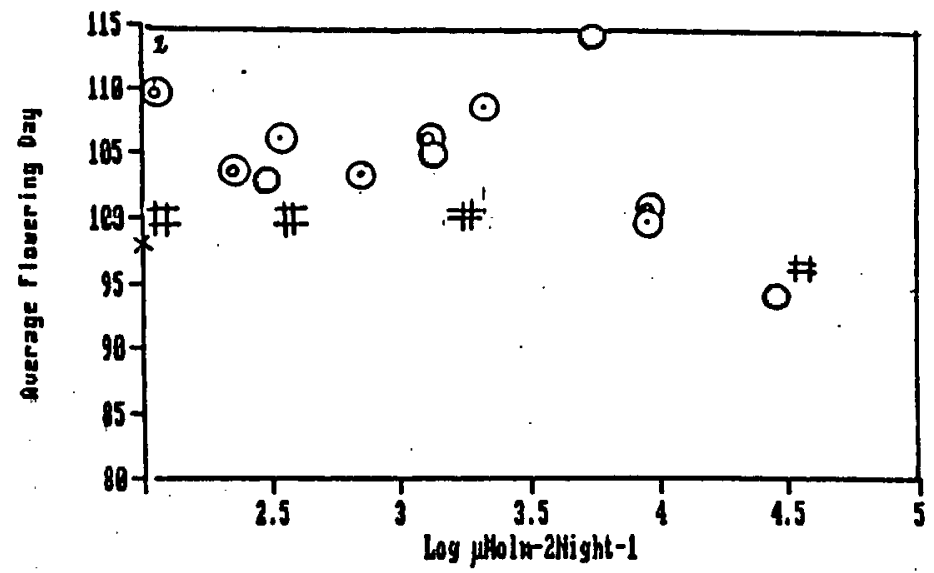

Sinapis $1985-6$

Average Ylotering Day

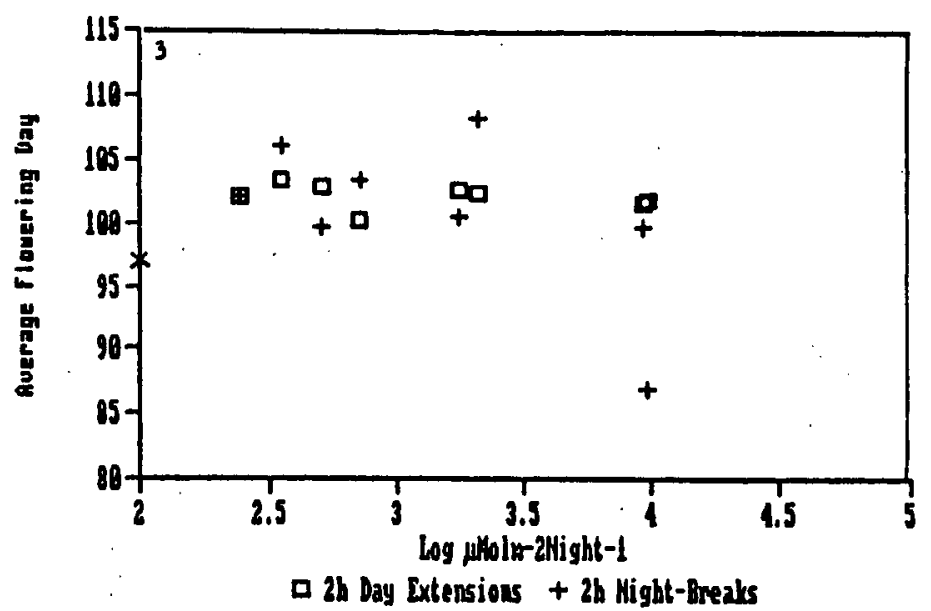

Timing

\begin{tabular}{|l|llll|}
\hline Lamp: & AN & DE & NB & SI \\
\hline InC & 0 & 0 & $\odot$ & $\odot$ \\
\hline InC CyCl & 0 & 0 & 0 & \\
\hline GL & $\Delta$ & $\Delta$ & $\Delta$ & $\Delta$ \\
\hline CW & $\square$ & $\square$ & $\square$ & G \\
\hline HPSBLPS & 0 & 0 & $\odot$ & \\
\hline FR & $\#$ & & & $\#$ \\
\hline Blue & 0 & & & \\
\hline ND & $X$ & & & \\
\hline
\end{tabular}




\section{Spinacia oleracea}

Spinach( Spinacia oleracea), is a long-day flowering plant. In short-days the plants form rosettes. LD conditions induce both stem elongation and flowering. It is a dioecious plant. We recorded separately the flowering of male and female plants, but, as no difference in the response was found, the results presented are for the population as a whole. Spinach was used in Exps. 3 and 4 and twice in Exp. 7. Herein are presented the results of ExP. 7, I and II.

Experiment 7 -I. Seeds from a dificult to bolt var (Thompson-seeds, England (?) were soaked in water and kept overnight at $17^{\circ} \mathrm{C}$. They were then transferred to $3^{\circ} \mathrm{C}$ for two additional days. On Nov. 5, 1986, germinated seeds were sown directly in the treatment plots: five pots, each containing four seeds, were placed in every plot (ten pots per position). However, since many seeds failed to germinate there were mostly 9-17 plants per position, but in a few cases only a few plants were present at the end of the experiment. Flowering day was the day of anthesis for the male plants, and when styles were first seen in the case of the female plants.

On Dec. 17, 1986, the first plants were flowering in positions "a" of the all-night (AN) GL treatment, 42 days after sowing, this was followed closely by the AN Inc treatment (Dec. 22). The experiment was terminated on March 1, 1987. At which date most plants were still in the rosette condition, but the experiments had to be terminated due to a heavy attack by red spider mites.

of all the plants receiving irradiations early in the evening, end of day (EOD) FR or GL and day extensions (DE) with Inc or GL, only a single plant flowered (In DE GL). These data are therefore not presented. In Table 1 the effects of the timing of $2 \mathrm{~h}$ irradiations with Inc or GL light are presented. In Inc light there was no flowering in response to irradiations close to the end of the dark period (EM), but in late evening ( $L E$ ) the effect was almost the same as in the middle of the night. In GL light there was some response in EM, but in late evening there was flowering only at the highest light fluence. Flowering percentage of the plants receiving irradiations around the middle of the night is presented in Fig. 1. No clear difference is evident between the GL or Inc lamps or between the different durations of the irradiations ( 15 min, $2 \mathrm{~h}$ or $10 \mathrm{~h}$ ).

Experiment 7-II. On Dec. 24, 1986, seeds of the early var. Viroflor were sown in the polyurethane boxes, two rows of 15 seeds per box. Germination was prompt and at a later stage the plants were thinned to nine plants per row ( 36 plants per position). The first flowers opened in AN GL on 
Feb. 1. 1987 ( 38 days from sowing) and in AN Inc on Feb. 5 . The experiment was terminated on March 29.

In Figs 1 and 2 the effects of the timing of $2 \mathrm{~h}$ irradiations with GL and Inc light on average flowering day are presented. The irradiations were most effective when applied in the middle of the night (NB). Irradiations early in the dark periods (DE) were barely effective, but again there was a difference between the response to the lights: irradiations in late evening were effective with Inc but not with GL. light while at the end of the night GL was more effective than Inc.

In Fig. 3 the effects of $30 \mathrm{~min}$ EOD GL or FR irradiations are compared with those of $2 \mathrm{~h} D E$ with GL or Inc light. It is interesting that at the highest intensity $30 \mathrm{~min}$ EOD GL did result in some flowering (16\%), but only DE with GL light resulted in more then $50 \%$ flowering $(60 \%)$.

Blue light was completely ineffective (Fig. 4) and no differences were noted between Inc and Gl light in $10 \mathrm{~h}$ AN irradiations. With Inc irradiations ( $\mathrm{Fig}$. 5) there was no difference in effectiveness among the different durations, but with GL light short irradiation periods ( 15 inm and 2 h) were more effective than $10 \mathrm{~h} \mathrm{GL}$ irradiations (Fig. 6), or any duration of Inc irradiations.

It is interesting that although more plants flowered in Exp.7-II than in Exp 7-I, there was no difference in the time from germination to flowering in the two most influential treatments. 
Spinach I 1986/7. Percent Flowering

( $2 \mathrm{~h}$ Light at different hours of the night)

Treatment DE LE NB EM LOg UMOIm-2Night-1

Hour of Night 18-20 19-21 23-01 03-05 Ver AvgVe+M

$\begin{array}{lrrrrrrr}\text { Inc } & \text { a } & 0 & 100 & 100 & 0 & 4.20 & 4.20 \\ & b & 0 & 67 & 38 & 0 & 3.63 & 3.73 \\ & c & 0 & 0 & 17 & 0 & 3.02 & 3.27 \\ & \text { d } & 0 & 0 & 0 & 0 & 2.65 & 2.96 \\ & & & & & & & \\ \text { Grolux } & \text { a } & 17 & 54 & 75 & 100 & 4.24 & 4.24 \\ & \text { b } & 0 & 0 & 50 & 29 & 3.58 & 3.71 \\ & \text { c } & 0 & 0 & 0 & 0 & 2.98 & 3.20 \\ & \text { d } & 0 & 0 & 0 & 0 & 2.55 & 2.81\end{array}$


Spinacia oleracea. Legend for figures

Fig. 1 Exp. 7a, 1986. Effects of irradiations around midnight with $15 \mathrm{~min}, 2 \mathrm{~h}$ or $10 \mathrm{~h}$ of $\mathrm{GL}$ or Inc light.

$y$ axis: Percent Flowering.

x axis: Log light fluence per night.

Figs. 2 - 7, Exp. 7b, 1986/7

Fig. 2, 3, Effects of the timing of $2 \mathrm{~h}$ irradiations with GL (Fig. 2) and Inc (Fig. 3)

$y$ axis: Average Flowering day

x axis: Log light fluence per night.

Figs. 4-7

$y$ axis: Average Flowering day

$x$ axis: Log light fluence per night.

Fig. 4 Effects of irradiation in the evenings: $30 \mathrm{~min}$ EOD FR or GL or $2 \mathrm{~h} \mathrm{DE}$ GL or Inc.

Fig. 5 Effects of $10 \mathrm{~h}$ irradiations with Blue, GL, or Inc light.

Figs. 5, 6 Effects of irradiations around midnight with 15 min, $2 \mathrm{~h}$ or $10 \mathrm{~h}$ of GL (Fig. 5) or Inc (Fig. 6) light. 
Spinach 1 1986-7

All Night + HB

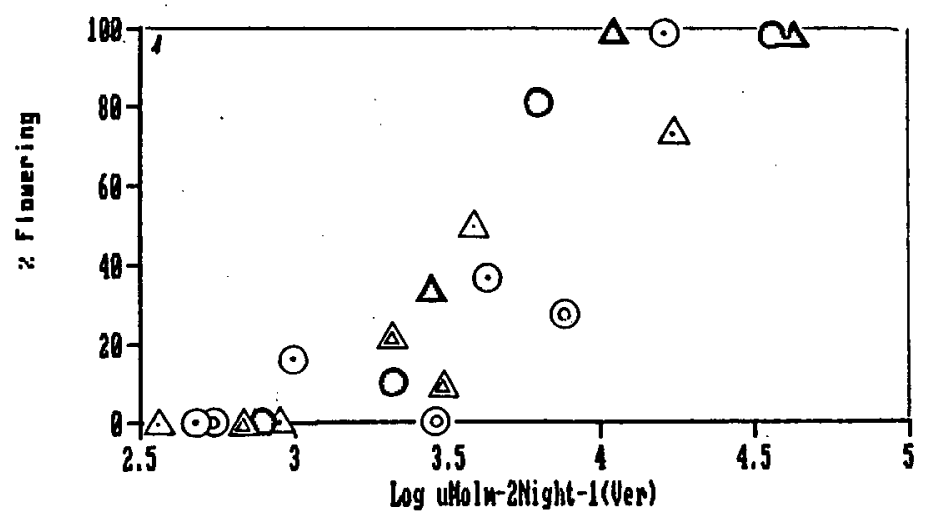

Timing

\begin{tabular}{|l|llll|}
\hline Lamp: & AN & DE & NB & SI \\
\hline Inc & 0 & 0 & $\odot$ & 0 \\
\hline Inc Cycl & 0 & 0 & 0 & \\
\hline GL & $\Delta$ & $\triangle$ & $\Delta$ & $\Delta$ \\
\hline CW & $\square$ & $\square$ & $\square$ & ⿴囗十 \\
\hline HPS LLPS & 0 & 0 & $\odot$ & \\
\hline FR & $\#$ & & & $\#$ \\
\hline Blue & 0 & & & \\
\hline ND & $X$ & & & \\
\hline
\end{tabular}



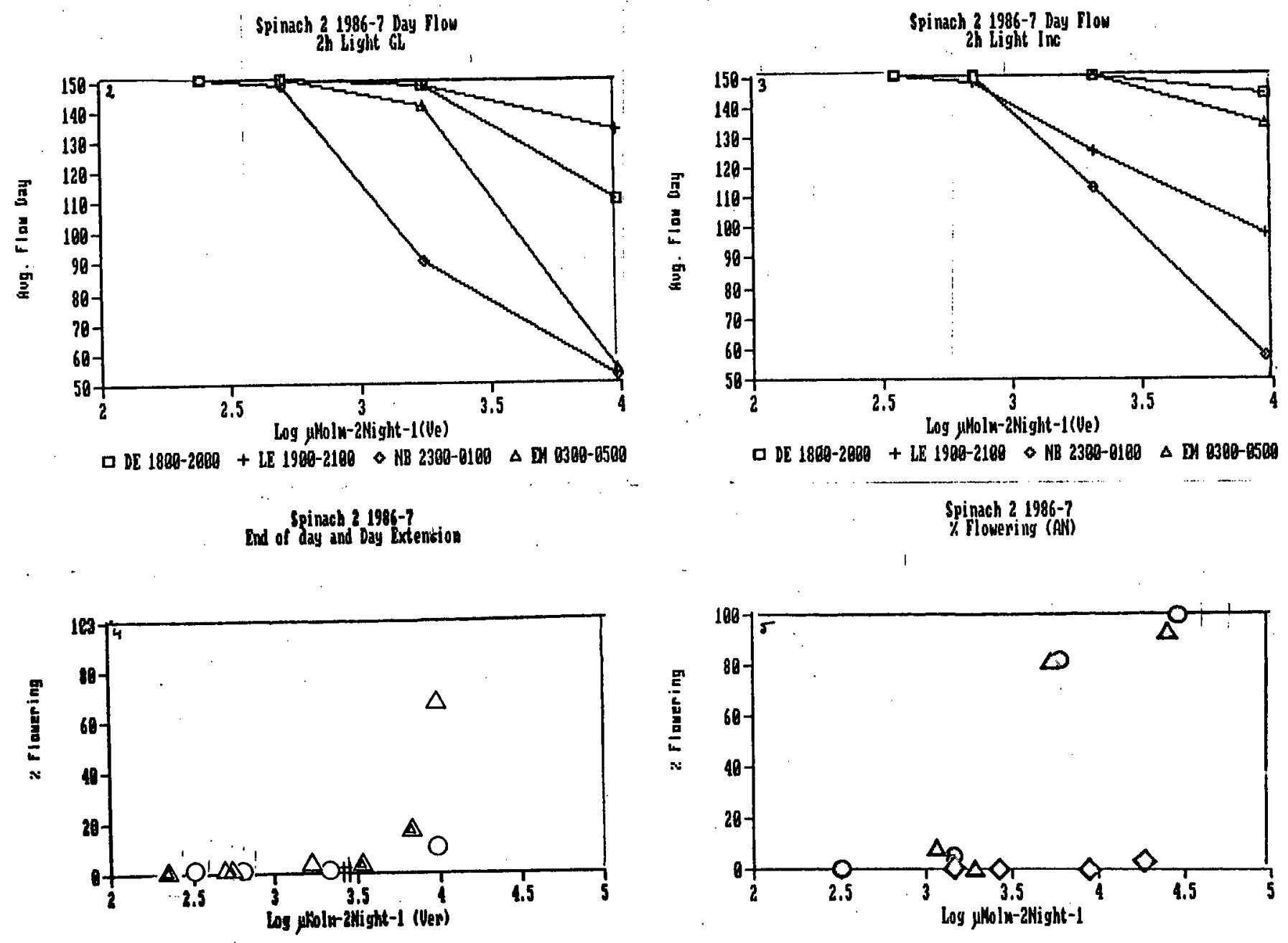

Spinach 2 1986-7

Spinach ? 1986-?

$\%$ Flovering GL
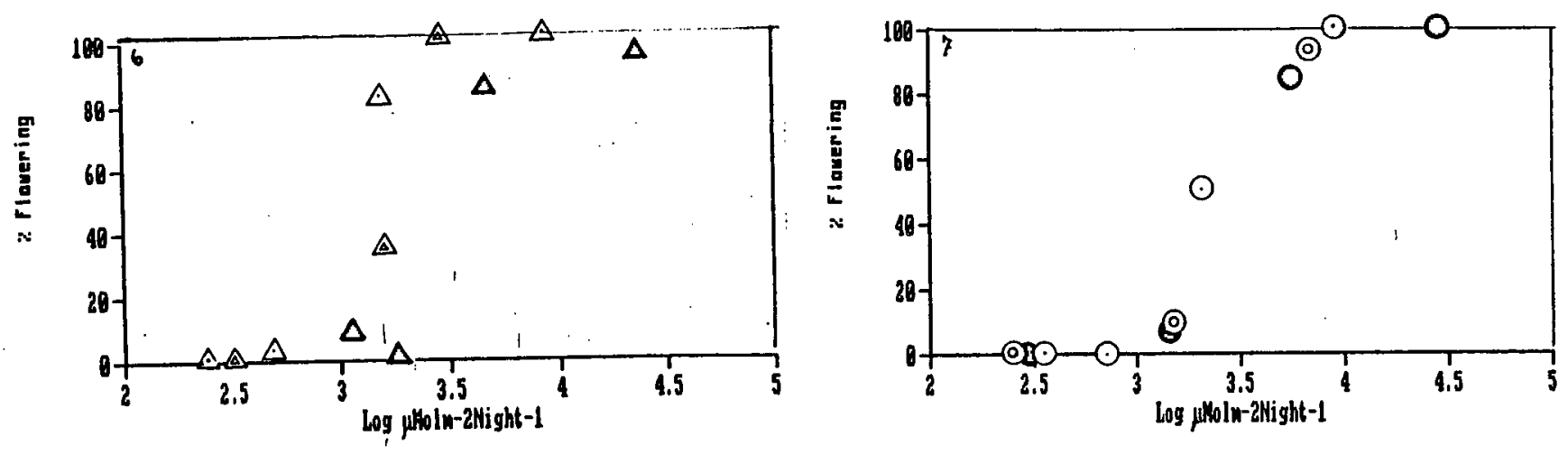
Xanthium strumarium.

Xanthium strumarium is another plant widely used in the study of the physiology of flowering. Like Pharbitis nil it is a summer annual, short-day flowering plant and it can be induced to flower by a single long dark period. It was included in Exps. 4, 5 and 7, and herein are given mainly the results of exp. 7 .

Xanthium fruits each have two unequal seeds, these may germinate together, or one seed (usually the bigger one) may germinate first and the other one remain dormant for one or more years. In Exp. 4 single fruits were sown in each pot. Subsequentiy, when the plants were collected, it was recorded for each plant whether there were one or two plants in the pot. When two plants were present it was noted whether the plant was the big or the small sibling. No difference were found in the time of flowering - but the large plants had on the average two more leaves and the first internode was somewhat longer on the small plant - probably a response to being shaded by its larger sibling. When only one plant developed, the length of the first internode was somewhat shorter then in plants were two plants developed in one pot.

In Exp. 7 Xanthium fruits were washed and then placed in germination trays at $35^{\circ} \mathrm{C}$ for 4 days. On Sept. 25, 1986 fruits were sown into the experimental treatments (Table 2). Two fruits were sown per pot and four pots were placed in each plot. However, since some fruits failed to germinate, and sometimes two plants germinated per fruit, the final number of plants was 10 - 19 plants per position. Flowering of the plants was checked twice a week. The appearance the first apical inflorescence bud was recorded, for each plant, as was the day of anthesis. The plants were collected for measurements on Nov. 3, 1986. Data on small or underdeveloped plants were not included in the results. Plants which appeared vegetative were dissected under a dissecting binocular microscope to ascertain their condition. The number of additional leaf primordia was also recorded. For the summary of the results, the condition of the apex was assigned numerical values, as follows: vegetative, 1 ; visible bud, 2 ; anthesis, 3 ; small fruits, 4; and large fruit, 5. The effects of the treatments on apex condition are presented in Figs. 1-6 and the length of the first internodes of plants in position ' $a$ ' is presented in Fig. 7 . 
In Fig. 1 and Fig. 2 the effects of $2 \mathrm{~h}$ GL or Inc irradiations applied at different times are presented. It is evident that, as in Pharbitis nil irradiations in the middle of the night (NB, 2300-0100 hours) were most effective, and irradiations early in the evening (DE 18002000 hours) were clearly less effective. However, surprisingly, and unlike Pharbitis, irradiations somewhat later in the evening ( $L E, 1900-2100$ hours) were in this experiment the least effective, and irradiations early in the morning (EM, 0300-0500 hours) were almost as effective as those of the NB. In every period the effectiveness was similar for $G L$ and Inc light. In Fig. 2 the effects of $2 \mathrm{~h}$ DE with GL or Inc light is compared with those of 30 min EOD (immediately following sunset), with GL or FR light. It is evident that EOD did not affect flowering score even at light fluences that had considerable effect when applied somewhat later. Again it is seen that with DE there was no difference between the effects of Inc and GL light. A look at Fig. 7 may prove that the EOD light was in fact perceived by the plants: the length of the first internode was greatly increased by 30 min EOD FR.

In Fig. 4 the effects of $10 \mathrm{~h}$ irradiations are compared. It is seen that, in contrast with Pharbitis nil, Blue was quite effective, at least at the two highest fluences. Blue was found to be effective also in the two previous experiments. In those experiments $10 \mathrm{~h}$ FR was not effective in Exp. 5 and $12 \mathrm{~h}$ FR was only very slightly effective in Exp. 4. In Exp. 4 there was no flowering in any of the positions receiving $12 \mathrm{~h}$ irradiations with Inc, GL or HPS light, and in positions ' $a$ ', ' $b$ ' and ' $c$ ' receiving $4 \mathrm{~h} \mathrm{NB}$ with Inc, GL, CW or LPS.

In Fig. 5 (Gi) and Fig. $\dot{6}$ (Inc) the effects of the duration of the irradiations applied around the middle of the night are again shown to depend on the amount of light quanta, without regard to the duration of the irradiations, and probably there was no significant difference between Inc and GL light.

In Fig. 7 the length of the first internades of plants grown under the different light treatments (in positions 'a' only), is presented. There was no correlation between the length of the internodes and flowering. The internodes were shortest in the plants in the ND control group, probably because this treatment was placed on the west side of the greenhouse, receiving more sunlight than any of the other groups (see Materials and Methods). As already mentioned, $30 \mathrm{~min}$ of high intensity FR caused a marked increase in internode length. Among the other treatments there was no clear order, except that most of the plants receiving GL light had shorter internodes than those receiving Inc(or Blue) light. 
Xanthium strumarium. Exp. 7, 1986/7 Legend for figures

Figs. 1-6 y axis: Apex score.

axis: Log light fluence per night.

Fig. 1, 2 Effects of the timing of $2 \mathrm{~h}$ irradiations with GL (Fig. 1) and Inc (Fig. 2)

Fig. 3 Effects of irradiations in the evenings: $30 \mathrm{~min}$ EOD FR or GL or $2 \mathrm{~h} \mathrm{DE}$ GL or Inc.

Fig. 4 Effects of $10 \mathrm{~h}$ irradiations with Blue, GL, or Inc light.

Figs. 5, 6 Effects of irradiations around midnight with 15 min, $2 \mathrm{~h}$ or $10 \mathrm{~h}$ of GL (Fig. 5) or Inc (Fig. 6) light.

Eig. 7 Length $(\mathrm{cm})$ of the first internode in plants grown in the different light treatments. (Position a only). 


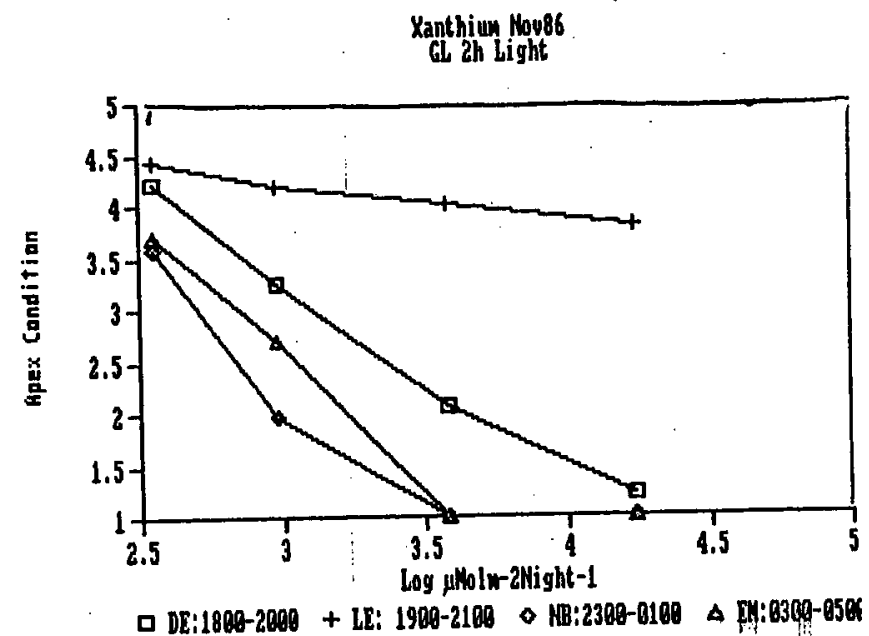

Xanthium, Nov 1986

EDot 0 D

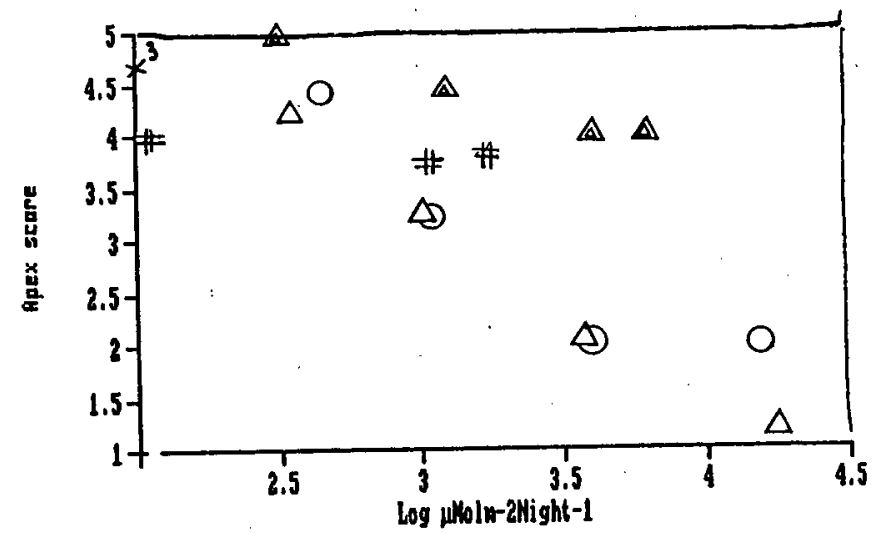

Xanthium. Nov 1986

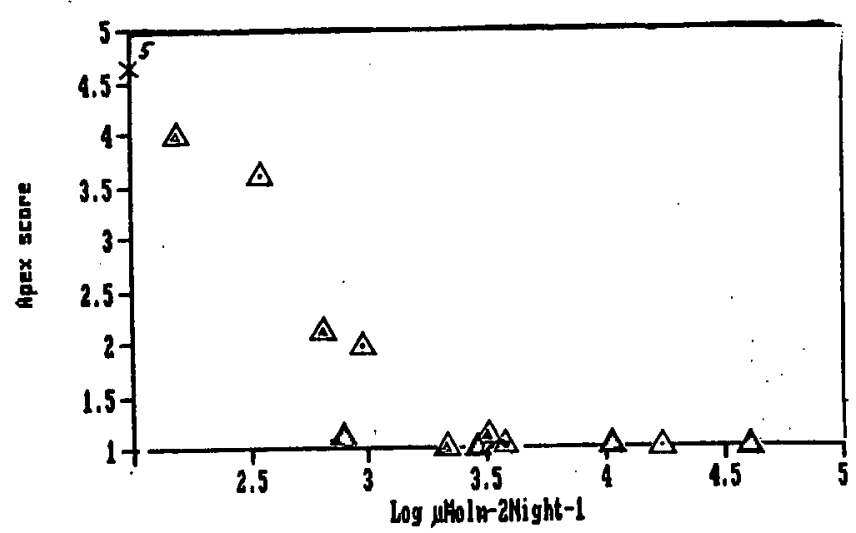

Kanthiun Nou86

Ine $2 \mathrm{~h}$ light

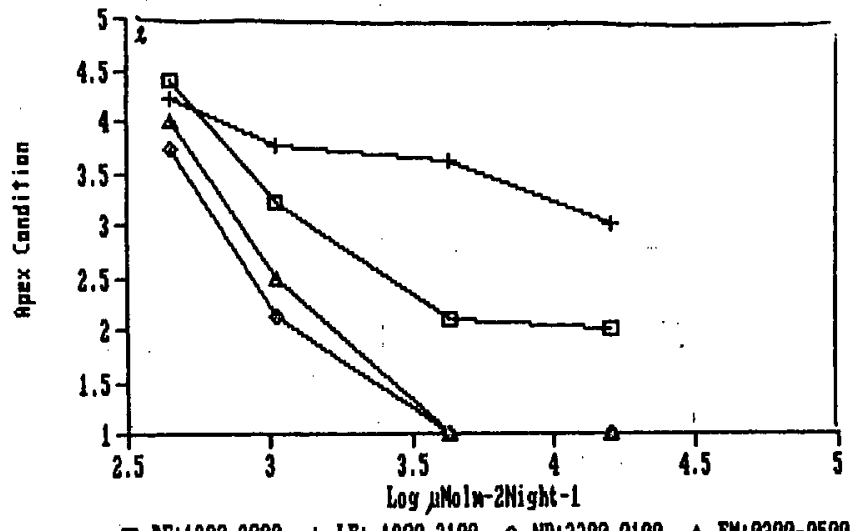

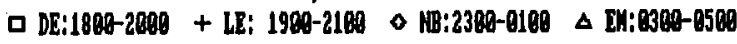

Xanthiou, Hov 1986

AN (Score:1-Veg 5-Iruits)

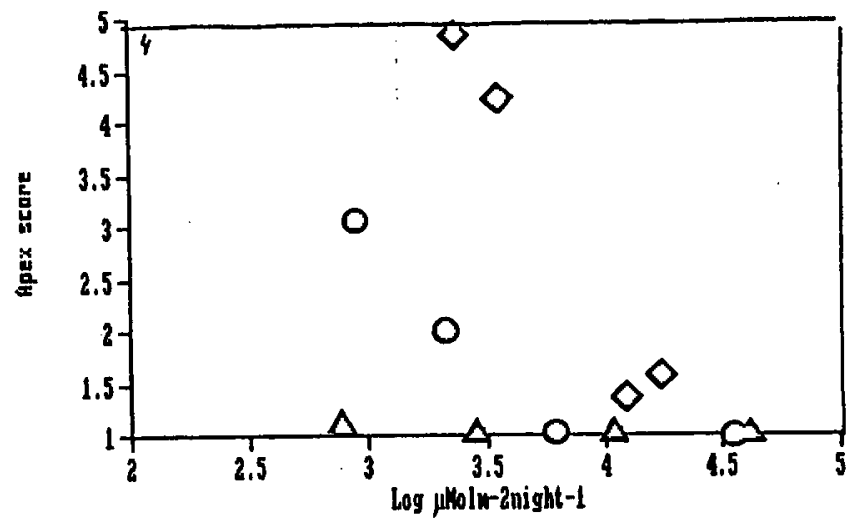

Xenthium. Nou 1986 Inc fittil

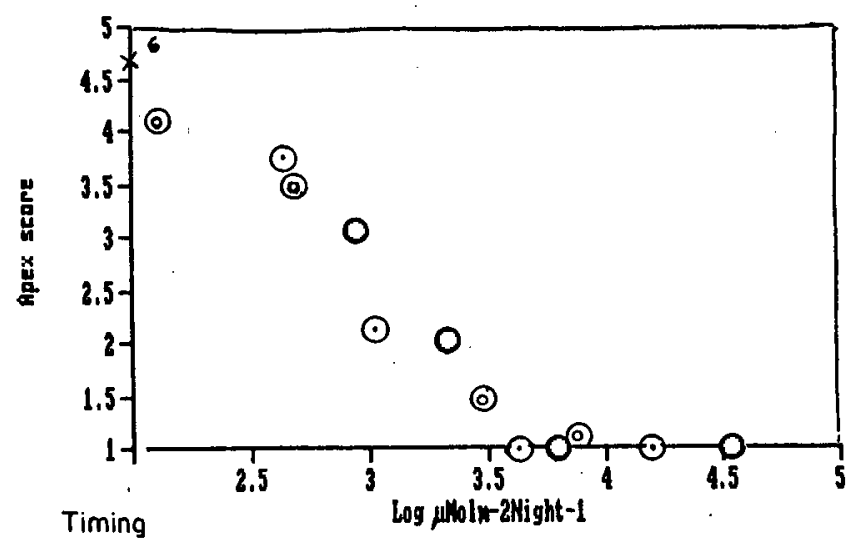

\begin{tabular}{|c|c|c|c|c|}
\hline Lomp: & AN & $\mathrm{DE}$ & NB & SI \\
\hline Inc & 0 & 0 & $\odot$ & ○ \\
\hline Inc Cycl & 0 & 0 & 0 & \\
\hline $\mathrm{GL}$ & $\Delta$ & $\Delta$ & $\Delta$ & $\Delta$ \\
\hline $\mathrm{CW}$ & $\square$ & 口 & Q & 回 \\
\hline HPS\&LPS & 0 & 0 & $\odot$ & \\
\hline FR & $\#$ & & & $\#$ \\
\hline Blue & 0 & & & \\
\hline ND & $x$ & & & \\
\hline
\end{tabular}




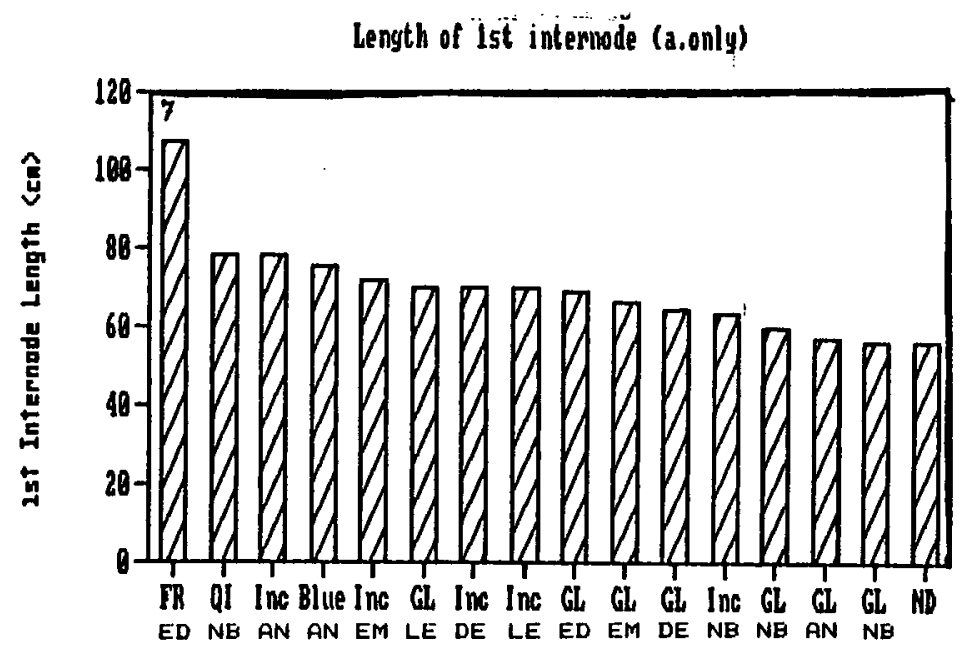




\section{Summary}

The objective of this research was to compare the photoperiodic and photomorphogenetic effects of different lamps. With different illumination regimes and to define their agricultural efficiency (i.e., costs as against added benefits). It was determined that the amount of light needed for optimal winter flowering in Gypsophila was much higher than previously recomended. However, the production time of Gypsophila could be shortened by 1 to 2 months by incresing the total light quanta applied per night.

The photoperiodic response was a function of the time of application of the irradiations and of the total light fluence administered. End-of-Day irradiations with Far-Red or GL (Red) light for $30 \mathrm{~min}$ immediately following sunset had almost no effect on flowering (with light fluences up to $1.7-6.5 \mathrm{mmol} \cdot \mathrm{m}^{-2}$.night ${ }^{-1}$ ), although the FR did increase stem length. In most cases light applied in the central part of the night was much more effective thanthat applied early. in the evening or early in the morning. With Incandescent light there was no difference between continuous and intermittently applied light, provided the same total fluence was applied.

The response-curves were always Sigmoidal in shape. Although great differences were observed between the different species, and at different ambient daylengths the entire scale between threshold and saturation of response. of all the plants tested so far, did not exceed much over four orders of magnitude: The lowest threshold response - about $0.12 \mathrm{mmol} \cdot \mathrm{m}^{-2}$.night-1 - was found for Spinacia, in spring, and the highest saturating fluence response - about $160 \mathrm{mmol}^{-2}$. night-1 - for Gypgophila and sinapis. Between threshold and saturated response there was a log-linear response-curve.

There was no consistent difference between LDP and SDP in their spectral reponse or in the amount of light quanta needed to elicit a LD response. In most plants the 
differences in the effectiveness of light of lamps emitting light in the range 500-700 nm (Incandescent, CW and GLFluorescent, High-Pressure Sodium, and Low-Pressure Sodium) were rather slight. Far-Red light was somewhat effective only with Gypsophila and Hyoscyamus. Blue was effective only under conditions when very low light fluences already generated a response, as was found with Centaurea, Pharbitis and Xanthium, and then only at very high light fluences.

In the central part of the dark period the "reciprocity law" was found to be valid: at the same total light fluences, $15 \mathrm{~min}$ of irradiation with very high fluence rates was in most cases as effective as $10 \mathrm{~h}$ of irradiation with very low fluence rates. 
Regulation of Plant Growth with Nightbreak

Irradiation with Different Lamps

T.W. Tibbitts and Ann Fitzpatrick
Madison, WI
Summer, 1985

MATERIALS AND METHODS

Seeds of Hyoscyamus niger var. Pallidus, Spinacia oleracia hybrid \#424 (Alf. Christianson Seeds, Mt. Vernon, WA), and tissue culture plantlets of Solanum tuberosum cv 'Russett Burbank' were planted in a peat-lite mix and grown to treatment size in a Biotron growth room. Temperature and relative humidity were maintained at $20^{\circ} \mathrm{C}$ and 708 . An 11 hour photoperiod of $365 \mu \mathrm{mol}$ $\mathrm{s}^{-1} \mathrm{~m}^{-2}$ was provided by $\operatorname{cool}$ white fluorescent lamps.

For night break treatments, plants were moved to reach-in chambers fitted with different types of treatment lamps that were turned on for 4 hours in the middle of each dark period. The lamps utilized for these night break treatments were as follows.

MANUFACTURER'S DATA

\begin{tabular}{cccccc}
\hline & & \multicolumn{2}{c}{ Wattage } & $\begin{array}{c}\text { Rated } \\
\text { Life } \\
\text { (hrs) }\end{array}$ & $\begin{array}{c}\text { Lumens } \\
\text { Per } \\
\text { Input } \\
\text { Watt }\end{array}$ \\
Sylvania & 10 Lam14 & 10 & $\ldots$ & 1000 & 11.5 \\
Sylvania & F20T12/CW & 20 & 4 & 9000 & 52.5 \\
Sylvania & F20T12/236 & 20 & 4 & $\ldots$ & $\ldots$ \\
Sylvania & F20T12/GRO & 20 & 4 & 9000 & $\ldots$ \\
\hline
\end{tabular}

Three henbane, 4 spinach and 2 potato plants were moved into each treatment chamber and treatments were maintained for a 3 week period. At the start of treatment, spinach and henbane had formed rosettes and were $10-15 \mathrm{~cm}$ and $20-30 \mathrm{~cm}$ in diameter respectively. Potato plants had a diameter of 15-25 $\mathrm{cm}$ and height of $5-8 \mathrm{~cm}$. A series of 3 experiments were conducted. The first was undertaken to establish a desirable level of photon flux to obtain some, but not a 'saturated' response with cool white fluorescent lamps. The second experiment was undertaken to establish desirable levels of flux for both cool white fluorescent and incandescent lamps and the third study was undertaken to carefully document the effectiveness of incandescent lamps in comparison to different types of fluorescent lamps. The night break photons provided in each study were as follows. 
Photosynthetic Photons

Chamber

Number

\begin{tabular}{|c|c|}
\hline A & $\begin{array}{c}\text { Experiment } \\
\text { B }\end{array}$ \\
\hline $\begin{array}{l}\text { Lamp } \\
\text { type }\end{array}$ & $\begin{array}{l}\text { Lamp } \\
\text { type }\end{array}$ \\
\hline
\end{tabular}

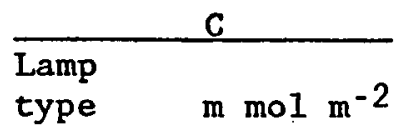

\begin{tabular}{|c|c|c|c|c|c|c|c|c|c|}
\hline 1 & CWF & 1.58 & $\begin{array}{ll}51 \\
3.64\end{array}$ & $4 n$ & None & & CWF & 8.35 & \\
\hline 2 & CWF & 7.34 & $\approx \cdots$ & CWF & 1.58 & 3.14 & GRO & 8.21 & \\
\hline 3 & CWF & 23.62 & $4,3 \div$ & CWF & 6.48 & $\Delta !$ & RED & 8.35 & : \\
\hline 4 & INC & 6.34 & $\vdots \hat{i}$ & INC & 6.77 & $3.2=$ & & & \\
\hline 5 & & None & & INC & 2.16 & $3:$ & INC & 8.50 & \\
\hline
\end{tabular}

The photon levels were determined by measuring the spectra from each lamp and applying a photosynthetic efficiency correction to the measured photon. The correction values for $5 \mathrm{~nm}$ wavelengths from 355 to $795 \mathrm{~nm}$ were derived by John Sager of the Radiation Biology. Laboratory of the Smithsonian Institute from McCree's (1968) average quantum efficiency curve. This correction reduced photon levels measured under different lamps with a LiCor LI 185 quantum meter by the following amounts.

\begin{tabular}{lc} 
Lamp type & $\begin{array}{l}\text { Correction of } \\
\text { Measured Photons } \\
\text { with LI 185 meter }\end{array}$ \\
\hline INC & $\times 0.85$ \\
CWE & $\times 0.76$ \\
REDF & $\times 0.75$ \\
GROF & $\times 0.72$
\end{tabular}

The particular levels desired in each chamber were obtained by encircling tubes and lamps with strips of aluminum foil and adjusting the width of the light gap between successive strips.

During treatment the main light irradiation was maintained with coolwhite fluorescent lamps for $11 \mathrm{hrs}$. Light levels were measured weekly and exhibited a slight decline with each experiment, averaging $446 \pm 12 \mu \mathrm{mol} \mathrm{m} \mathrm{m}^{-2}$ $s^{-1}$ in experiment $A, 429 \pm 14$ in $B$, and $411 \pm 13$ in $C$. Temperature and humidity were monitored continuously throughout the treatment period and averaged $19.9 \pm 1.0^{\circ} \mathrm{C}$ and $73 \pm 88$, respectively.

Following the night break treatment period of 3 weeks the potato plants were harvested, and the spinach and henbane plants were returned to the growth room for a final grow-out period under an 11-hour photoperiod. A summary of the duration of growth during each phase of the experiment is as follows. 


$\begin{array}{lcc}\text { Growth room } & \text { Time (days) } & \text { Growth room } \\ \text { (seedling) } & \begin{array}{l}\text { Treatment } \\ \text { chambers }\end{array} & \text { (final grow-out) }\end{array}$

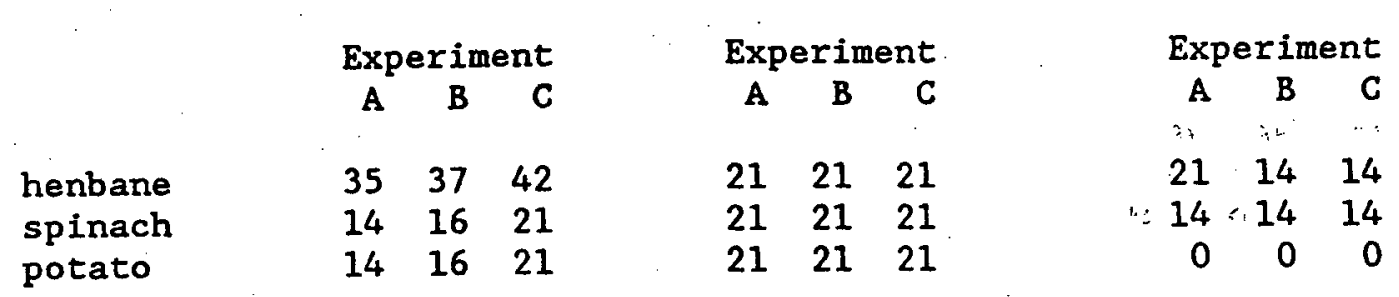

At harvest, potato plants were separated into leaves, stems, roots, stolons and tubers. Fresh and dry weight and number of tubers over $1 \mathrm{~cm}$ in diameter was obtained, as well as dry weight of all other plant parts. In addition, canopy height, main stem length and the number of nodes on the main stem were measured.

Measurements on henbane plants consisted of canopy height, main stem length and presence or absence of flowering. In experiment $C$ the number of side shoots greater than $2 \mathrm{~cm}$ in length also were counted. Similar measurements were made on spinach, and in addition the blade and petiole length of the 3 largest leaves of each plant were obtained. The width of the 3 largest leaves per plant were measured both with and without inclusion of the curled edges to determine the extent of leaf curl. This value is expressed as 'o flat' in the tables.

The effect of each night break light source on phytochrome was determined by irradiating a solution of purified phytochrome (obtained from oat coleoptiles) with the spectra from each lamp. This was undertaken with the cooperation of $\mathrm{Dr}$. Vierstra in his laboratory following a procedure described by Vierstra and Quail (Proc. Natl. Acad. Sci., USA 79:5272). The purified solution was first irradiated with sufficient monochromatic far-red light to obtain maximum phytochrome conversion and then the absorption spectra of the phytochrome solution was obtained through use of a Shimadzu UV 3000 dual monochromater dual-beam spectrometer. The time for maximum phytochrome conversion was determined by repeated irradiation exposures followed by spectrophotometer determinations until the absorption spectra showed no change. The solution was then exposed to a saturating quantity of monochromatic red light, which results in 868 of the phytochrome converting to $P_{F R}$, and a second absorption spectra obtained. Next the solution was exposed to irradiation from a treatment lamp for a sufficient time to obtain maximum phytochrome conversion and a third absorption spectra obtained. The absorption at $730 \mathrm{~nm}$ following irradiation with both red light and the treatment lamp was corrected for the background absorption that was seen at this wavelength when irradiated with far-red. The corrected phytochrome absorption at $730 \mathrm{~nm}$ following irradiation with red light was then divided by the corrected absorption following irradiation with the treatment lamp to determine the relative effectiveness of the treatment lamp compared to the red light source. This relative value was then multiplied by 0.86 (the percentage of $P_{F R}$ present following red light irradiation) to obtain a value 
for the \& $P_{F R}$ shown in Table 1 .

A second determination of phytochrome conversion was then made for each treatment source by placing a spinach leaf between the lamp and the phytochrome solution to compensate for wavelengths absorbed by chlorophyll and other pigments in the leaf blades. An irradiation period in excess of 20 minutes was required to obtain maximum phytochrome conversion for each lamp because the leaf absorption reduced the irradiation reaching the phytochrome solution.

\section{RESULTS}

The first two experiments documented that a radiation level of approximately $7.0 \mathrm{~m} \mathrm{~mol} \mathrm{\textrm {m } ^ { - 2 }}$ of photosynthetically active radiation (400-700 $\mathrm{nm}$ ) in the $4 \mathrm{hr}$ treatment period would provide the best level of photoperiodic response for both incandescent (INC) and cool-white fluorescent (CWF) lamps for the three species being investigated. This level provided the possibility of quantifying the differences in activity between CWF and INC lamps for most of the physiological responses being investigated. A radiation level of $2.0 \mathrm{~m} \mathrm{~mol} \mathrm{~m} \mathrm{~m}^{-2}$ provided no regulation using CWF lamps and regulation of only certain physiological responses using INC lamps. A radiation level of $24 \mathrm{~m} \mathrm{~mol} \mathrm{~m}^{-2}$ (studied only with CWF lamps) provided very little additional response over $7.0 \mathrm{~m} \mathrm{~mol} \mathrm{~m}-2$.

Flowering of henbane was promoted by radiation from INC lamps but appeared to have little promotion from fluorescent lamps. In contrast flowering in spinach was promoted essentially to the same degree by incandescent and fluorescent lamps (Tables 2 and 3 ). Plants in experiment $C$ had progressed further into flowering than in experiment A \& B apparently as a result of the inadvertent application of continuous light through one dark period one week before treatments were to be initiated.

Main stem elongation of potatoes, a response not directly associated with flowering in this species, appeared to be stimulated only by INC lamps in experiment $C$ but not in $B$. There was no apparent effect from the fluorescent lamps (Table 4). The stimulation of stem elongation by INC lamps, and not CWF lamps, is consistent with previous studies of potato response reported by Wheeler and Tibbitts (1985).

Leaf elongation of spinach was stimulated by all lamps, with greatest stimulation from INC lamps (Table 5). Spinach leaves developed a flat surface morphology under INC lamps in contrast to having curled margins under all other lamps when no night break lighting was provided.

Tuberization of potatoes appeared to be somewhat suppressed by night breaks but equally by all lamp treatments with no evidence for increased response by INC lamps (Table 6). The precision in this response is quite poor because of the variation inherent in number and size of tubers developing on each plant.

The number of axillary branches or side shoots developing on henbane and spinach plants did not appear to be regulated to any significant extent by 
the lamps and/or radiation levels provided (Table 7). There was an indication that side shoots of spinach were stimulated by the REDF lamp.

Thus in summary, INC lamps appear to be more promotive than fluorescent lamps for flowering in henbane, leaf length of spinach, leaf 'flattening' of spinach and apparently of equal promotive value to fluorescent lamps in suppressing tuberization of potatoes. Calculation of the quantity of photosynthetic radiation obtained from these lamps indicates that there is about $50 \%$ less PAR emitted per each lamp watt by the INC lamps compared to CWF lamps (Table 8). The calculation of radiation from the fluorescent lamps indicates that there is 158 less PAR from REDF and 418 less PAR from GROF than from CWF (Table 9). This would suggest that $2 \mathrm{x}$ greater wattage of incandescent lamps than cool-white fluorescent lamps would have to be installed to obtain equal photon irradiance levels. Also, 15 and 418 additional wattage of REDF and GROF respectively, would have to be installed to equal levels obtained with CWF. However this calculation does not take into consideration any differences in the effectiveness of different reflectors over the indicated lamps in directing the emitted radiation downward to the plant.

The reasons for the greater activity of INC lamps is not readily apparent. The INC lamps have a significant proportion of far red radiation in the absorption bands of the $P_{F R}$ form of phytochrome whereas the fluorescent lamps utilized have very little. Thus the percentage of $P_{F R}$ compared to $P_{R}$ produced by INC lamps will be less. This was documented by irradiation of pure phytochrome which indicated that INC lamps provided only $538 P_{F R}$ whereas the fluorescent lamps produced 80 to $838 P_{F R}$, with GROF producing the highest percentage (Table 1 ). This was further documented by the percentage of $P_{F R}$ produced in pure phytochrome after passage of the lamp irradiation through a spinach leaf. Only $6 \% \mathrm{P}_{\mathrm{FR}}$ was produced with INC lamps whereas CWF produced 668 , REDF produced 728 and GROF produced 738 . Thus it must be concluded that it is not the percentage of $P_{F R}$ that is stimulating these responses but rather...???!!!. 
Table 1. Phytochrome conversion under different lamps, with and without a spinach leaf filter.

\begin{tabular}{lcc}
\hline Lamp & lamp alone & lamp with leaf \\
\hline & $\mathrm{PFR}^{2}$ & \\
& & \\
CWF & 80 & 66 \\
REDF & 82 & 72 \\
GROF & 83 & 73 \\
INC & 53 & 6 \\
Monochromatic red & 86 & - \\
Monochromatic far-red & 0 & - \\
\hline
\end{tabular}

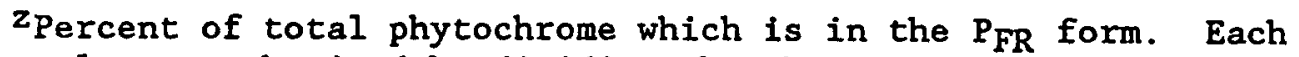
value was obtained by dividing the absorption peak at $730 \mathrm{~nm}$ obtained with the test lamp by the absorption peak at $730 \mathrm{~nm}$ obtained with the monchromatic red source and multiplying the quotent by 0.86 . 
Table 2. Flowering of Henbane

\begin{tabular}{|c|c|c|c|}
\hline & nent & Length of & Plants with \\
\hline $\mathrm{zy}$ & $\left(\mathrm{m}\right.$ mol $\left.\mathrm{m}^{-2}\right)$ & $(\mathrm{cm})$ & $(z)$ \\
\hline
\end{tabular}

Experiment 1

$\begin{array}{lrlr}\text { None } & - & -- & 0 \\ \text { CWF } & 1.58 & -- & 0 \\ \text { CWF } & 7.34 & -- & 0 \\ \text { CWF } & 23.62 & -- & 0 \\ \text { INC } & 6.34 & -- & 50\end{array}$

Experiment 2

$\begin{array}{ll}\text { None } & -- \\ \text { CWF } & 1.58 \\ \text { CWF } & 6.48 \\ \text { INC } & 2.16 \\ \text { INC } & 6.77\end{array}$

$\begin{array}{lr}-. & 0 \\ -- & 0 \\ \cdots & 0 \\ -- & 0 \\ -- & 67\end{array}$

Experiment 3

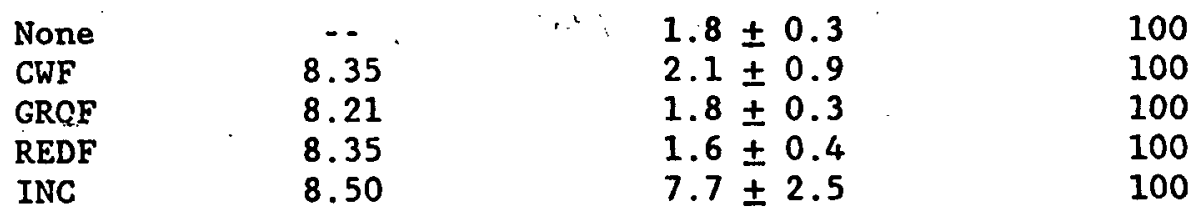

*Photons from treatment lamp during each $4 \mathrm{hr}$ night break corrected for photosynthetic effectiveness at each wavelength (see text). 
Table 3. Flowering of Spinach

$\begin{array}{lr}\text { Lamp } & \frac{\text { Treatment }}{\text { Photons* }} \\ \text { type } & \left(m \text { mol } \mathrm{m}^{-2}\right)\end{array}$

$$
\begin{aligned}
& \text { Length of } \\
& \text { Flowering Stem } \\
& (\mathrm{cm})
\end{aligned}
$$

Plants with

Visible Buds

(z)

Experiment 1

\begin{tabular}{lr} 
None & \multicolumn{1}{c}{-} \\
CWF & 1.58 \\
CWF & 7.34 \\
CWF & 23.62 \\
INC & 6.34
\end{tabular}

$\begin{array}{lc}\text { None } & -- \\ \text { CWF } & 1.58 \\ \text { CWF } & 6.48 \\ \text { INC } & 2.16 \\ \text { INC } & 6.77\end{array}$

$0.1 \pm 0.0$

no data

$0.6 \pm 0.4$

$0.4 \pm 0.0$

$0.3 \pm 0.1$

0
no data
100
100
50

Experiment 2

$0.2 \pm 0.1$

$0.3 \pm 0.1$

$3.6 \pm 2.4$

$0.1 \pm 0.1$

$0.8 \pm 0.6$
0
0
100
0
100

\section{Experiment 3}

$\begin{array}{ll}\text { None } & - \\ \text { CWF } & 8.35 \\ \text { GROF } & 8.21 \\ \text { REDF } & 8.35 \\ \text { INC } & 8.50\end{array}$

$1.2 \pm 0.5$

$2.5 \pm 1.3$

$2.5 \pm 1.0$

$4.2 \pm 1.3$

$3.5 \pm 1.9$
0

75

100

100

100

*Photons from treatment lamp during each $4 \mathrm{hr}$ night break corrected for photosynthetic effectiveness at each wavelength (see text). 
Table 4. Stem Elongation of Potatoes

$\begin{array}{lcc}\text { Lamp } & \frac{\text { Treatment }}{\text { Photons* }} & \begin{array}{c}\text { Main Stem } \\ \text { Length }\end{array} \\ \text { type } & \left(\mathrm{mmol} \mathrm{m} \mathrm{m}^{-2}\right) & (\mathrm{cm})\end{array}$

Experiment 1

$\begin{array}{lrr}\text { None } & - & 12 \pm 0 \\ \text { CWF } & 1.58 & 15 \pm 4 \\ \text { CWF } & 7.34 & 12 \pm 2 \\ \text { CWF } & 23.62 & 12 \pm 1 \\ \text { INC } & 6.34 & 18 \pm 4\end{array}$

Experiment 2

$\begin{array}{lcc}\text { None } & - & 19.0 \pm 1.4 \\ \text { CWF } & 1.58 & 15.5 \pm 2.1 \\ \text { CWF } & 6.48 & 13.5 \pm 0.7 \\ \text { INC } & 2.16 & 19.5 \pm 0.7 \\ \text { INC } & 6.77 & 18.5 \pm 2.1\end{array}$

Experiment 3

None

$8 .-$

$25.0 \pm 0.7$

CWF

8.35

$25.0 \pm 0.7$

GROF

8.21

8.35

$24.5 \pm 0.7$

REDF

8.50

$32.7 \pm 5.3$ 
Table 5. Leaf Enlargement of Spinach

$\begin{array}{lc}\text { Lamp } & \frac{\text { Treatment }}{\text { Photons* }} \\ \text { type } & \left(\mathrm{m} \text { mol m } \mathrm{m}^{-2}\right)\end{array}$

$$
\begin{gathered}
\text { Petiole } \\
\text { Length } \\
(\mathrm{cm})
\end{gathered}
$$

\section{Experiment 1}

$\begin{array}{lr}\text { None } & - \\ \text { CWF } & 1.58 \\ \text { CWF } & 7.34 \\ \text { CWF } & 23.62 \\ \text { INC } & 6.34\end{array}$

$\begin{array}{ll}\text { None } & - \\ \text { CWF } & 1.58 \\ \text { CWF } & 6.48 \\ \text { INC } & 2.16 \\ \text { INC } & 6.77\end{array}$

None

CWF

GROF :-

REDF

INC
8. 35

8.21

8.35

8.50
Experiment 2

Experiment 3

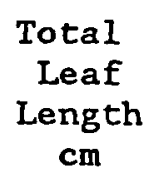

Blade Curling ( 8 flat)

$\begin{array}{lll}5.0 \pm 1.1 & 19.5 \pm 2.3 & 75 \pm 6 \\ 6.6 \pm 1.1 & 24.6 \pm 1.3 & 73 \pm 15 \\ 7.1 \pm 0.9 & 25.6 \pm 1.3 & 84 \pm 8 \\ 5.6 \pm 0.5 & 26.8 \pm 3.2 & 77 \pm 5 \\ 8.6 \pm 1.1 & 20.4 \pm 1.1 & 93 \pm 7\end{array}$

$\begin{array}{rll}4.5 \pm 1.0 & 23.3 \pm 3.4 & 66 \pm 8 \\ 7.4 \pm 1.3 & 27.4 \pm 2.3 & 73 \pm 9 \\ 8.3 \pm 1.4 & 28.3 \pm 2.1 & 76 \pm 13 \\ 8.8 \pm 0.7 & 29.6 \pm 2.2 & 76 \pm 12 \\ 10.8 \pm 1.0 & 32.0 \pm 1.4 & 92 \pm 8\end{array}$


Table 6. Tuberization of Potatoes

\begin{tabular}{|c|c|c|c|}
\hline & Ement & Tuber & Tuber \\
\hline $\begin{array}{l}\text { Lamp } \\
\text { type }\end{array}$ & $\begin{array}{l}\text { Photons* } \\
\left(\mathrm{m} \text { mol } \mathrm{m}^{-2}\right)\end{array}$ & $\begin{array}{l}\text { Number } \\
\text { (over } 1 \mathrm{~cm} \text { ) } \\
\text { diam }\end{array}$ & $\begin{array}{c}\text { Weight } \\
\text { (\&) }\end{array}$ \\
\hline
\end{tabular}

Experiment 1

$\begin{array}{lrrr}\text { None } & -- & 6 \pm 1 & 8.4 \pm 1.0 \\ \text { CWF } & 1.58 & 6 \pm 3 & 2.2 \pm 1.0 \\ \text { CWF } & 7.34 & 2 \pm 0 & 0.4 \pm 0.3 \\ \text { CWF } & 23.62 & 1 \pm 1 & 0.2 \pm 0.2 \\ \text { INC } & 6.34 & 4 \pm 1 & 1.6 \pm 0.2\end{array}$

Experiment 2

$\begin{array}{ll}\text { None } & \\ \text { CWF } & 1.58 \\ \text { CWF } & 6.48 \\ \text { INC } & 2.16 \\ \text { INC } & 6.77\end{array}$

$11 \pm 4$
$13 \pm 1$
$12 \pm 1$
$12 \pm 4$
$5 \pm 1$

Experiment 3

$\begin{array}{ll}\text { None } & \\ \text { CWF } & 8.35 \\ \text { GROF } & 8.21 \\ \text { REDF } & 8.35 \\ \text { INC } & 8.50\end{array}$

$9 \pm 1$
$11 \pm 1$
$7 \pm 0$
$8 \pm 0$
$5 \pm 2$
$14.0 \pm 1.7$

$17.0 \pm 3.6$

$6.0 \pm 1.7$

$12.1 \pm 5.4$

$6.0 \pm 1.0$

$22.6 \pm 9.3$

$7.4 \pm 4.9$

$14.3 \pm 1.3$

$11.0 \pm 2.9$

$7.7 \pm 7.9$ 
Table 7. Axillary Branches on Henbane and Spinach

$\begin{array}{ll}\text { Lamp } & \frac{\text { Treatment }}{\text { Photons* }} \\ \text { type } & \left(\mathrm{mmol} \mathrm{m} \mathrm{m}^{-2}\right)\end{array}$

Axillary Branches

(No. over $2 \mathrm{~cm}$ in length)

Henbane

Spinach

Experiment 1

$\begin{array}{lr}\text { None } & -\cdot \\ \text { CWF } & 1.58 \\ \text { CWF } & 7.34 \\ \text { CWF } & 23.62 \\ \text { INC } & 6.34\end{array}$

Experiment 2

$\begin{array}{ll}\text { None } & -- \\ \text { CWF } & 1.58 \\ \text { CWF } & 6.48 \\ \text { INC } & 2.16 \\ \text { INC } & 6.77\end{array}$

Experiment 3

$\begin{array}{lc}\text { None } & -- \\ \text { CWF } & 8.35 \\ \text { GROF } & 8.21 \\ \text { REDF } & 8.35 \\ \text { INC } & 8.50\end{array}$

$3.0 \pm 1.0$
$2.7 \pm 1.2$
$2.3 \pm 1.5$
$2.3 \pm 0.6$
$3.3 \pm 0.6$

0

8.35

8.35

$1.7 \pm 1.0$

$4.2 \pm 1.5$

$1.5 \pm 1.9$

*Photons from treatment lamp during each $4 \mathrm{hr}$ night break corrected for photosynthetic effectiveness at each wavelength (see text). 


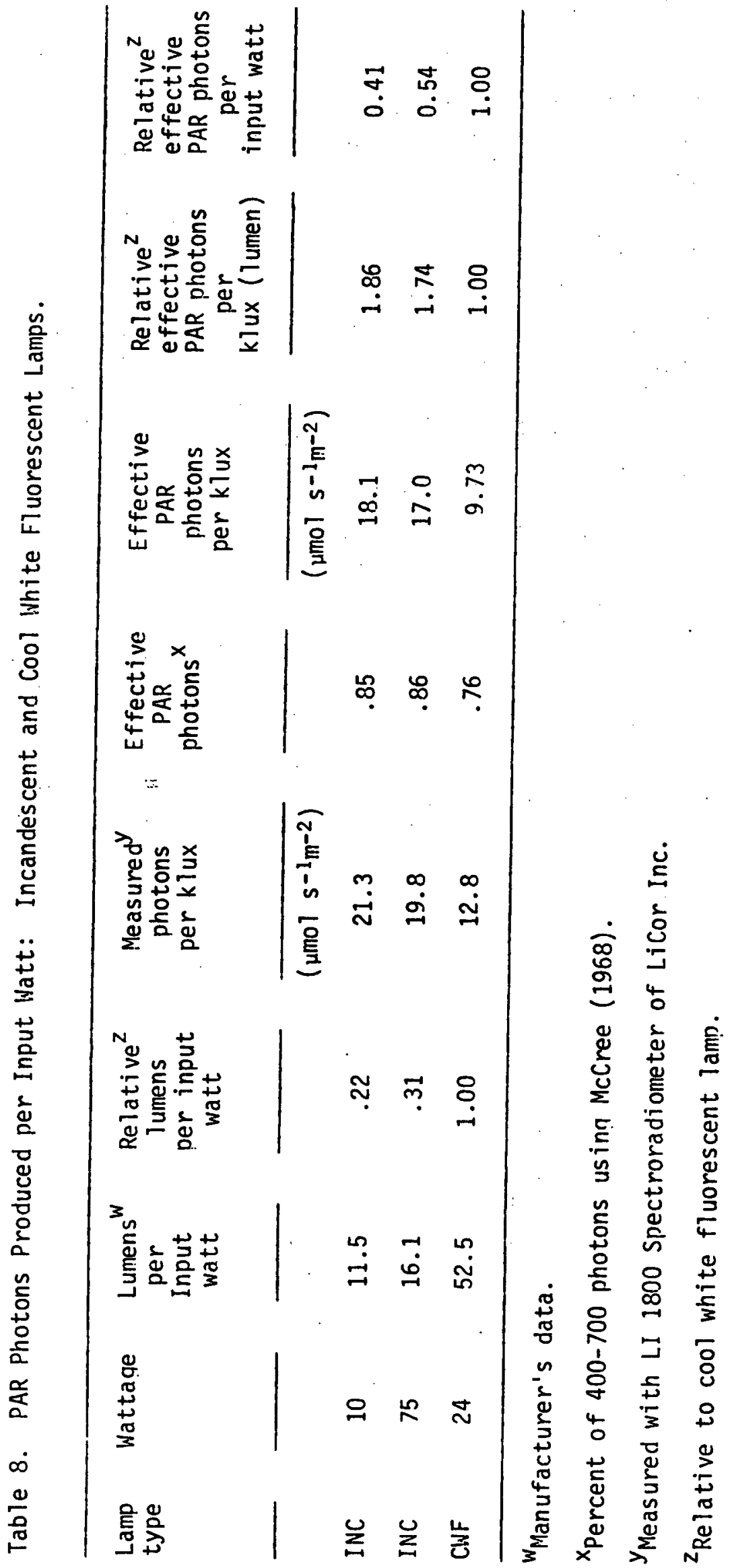


Table 9. Photons Produced per Input Watt: Cool White, Gro-lux and Red Fluorescent

$\begin{array}{lccccr}\begin{array}{l}\text { Lamp } \\ \text { type }\end{array} & \text { Wattage } & \begin{array}{c}\text { Measured } \\ \text { PAR Photons } \\ \left(\mu \mathrm{mol} \mathrm{s}^{-1_{\mathrm{m}}-2}\right)\end{array} & \begin{array}{c}\text { Effectivey } \\ \text { PAR Photons } \\ 8\end{array} & \begin{array}{c}\text { Effective } \\ \text { PAR Photons } \\ \left(\mu \mathrm{mol} \mathrm{s}^{\left.-\mathbf{1}^{-2}\right)}\right.\end{array} & \begin{array}{c}\text { Relativ } \\ \text { PAR Photo }\end{array} \\ \text { CWF } & 24 & 30.05 & .76 & 22.84 & 1.00 \\ \text { REDF } & 24 & 26.42 & .74 & 19.55 & 0.86 \\ \text { GROF } & 24 & 18.75 & .72 & 13.48 & 0.59\end{array}$

Xeasured with LI 1800 spectroradiometer of LiCOR Inc. in same fixture. YPercent of $360-740$ photons using McCree.

zelation to cool-white fluorescent lamp. 
The cooperation between the Israeli and the American investigators consisted of mutual planing of the research, frequent correspondence, One visit of Prof. T. Tibbitts in Israel and two visits of Dr. Kadman-Zahavi in Madison (The first of these not on Bard account the second only partially paid by Bard). Two of the plants tested in the Biotron in madison were also tested in the Israeli experiments and the results were compared. 
G. Evaluation of the research achievements with respect to the original research proposal, emphasizing the benefit to agriculture.

One of the expected aims of the present project was to cut the amount of electric light energy needed to induce winter flowering in Gypsophila paniculata, one of the major export cut-flower crops. Already in the first year of the project it was determined that the suggested timing of light application ( $5 \mathrm{~h}$ day-extensions) was wrong, and the amount of light as recomended by the Extension Service was, in fact, much too low. The production time of gypsophila could be shortened by 1 to 2 months by increasing the total light quanta applied. by prolonging the duration of the irradiations, and by providing the light continuously instead of in a cyclic regime. This finding was brought to the attention of the Extension Service and published in Hebrew, in Hassadeh. The Extension Service repeated and confirmed the results, and consequently the adsvisors' directions are now to increase the illuminations accordingly. Gypsophila was also found to be one of two plants (the other being Hyoscyamus niger) in which the active spectrum includes the Far-Red range above $700 \mathrm{~nm}$. Sodium lamps (HPS and LPS) were also very effective for flower induction in gypsophila. Thus, this research provides a basis for economic considerations for the erection of photoperiodic illumination systems (see chapter on eypsophila in this report).

A more general finding was the effect of the timing of the irradiation. It was found consistently that much higher light fluences were needed at the beginning and toward the end of the night than 1 to 2 hours later. In fact, during the first hour the light is almost wasted. This contradicts the very common agricultural practice of providing the irradiations as day extensions.

The fact that the "reciprocity law" was found valid for irradiations in the central part of the dark period implies that the same effect may be elicited by providing low light fluence rates (low-intensity light) over prolonged periods of irradiation, as with short irradiation periods using high-intensity light. The former will always be more economical because lamps of lower wattage ratings may be used. Still, shorter durations of irradiation at higher light intensities may be applied wherever electricity prices differ greatly during different parts of the night. It was also found that with all the illumination regimes and with all the plants tested, there was no consistent difference whether the light was applied continuously or in intermittent cycles. This is again of practical importance because cyclic light systems are elaborate and costly. 
Two somewhat unexpected results were: (a) for most plants there was no consistent difference in the effectiveness of light from incandescent lamps - emitting light of mainly long-wave bands, and that of discharge lamps such as CWF, GLF HPS and LPS; and (b) that there were no consistent differences between Long-Day plants and Short-Day plants in the induction of "Long-Day" responses.

One of the original objectives of this project was to study whether the differences in response to different lamps during different parts of the dark period - found in growth-room studies - were dependent on night length. It had been intended to study this effect mainly in the Biotron, but that proved to be too complicated. In the greenhouses the curtain system proved to be the most problematic part of the system, needing constant attention and repair. It was not possible to complicate this system further. 
h. List of Publications. Two papers were published in Hebrew both were concerned with Gypsophyla: 1. Lighting in Gypsophyla, "Hassadeh"85, C, pp 526-530, 1984. 2. Lighting for Gypsophyla "Dapei Meda" 4/15 1986. The results of Aster-Pilosus were presented as a Poster at the: University of Nottingham Easter school on "The Manipulation of Flowering". And a description of the preliminary results of the project and a chapter on Kalanchoe appeared in the Scientific report of the Institute of Field and Garden Crops, 198 
